Taking Risk Seriously:

\title{
Discourses and Worldviews in a Nuclear Waste Controversy
}

\author{
Submitted by \\ Suzanne Maureen Waldman, B.A., M.A., PhD
}

A thesis submitted to the Faculty of Graduate and Postdoctoral Affairs in partial completion of the requirements of the degree of

Doctor of Philosophy

in the

PhD Program in Communication

School of Journalism and Communication

Carleton University

Ottawa, Ontario

(C) 2017

Suzanne Maureen Waldman 


\begin{abstract}
Policy controversies over technologies with uncertain risks are highly polarizing. Stakeholder and public discussions about such 'risky technologies' typically divide over policy frames grounded in different underlying narratives concerning the relational dynamics among humans, technologies, and the environment that warrant distinct approaches for understanding and managing risk. The dissertation presents an approach to depolarizing risk that involves surfacing cultural narratives and finding discursive and institutional means to bridge them. Through an interpretive policy analysis, this dissertation examines the discourse of two key policy actors in the controversy over Ontario Power Generation's (OPG's) proposed deep geological repository (DGR) for low and intermediate level nuclear waste sited near Lake Huron. Specifically, it examines how the regulator (OPG) and a community action group, Stop the Great Lakes Nuclear Dump (STGLND), engaged in a framing struggle about the DGR and its putative environmental effects. It shows that key elements of OPG's discursive frame were anchored to a cultural narrative describing the ability of rock to protect ecologies and humans from nuclear waste. The same elements of STGLND's discursive frame anchored emphasized the vulnerability of water to contamination from nuclear waste. The dissertation argues that these competing narratives align with longstanding socio-technological worldviews.

The dissertation also discovers the presence of an intertext - a backdrop of discursive common ground - for the policy controversy amid statements by geologists describing DGRs as a promising technology that, due to environmental risks involved, requires more exhaustive and publicly accountable study. The "Responsible Geologist" intertext, it argues, has potential to act as a neutral policy frame for depolarizing public and stakeholder dialogue about DGRs. Finally, the dissertation describes how polarized dialogues around technological and environmental risk
\end{abstract}


issues could be alleviated through the creation of distinctly collaborative environmental impact assessment and risk assessment procedures. Such processes would engage citizens from different socio-cultural worldviews in a deliberative mode that is at once synthetic of diversity and evidence-based while being simultaneously committed to both ethics and innovation. 


\section{Acknowledgements}

I would like to acknowledge some of those who made it possible for me to complete this dissertation. Bruce Wallace, Brian Johnson, and Oliver Johnson supported me while I wrote it. My dissertation committee, Mary Francoli, and Graham Smart, provided immensely helpful and encouraging comments. Josh Greenberg, my fantastic supervisor, gave me invaluable advice on how to structure my ideas. My copy-editors Thea Foss Wallace and Colette Stoeber likewise helped me greatly. I am also grateful for the support of the Communication Program at Carleton, for the Ontario Graduate Scholarship I obtained in the second year of my graduate program, and for the fellowship provided to me by the Breakthrough Institute. 


\section{Table of Contents}

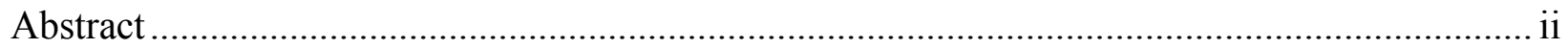

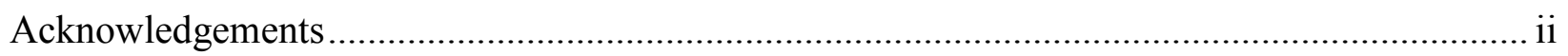

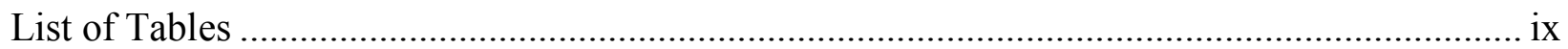

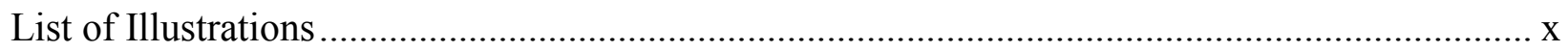

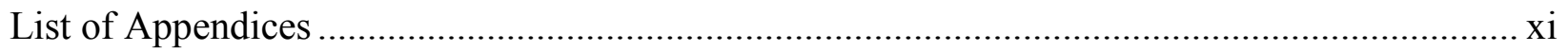

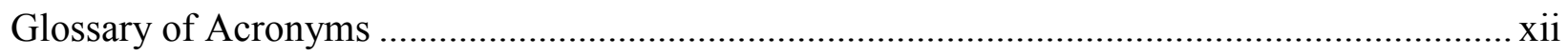

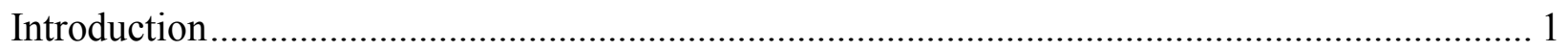

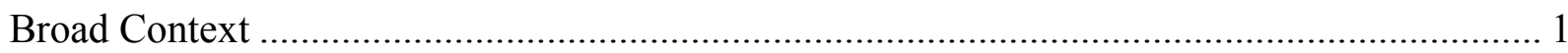

Research Questions, Contributions, and Overview................................................................. 5

Chapter 1: Literature Review on DGR Policy Controversies .................................................... 13

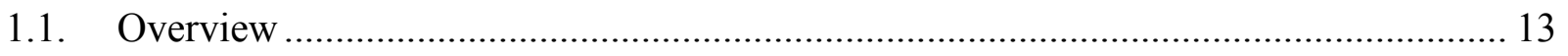

1.2 Technical and Political Issues in Nuclear Waste Disposal ......................................... 13

1.3 The Pursuit of Nuclear Waste Disposal Solutions in Canada ..................................... 16

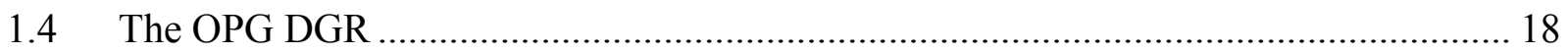

$1.5 \quad$ Public Consultation on Nuclear Waste Disposal....................................................... 22

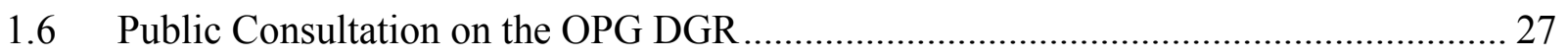

$1.7 \quad$ Social Divisions around Nuclear Waste...................................................................... 32

$1.8 \quad$ Gaps in the Nuclear Waste Controversies Literature ................................................... 35

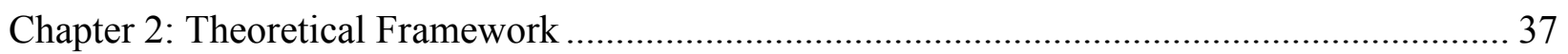

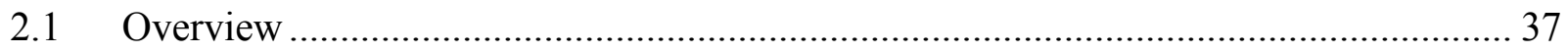

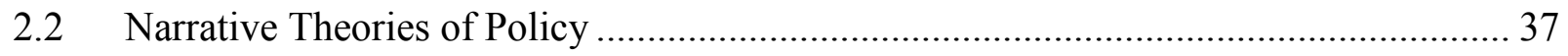

2.3 Cultural Theories of Risk Perception ………….......................................................... 42 


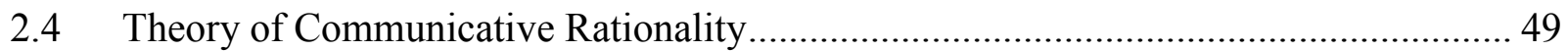

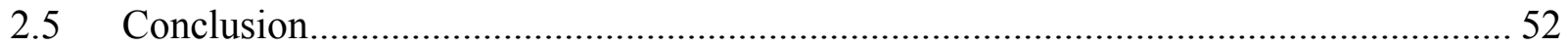

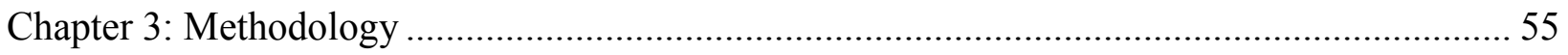

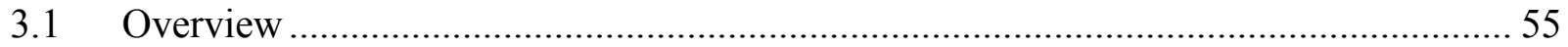

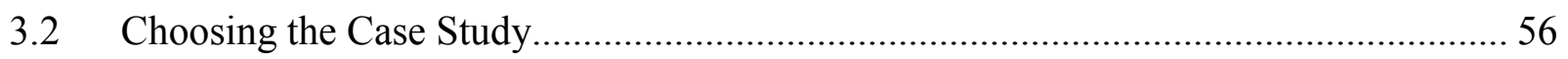

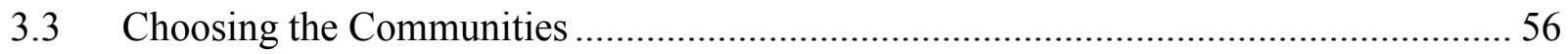

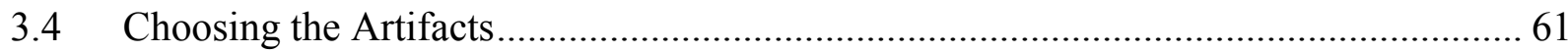

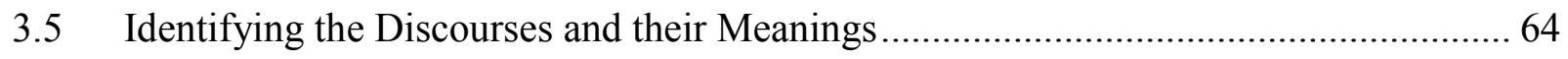

3.6 Identifying the Points of Conflict and their Sources ...................................................... 68

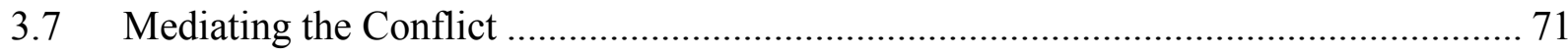

Chapter 4: Interpretive Policy Analysis of OPG's Discourse ..................................................... 70

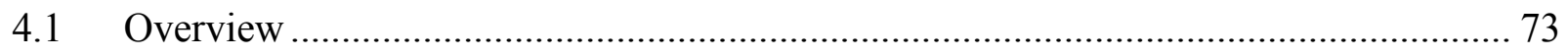

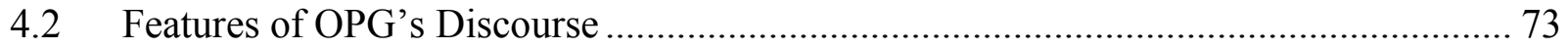

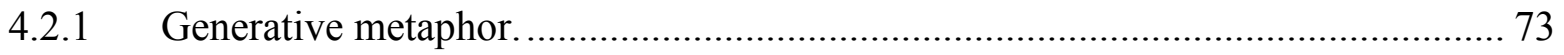

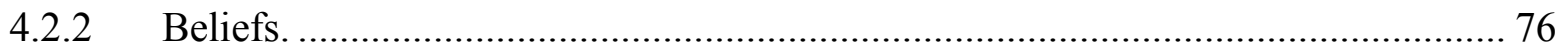

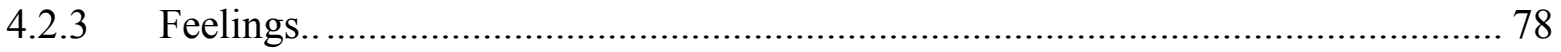

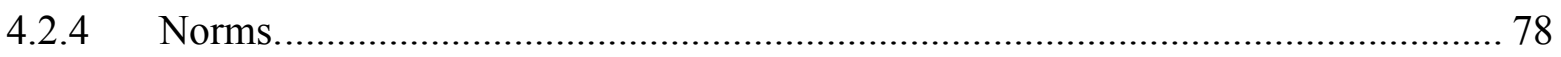

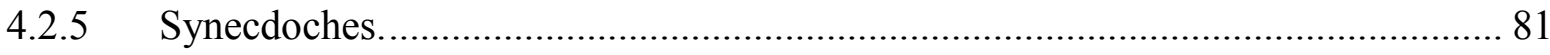

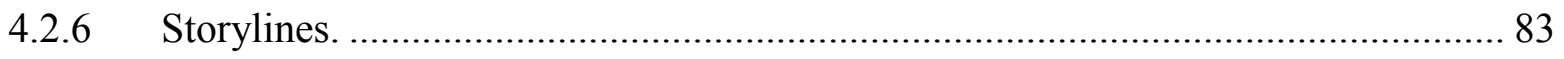

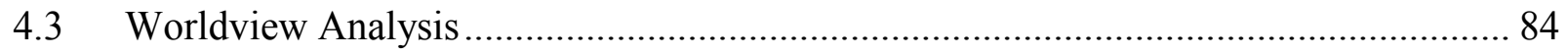

4.4 Reflections on the Interpretive Policy Analysis .......................................................... 86

Chapter 5: Interpretive Policy Analysis of STGLND's Discourse .............................................. 89

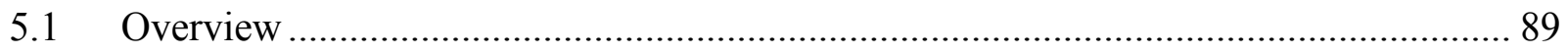




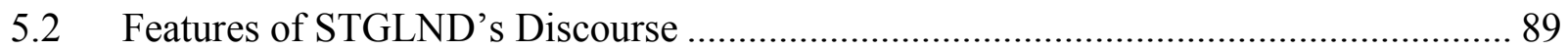

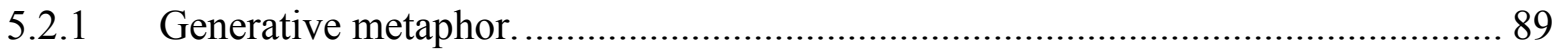

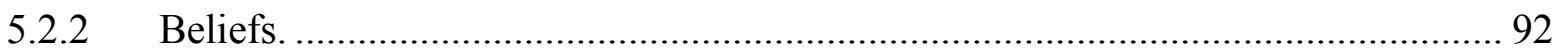

5.2.3 Norms

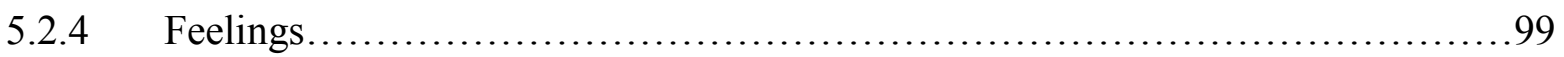

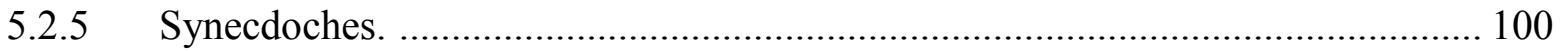

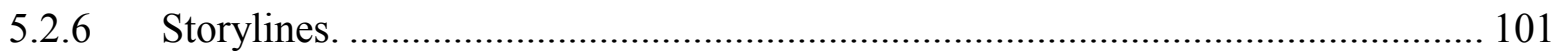

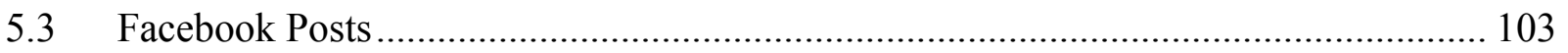

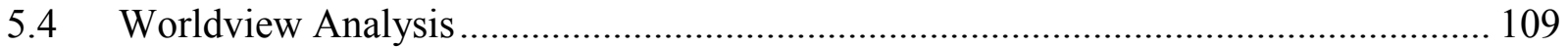

5.5 Reflections on the Worldview Analyses ................................................................. 111

Chapter 6: An Intertext for the OPG DGR controversy ....................................................... 115

6.1 Reflection on the Interpretive Policy Analyses......................................................... 115

6.2 Narrative Policy Analysis................................................................................... 125

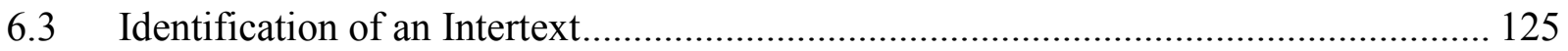

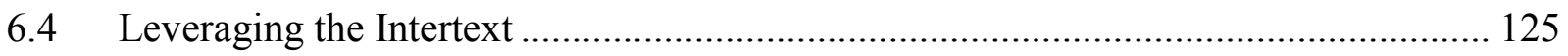

Chapter 7: Improving the Methods and Conditions of the Debate …….................................... 135

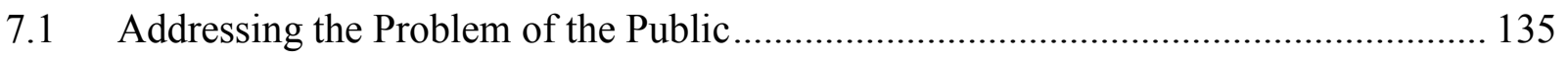

7.2 Creating Collaborative Regulatory Procedures .......................................................... 137

7.3 Building Communicative Competence ……………............................................ 144

7.4 Cultivating Responsible Innovation .................................................................... 149

7.5 Envisioning Democratic Regulatory Processes............................................................. 151

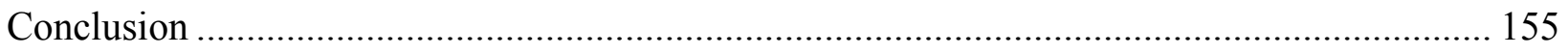

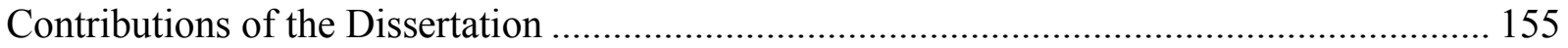


Limitations of the Dissertation ................................................................................. 159

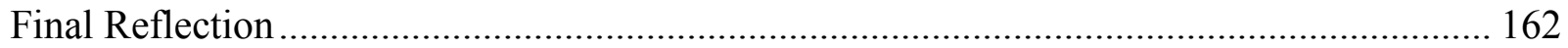

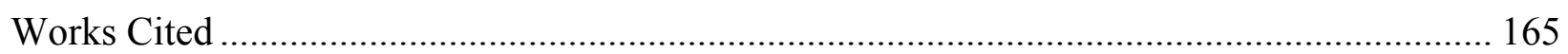

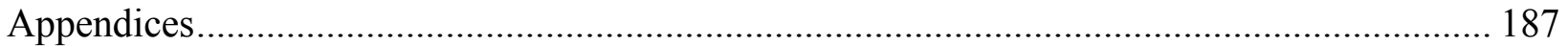

Appendix A: List of Documents Analyzed ................................................................ 187

Appendix B: Features Coded in OPG's and STGLND's Discourse .................................. 192

Appendix C: Themes in STGLND's Facebook Posts (Disaggregated) ............................. 196 


\section{List of Tables}

Table 1: Buss, Craik, \& Dake's (1986) overview of socio-technological worldviews ............... 46

Table 2: Yanow’s “Table 1.1: Steps in Interpretive Policy Analysis,” (2000, p. 22)................ 57

Table 3: Most common beliefs and norms expressed by OPG and STGLND ......................... 69

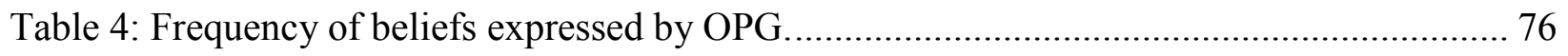

Table 5: Frequency of norms expressed by OPG. ................................................................ 79

Table 6: Frequency of synecdoches and storylines expressed by OPG................................. 82

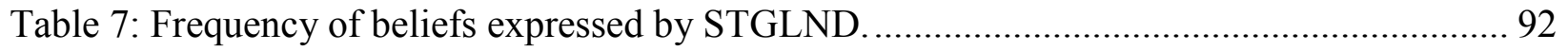

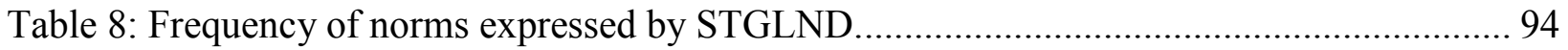

Table 9: Frequency of synecdoches and storylines expressed by STGLND ......................... 100

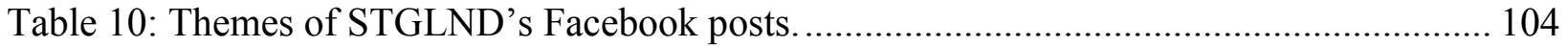




\section{List of Illustrations}

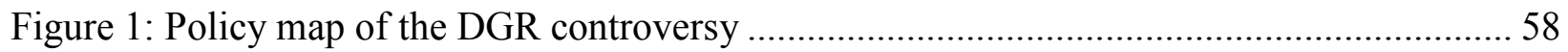

Figure 2: OPG's illustration of the DGR as a vault, from its website. .................................. 75

Figure 3: Banner logo of Stop the Great Lake Nuclear Dump, from its website ...................... 91

Figure 4: STGLND Facebook post from October 30, 2014............................................ 107

Figure 5: STGLND Facebook post from September 23, 2013 ........................................ 106

Figure 6: STGLND Facebook post from November 23, 2014. ....................................... 107

Figure 7: STGLND Facebook Post from November 16, 2014........................................... 108

Figure 8: U.S. National Research Council analytic-deliberative risk assessment process ....... 139

Figure 9: Abbreviated version of Flüeler's (2006) learning curve for public participation. ...... 142 


\section{List of Appendices}

Appendix A: List of Documents Analyzed.................................................................... 187

A.1 Ontario Power Generation Documents .................................................................. 187

A.1.1 Submissions to the Joint Review Panel................................................................ 187

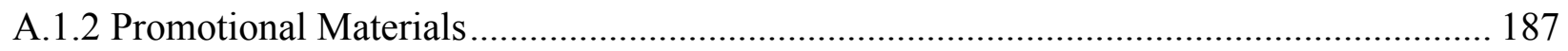

A.2 Stop the Great Lakes Nuclear Dump Documents ...................................................... 187

A.2.1 Submissions to the Joint Review Panel.................................................................... 187

A.2.2 Promotional Materials ........................................................................................... 187

A.3 Mass Media Coverage of OPG and/or STGLND ..................................................... 188

Appendix B: Features Coded in OPG's and STGLND's Discourse .................................... 192

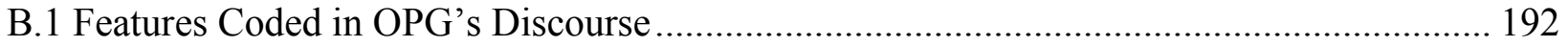

B.2 Features Coded in Stop the Great Lakes Nuclear Dump's Discourse............................... 194

Appendix C: Themes in STGLND’s Facebook Posts (Disaggregated) ................................. 196 


\section{Glossary of Acronyms}

CEAA Canadian Environmental Assessment Agency

CEAA 2005 Canadian Environmental Assessment Act of 2005

CEAA 2012 Canadian Environmental Assessment Act of 2012

CNSC Canadian Nuclear Safety Commission

DGR Deep Geological Repository

ECCC Environment and Climate Change Canada

JRP Joint Review Panel

NWMO Nuclear Waste Management Organization

OPG Ontario Power Generation

STGLND Stop the Great Lakes Nuclear Dump

US NRC United States National Research Council 


\section{Introduction}

\section{Broad Context}

This dissertation addresses the controversy that has arisen around Ontario Power Generation's (OPG) proposed deep geologic repository (DGR) for the burial of low and intermediate level nuclear waste adjacent to the Bruce Power plant near Lake Huron. This controversy largely centers on the putative risks the project would present to the Great Lakes ecosystem and water supply. From OPG's perspective, the waste in question is not especially hazardous; the hole in which it would be buried is deep; the rock in which the waste would be housed is exceedingly stable and favourable for containing and absorbing the radionuclides; and the project should be judged as low in risk to the health and well-being of humans and ecosystems. That this project does not present significant radiological risks and should proceed is a position shared by the Joint Review Panel of independent experts appointed by two agencies of the Canadian Government (Swanson, Archibald, \& Mueke, G., 2015). However, the DGR has been vociferously opposed by community action groups such as Stop the Great Lakes Nuclear Dump (STGLND), which express serious concerns about the idea of nuclear waste being buried so close to the Great Lakes. As such, the OPG DGR is currently under a second review by the recently elected federal Liberal government, which inherited the file from the Conservative government that preceded it. Accordingly, the OPG DGR exists in limbo, as do numerous other

DGR plans in around the world: not quite alive but not quite dead, largely owing to the difficulty of getting the various stakeholders to agree on the degree of risks involved. ${ }^{1}$

\footnotetext{
${ }^{1}$ Some notable projects for deep geological disposal of nuclear waste that have been at least temporarily tabled are Yucca Mountain, in the United States, as well as Schacht Konrad, in Germany.
} 
To better understand the terms of this debate and the scope for resolving policy controversies about nuclear waste both now and in the future, the dissertation draws on interpretive policy analysis to examine how the two main stakeholder groups (OPG and STGLND) are divided in their framing of the key issues related to how we define, measure, and make decisions about risk. It then presents a narrative analysis of the stories underlying the competing frames of the issues to demonstrate how the risk positions of these stakeholders may not be as irreconcilable as they appear. Finally, it proposes some approaches to finding common ground on substantive risk issues related to nuclear waste management and thereby moving conversations about these complex issues forward.

In approaching these questions, it is first necessary to consider why people disagree so profoundly about risks, and in particular about which risk-laden technologies and projects ought (and ought not) to be pursued. Researchers have studied why the public is divided about technological risk for at least three decades. The dominant assumption underlying these analyses has largely been that divisions around risk issues primarily reflect the different ways that experts and laypeople understand the risks of technology. However, different analyses give sharply different epistemological and moral weight to what they characterize as expert and lay understanding. On one hand, cognitive psychologists argue that laypeople are vulnerable to taking heuristic, or cognitive, shortcuts that distort their perception of the severity and probability of risk impacts, including those associated with new or experimental technology (Starr, 1969; Peters \& Slovic, 1996). These researchers regard experts as having more technically accurate views of risks, and accordingly recommend clearer, more persuasive communication that presents accounts of risks appropriately contextualized for the public. On the other hand, a notable lineage of sociologists propose that the public is in touch with many important aspects of 
technology that evade expert awareness or understanding, such as mistakes that occur when people are using or managing technology and more subtle impacts that new technologies can have on health, the environment and communities (Beck, 1988; Fischer, 2000). These scholars also show that even if lay knowledge is influenced by feelings and values, so too is scientific knowledge, which may be compromised by economic self-interests, groupthink or in-group conformity with respect to the acceptability of scientific ideas (Fischer, 2000, pp. 98-105). These researchers thus see citizen perspectives as equivalent or even superior to expert perspectives and call for more consultative decision-making processes in which, for the sake of justice as well as better risk management, public input would be a determining factor over whether projects involving technological risk go ahead.

Yet there is reason to question the usefulness of these understandings of social division around risk, given how little help they have afforded to helping settle risk controversies, which have only been growing thornier over time. As Sarowitz (2004) has observed, policy issues involving scientific complexity and uncertainty are encountering "growing political controversy and gridlock" amidst cohorts of both experts and citizens, as in complex situations "[p]articular sets of facts may stand out as particularly compelling, coherent, and useful in the context of one set of values and interests, yet in another appear irrelevant" (p. 390). For Sarowitz, the relevant ruptures abide not primarily between experts' and citizens' framings of controversial issues, but amongst innumerable frames that both transcend and fracture these fields. Cultural scholars similarly claim that social divisions are not primarily founded in divided perceptions of technological risks and benefits between experts and citizens, but in divided socio-cultural worldviews with which different groups of the public, as well as different groups of experts, identify. For example, technologies such as nuclear power, natural gas fracking, genetically 
modified organisms, and even vaccines elicit different views from different representatives of the public and expert class. The foundational view that cultural theorists of risk draw upon, first presented by Douglas and Wildavsky (1982), holds that the risks that social cultures (encompassing both leaders or experts and the citizens that follow them) focus on are virtually always congruent with their broader socio-political worldviews. Essentially, these cultures select certain risks to fear based on congruence with their social aims and desires rather than because the risks threaten the most likely or severe impacts. These arguments from cultural theories of risk have been centralized most recently at the Cultural Cognition Project led by Kahan et al. at Yale University, who have elaborated the socio-cultural understanding of risk perception by demonstrating that individuals unconsciously adopt risk perceptions matching those of their cultural groups to maintain benefits of membership in those groups (Kahan et al., 2011). Highlighting the fundamentally tribal character of risk choices, these theories indicate that standard communicative methods proposed to overcome social divisions around risk may not work in the case of extremely polarized risk issues because they are not capable of overcoming these powerful tribal affinities.

Instead, these arguments point those seeking greater public consensus around contentious policies towards a deeper consideration of cultural identity and its impacts on risk cognition and political communication. Kahan, Braman, and Jenkins-Smith (2011) recommend conducting policy conversations around highly practical local matters that are less likely to invoke cultural identity in polarizing and paralyzing ways. Roe's (1994) method of narrative policy analysis offers another approach, which is to look beyond the prevailing narratives around a policy issue in order to find an intertext for the policy issue that spans and connects what otherwise appear to be opposed narratives (p. 3). An intertext, as Roe explains, can provide a "policy-relevant and 
useful story" that "rationalizes but does not slight in any way a controversy's divisions" and so can help to prompt more productive discussion among diverse policy actors (p. 145). Drawing on these approaches, I argue that within the broader frame of a counter-narrative, participants may be more willing and able to draw on what Habermas (1970) and Webler (1995) call "communicative competence" - the ability of a group of deliberators to pool their diverse understandings and perspectives "to construct[] the most valid understandings and agreements possible, given what is reasonably knowable at the time" (Webler, 1995, p. 58).

\section{Research Questions, Contributions, and Overview}

This study of the OPG DGR debate is situated in this context of social polarization around nuclear technology and its waste. The dissertation first performs an interpretive policy analysis to discern the underlying frames that circumscribe how groups see issues by focusing on texts generated by two key policy actors in the OPG DGR controversy (Fischer, 2003): OPG, the proponent of the DGR, and Stop the Great Lakes Nuclear Dump (STGLND), a community action group that emerged as the most nuclear generator's most prominent and effective adversary. The analysis looks at submissions to environmental hearings, publications oriented to the public sphere, and public statements reported in the media by each of these actors and identifies discursive elements bearing on policy frames such as beliefs, norms, feelings, and storylines relating to the issue. The study also identifies generative metaphors as culturally resonant symbolic narratives that, according to Schön and Rein (1994), anchor policy frames at an unconscious level (pp. 26-28). Throughout the study, moreover, OPG and STGLND are understood as representing not only of their own policy arguments and beliefs, but also those of larger "communities of meaning" (Yanow, 2000). As Yanow argues, communities of meaning are "policy-relevant" communities that are "not place-specific" but bound together by shared 
organizational membership, training and/or "myriad other possible dimensions lead[ing] to a [shared] set of values, beliefs and feelings" as well as "cognitive, linguistic, and cultural practices" $(2000$, p. 20). Communities of meaning "may be fluid, changing from issue to issue," though they often have "some overlap, e.g., according to positions along a spectrum of political or religious ideology" (p. 20). In theory, therefore, communities of meaning comprise many individuals and groups who identify with different sides of highly charged and relevant questions that our societies constantly confront.

Since Schön and Rein (1994) and Yanow (2000) developed their approaches, the coexistence of culturally divergent communities of meaning has emerged as an increasingly salient element of our animated pluralist democracy and a bedeviling aspect of the ongoing struggle to manage the tangled, risk-laden problems of public health and welfare and environmental integrity. The issue of nuclear waste management, and the policy actors at the center of this issue, exemplify the far broader problematic of how to develop solutions to wicked problems in societies that are culturally, politically and economically diverse. The purpose of this dissertation is thus to advance understanding of how, and why, some risks become highly polarizing, as well as how policy-makers can keep moving policy conversations on these risks forward when this occurs. Why are societies divided into divergent risk cultures, and what are some strategies and tools we can develop for trying to heal these divisions? Accordingly, the study is driven by the following research questions:

- How do the two policy actors at the center of this controversy frame the nuclear waste risk issue in distinctive ways, and are there indications of unique generative metaphors—culturally symbolic narratives with "diagnostic-prescriptive" features (Schön and Rein [1994], 26-28)—underlying their distinct frames? 
- How do the policy actors' manner of framing and narrating the nuclear waste risk controversy align these actors amidst prominent socio-cultural worldviews that have been identified in relation to technological and environmental risk?

- What, if any, insight and practical methodological guidance for remediating sociocultural conflicts about risk can we derive from and extend from how these actors frame and narrate the controversy around nuclear waste?

As these research questions indicate, the interest of the thesis in examining risk-related policy discourse is not solely to explore methodological, theoretical, or literary questions about the linguistic and symbolic formations that determine how struggles around technology and the environment are conducted and play out. Nor is the interest confined to mapping the political, sociological, or psychological dimensions of these struggles, though many of these vantage points on cultural polarization have arisen in various phases of this project. Rather, my primary interest is to pursue pragmatic guidance on the vexing question of how polarization around technological and environmental risk might be better addressed. Thus, after explicating the narratives of these policy actors, I consider what elements of the larger policy discourse has the most potential to be reconciled with each other into a new starting point, or neutral zone. I then push further to look at what types of conditions might permit a more constructive deliberation on these issues.

This dissertation makes three central contributions to the literature on nuclear waste controversies and to the literature of technology and environmental policy-related risk controversies generally. First, the dissertation makes a theoretical contribution to the literature on risk controversies by linking cultural theories of risk (e.g., Douglas, 1982; Kahan, Braman \& Jenkins Smith, 2011; Kahan et al., 2011 Kahan, 2015a, 2015b) with policy frame theory (Schön 
and Rein, 1994). Cultural theories of risk have been exceedingly valuable for pointing to the ways that views on risk do not merely abide in individual minds but rather in the collective perspectives of socio-cultural groups. However, these theories do not offer an explanation of how risk perceptions become so fixed and dominant at the group level, beyond Douglas and Wildavsky's idea that socio-cultural groups “select[]" risks (1982) and Kahan et al.'s (2011) hypothesis that individuals unconsciously adopt group-conforming risk views to obtain benefits from cultural group membership. The dissertation accordingly specifies Schön and Rein's (1994) idea of the determinative character of symbolically-resonant narratives, or "generative metaphors," on policy frames as key to the process by which collective risk perceptions are generated and proliferated amid the discourse of cultural communities (pp. 26-28).

Second, the dissertation makes a methodological contribution to the literature on nuclear waste controversies, and by extension to that of other environmental and technological risk controversies. As is discussed in Chapter 1, numerous writings on nuclear waste controversies that have described the different socio-cultural groups who confront each other in these issues and the different values and positions held by these groups (e.g. Berkhout, 1991, Easterling \& Kunreuther, 1995; Slovic \& Peters, 1996; Flüeler, 2006; Fuji Johnson, 2008). However, these writings have not paid heed to the wider socio-cultural policy frames held by these groups, nor have they analyzed these frames in relation to the unconscious symbolic narratives that structure them, as Schön and Rein (1994) and Yanow (2000) have described. As the dissertation proposes, a lack of understanding of the underlying narratives motivating divergent social positions on risk policy issues ensures that deliberative strategies for mediating these issues are unlikely to resolve these divisions, but instead to replay them interminably. Accordingly, this dissertation applies interpretive policy analysis (Yanow, 2000) to surface the way different socio-cultural 
communities of meaning interpret the nuclear waste disposal issue, the risks that are involved in it, and the appropriate societal tools and processes for making decisions about it. Additionally, in keeping with Schön and Rein (1994), the dissertation observes the powerful impact of symbolically resonant generative metaphors on the socio-technological communities' ways of framing and narrating these issues. It accordingly initiates a narrative policy analysis (Roe, 1994) to mediate the gaps between the two communities' discordant narrative approaches to technology and the environment by finding a third counter-narrative that is respectful of both groups' narratives and that could have the potential to orient more productive ongoing discourse about the nuclear waste issue in Canada. The sequencing of analytic moves presented here, which emphasizes the value of carefully examining the plural discourses and narratives through which different policy actors frame their interests, provides a framework that may be applied across myriad other policy controversies involving risk.

Finally, the dissertation contributes to the literature on environmental and technological policy directions in Canada by mapping challenges, requirements, and potential directions for more effective deliberation about polarized policy issues that pertain to risk, such as nuclear waste. There is a current belief expressed in the Canadian literature on environmental assessment that more extensive public and stakeholder deliberation can itself yield meaningful and satisfying resolutions to complex issues and controversies (Fuji Johnson, 2008; ECCC 2017). Yet as I discuss in Chapter 1 and again in Chapter 7, given how sustained the cultural polarization around technological risk issues such as nuclear waste is, the idea that real breakthroughs can be achieved by simply expanding the scope for more voices to be heard and issues to be raised is unrealistic. As Lövbrand, Pielke Jr., \& Beck (2010) argue, citizen deliberations on environmental issues are not actually formulated in relation to the guiding norms of deliberative democracy, i.e., 
mutual understanding and consensus. Accordingly, environmental deliberations tend not to move towards these goals, but to give a hearing to pluralist struggle with "no obvious end-point to the discursive process" (p. 12). Thus, rather than endorsing the idea that more deliberation will, on its own, resolve political conflicts, this dissertation agrees with Gregory (2017) that the quality of deliberation about complex social and technical issues must become higher to produce real resolutions of the discrepant facts and values involved. It especially turns to Webler (1995), who identified some bases of what Habermas (1970) referred to as the "communicative competence" necessary for successful deliberation, including a willingness amongst participants to agree in advance to standards around how knowledge should be evaluated and how discrepant claims can be settled. As the dissertation finds, there is a strong basis for the importance of communicative competence in the literature on nuclear waste deliberation and on environmental deliberation overall. In the pursuit of higher quality deliberation on nuclear waste in Canada, the dissertation points to literature proposing that smaller and more prolonged risk assessment panels, in which a by participants representing a wide range of socio-cultural views are represented who are facilitated to engage with each other in a relatively rigorous way likely presents the most suitable vehicle for democratic decision-making about risk issues. Availed by more congenial counternarratives about technological risk around which diverse cultural communities have potential to converge, such forums could prospectively create more widely acceptable solutions to environmental and technologically dilemmas.

The dissertation unfolds as follows: Chapter 1 describes the literature and current state of policy controversies around nuclear waste from a technical and social perspective, highlighting the focus by many scholars on the need for extensive public consultation to help resolve these controversies (e.g. Easterling \& Kunreuther, 1995; Slovic \& Peters, 1996; Flüeler, 2006; Fuji 
Johnson, 2008; Metlay, 2013); as well as the international and Canadian experience of holding such consultations (e.g. Aikin, Harrison \& Hare, 1997, Brown \& Letourneau, 2001; Fuji Johnson, 2008; Fuji Johnson \& Durant, 2009). Chapter 2 outlines the theoretical framework of the dissertation, drawing principally on policy frame theory (Schön and Rein, 1994); cultural theories of risk (Douglas and Wildavsky, 1982; Kahan et al., 2011; Kahan, 2015a, 2015b); and theories of communicative competence (Habermas, 1970; Webler, 1995). Chapter 3 lays out the methodologies of interpretive policy analysis (Yanow, 2000), worldview analysis (based on Buss, Craik, \& Dake, 1986), and narrative policy analysis (Roe, 1994), and specifies the approach used for analyzing the texts of OPG and STGLND. Chapters 4 and 5 present the findings of the interpretive policy analysis, observing that the discourse of each policy actor was related to, and emerged from, certain generative metaphors. On the one hand, OPG presents a fundamentally conservative generative metaphor for the DGR as a stable rock vault, or inverted house, that can reliably separate dangerous nuclear waste from humanity and ecologies. STGLND, on the other hand, offers a decidedly romantic generative metaphor that depicts the water of the Great Lakes as a reservoir of natural purity highly susceptible to violation by exceptionally toxic nuclear waste, which accordingly must be kept far away from such sites and, ideally, cease to be made at all. These chapters further demonstrate how well the beliefs, norms, and narratives of these policy actors match up with longstanding bifurcated socio-cultural worldviews concerning appropriate and desirable socio-technological practices and ends.

In Chapter 6, Roe's narrative policy analysis is used to described how the divergent socio-cultural frames of OPG and STGLND can be spanned through a counter-narrative of "Responsible Geologist." This counter-narrative, which originates from and continues to be advanced by geologists working in nuclear waste storage, is neither confident nor cynical about 
the security offered by DGRs. Rather, it insists on the need for a prolonged phase of experimentation and study dedicated to comparative understanding of which geologies offer the best hope for storing nuclear waste to ensure the highest probability of success. The Responsible Geologist counter-narrative offers a more useful starting point than the polarized narratives of the two groups for discussing different methods and sites for nuclear waste disposal, and could prospectively be used as a basis for establishing regulatory processes dedicated to evaluating such sites and methods that are at once democratically inclusive and evidence-based. Chapter 7 considers a range of foundations for inclusive, evidence-based processes for obtaining policy guidance and decisions on controversial matters relating to technology and the environment. The dissertation concludes by situating the case study of the OPG DGR in a wider conversation with the themes and tensions discussed in my literature review and theoretical framework. The conclusion also offers a discussion of the study's limitations, opportunities for future research, and broader implications for navigating technological and environmental risk issues. 


\section{Chapter 1: Literature Review on DGR Policy Controversies}

\subsection{Overview}

Should nuclear waste be disposed of in deep geologic repositories (DGRs)? In the first place, this is a technical question that must consider what sort of barriers block radionuclides; how much stability can be presumptively attributed to these barriers; and with how much certainty this stability can be projected into the distant future. Yet, at the same time it is a complex political question, as concerns about nuclear power, like those about nuclear waste, are embedded in socio-cultural attitudes about what balance to strike between using technology to supply material resources in support of human welfare and minimizing undesirable impacts on human health and the environment. Finally, these questions relate intimately with policy-related questions about how to make social decisions about risk that are fair, functional, and acceptable to people with a range of viewpoints, concerns, and commitments. Accordingly, this chapter draws on scholarly research, policy documents, and grey literature to present a detailed backgrounder that addresses four topics: 1) the technical and political issues in nuclear waste disposal; 2) the history of attempts to pursue nuclear disposal solutions internationally, in Canada, and in the case of the OPG DGR; 2) the use of public consultation to try to resolve the social dimensions of these issues; and 4) persistent social divisions underlying the nuclear waste issue.

\subsection{Technical and Political Issues in Nuclear Waste Disposal}

The concept of burying nuclear waste in the ground is based on the idea that thick bedrock can form a long-term barrier to the radioactive release of nuclear waste into the ecosystem until the waste decays to the same level as the background radioactivity of the rock 
itself, which can take hundreds of thousands of years (Ontario Power Generation, 2016c, p. 1). The idea of burying nuclear waste in rock has a long lineage, originating in the 1960s after methods such as incineration, shallow land burial in trenches, and containers dumped in the ocean were increasingly found or regarded to be problematic (Burns \& Briner, 1987, pp. 20-30). Ultimately, the concept of nuclear waste burial has expanded to incorporate the use of engineered barriers for minimizing the impact of geological uncertainties involved in DGR siting. The need for engineered barriers became particularly salient after Asse II, a geological repository for nuclear waste improvised in a salt mine in Germany during the 1960s, was observed after several decades to be unstable (Pekinpaugh, 1987, pp. 47-49). Even with engineered barriers, however, it is extremely difficult to perfect contingency management, as was demonstrated when the United States Waste Isolation Pilot Plant (WIPP) in New Mexico experienced a minor radioactive release in 2014 due to poor packing of materials by a contractor (United States Department of Energy, 2016).

Despite these setbacks, nuclear scientists and regulators continue to favour the option of geological burial and to regard it as the safest prospect for disposing of nuclear waste (Brown \& Letourneau, 2001, p. 125; Slovic, 1993, p. 676). DGRs are accordingly now in various phases of testing, construction, and use in numerous countries, including Sweden, Finland, Japan, Korea, France, Switzerland, the United States, and Canada. However, many scholars and observers argue that efforts to bury nuclear waste underground should be halted due to long-term uncertainties (Shrader-Frechette, 1993; Fuji Johnson, 2008; Durant, 2009c; Murphy \& Kuhn, 2009). Such scholars instead give preference to above-ground storage options that would enlist ongoing institutional and social measures for more directly monitoring the nuclear waste over the long-term. Gordon Edwards, President of the Canadian Coalition for Nuclear Responsibility, 
envisions a set of procedures he calls "rolling stewardship" for securing and monitoring nuclear waste above ground that would incorporate "a ceremonial 'changing of the guard' every 20 years accompanied by a thorough refamiliarization with and recharacterization of the waste" (Edwards, 2015, p. 3). In response to such conceptions, nuclear engineers and regulators respond that “options which rely on monitoring, surveillance or other institutional controls as a primary safety feature for very long periods are not recommended ... because methods for ensuring the continuity of controls are not considered very reliable beyond a hundred years" (Atomic Energy Board of Canada, in Brown \& Letourneau, 2001, p. 25). Nor would rolling stewardship put to rest concerns of DGR critics regarding "the effects of human error in thwarting containment" (Shrader-Frechette, 1993, p. 67) due to the requirement of "periodic repackaging" it would introduce (Edwards, 2015, p. 3).

An additional complication in arbitrating among nuclear waste management options is that they bear tangibly, as well as symbolically, on the viability of nuclear energy production. Institutionally demanding proposals by anti-nuclear groups for ongoing management of nuclear waste in above ground storage are typically accompanied by the caveat that doing so is only feasible for existing levels of waste, so ongoing reactors must be phased out (Shrader-Frechette, 1993, p. 248). As such programs would have to be costed out by proponents for millennia, they make the aggregate expense of nuclear power even more exorbitant than it already is, militating against expansion. Finally, above-ground storage approaches reinforce the idea that the problem of nuclear waste is technically "unsolved," in the words of Shrader-Frechette (1993, p. 98). As Easterling and Kunreuther (1995) elaborate, groups opposed to nuclear power tend to "view geologic repositories as inappropriate regardless of how much might be achieved in the improved storage of spent fuel" because, as an ostensibly "permanent solution" for nuclear 
waste, they could help to "reinvigorat[e] the nuclear power industry" (p. 142). Conversely, Durant (2009b) argues that advocates of nuclear power are in pursuit of permanent solutions to nuclear waste disposal because they give "tacit approval to refurbish commercial nuclear reactors or build more" (p. 75). This entangling of nuclear waste storage with nuclear power generation raises the likelihood that policy actors have complex affinities with different storage solutions that extend beyond their calculations of the material risks involved.

\subsection{The Pursuit of Nuclear Waste Disposal Solutions in Canada}

The four-decades-long pursuit of geologic disposal of nuclear waste in Canada is captured in official government reports and documents as well as in critical reflections by scholars such as Durant (2009a) and Fuji Johnson (2008). The Canadian Ministry of Energy Mines and Resources initiated a study in 1977 to analyze how Canada's nuclear waste ought to be managed. This study culminated in the Hare Report, which concluded that deep geologic disposal in the impermeable granite of the Canadian Shield would be the best way to dispose of used nuclear fuel and proposed to develop a functioning DGR in that geographical region by 2000 (Aikin, Harrison \& Hare, 1997, p. 6). The idea of a DGR was further studied through the 1980s, with the Auditor General of Canada affirming that long-term disposal of nuclear waste should be undertaken as soon as possible in keeping with existing technical knowledge to minimize "federal liabilities" as well as "the burden on future generations" (Brown \& Letourneau, 2001, p. 115). These conclusions led the Government of Canada to initiate the Policy Framework for Radioactive Waste (1996), giving the federal government responsibility over high-level nuclear waste — that is, nuclear fuel—but leaving nuclear corporations with responsibility for dealing with low and intermediate level waste, which is essentially the 
radioactive garbage produced by mining and refining uranium as well as running and decommissioning nuclear reactors.

The quest to develop a DGR in Canada has, meanwhile, virtually always been accompanied by concerns about public resistance. As early as the Hare Report of 1977, it was recognized that "only wide public consultation can sweep away" the "myths and suspicions" that surround nuclear waste (Aikin, Harrison, \& Hare, 1997, p. 51). After a subsequent review of the DGR concept commissioned in 1988 by the Canadian Environmental Assessment Agency, the chair of the review panel, Blair Seaborn, expressed similar ambivalence in his report on the panel's findings. He concluded in this report that even if the DGR concept is relatively safe, and "industry has the best expertise to make technically and economically sound decisions," the social acceptability of the DGR had not been demonstrated amongst some policy communities, who were insisting on "the democratic incorporation into policy processes of a range of actors much broader" (Fuji Johnson, 2008, p. 27). Seaborn thereupon called for the initiation of a more publicly consultative policy process to examine "the social, economic, and environmental implications" of deep geologic burial of nuclear waste to existing and future generations (Fuji Johnson, 2008, p. 26). In keeping with the spirit of the Seaborn Report, the Nuclear Waste Management Organization (NWMO), a non-profit organization established under the 2002 Nuclear Waste Fuel Act and funded by the nuclear energy industry, launched a consultation in 2003 with the purpose of permitting "non-traditional policy actors from a range of environmental and religious organizations, local communities, and aboriginal nations [to be] active in decisionmaking processes" (Fuji Johnson, 2008, pp. 24-25, 31). The consultation, which led to the development of a nuclear waste policy framework in Canada, was described as a "collaborative . .. management approach for the long-term care of Canada's used nuclear fuel that is socially 
acceptable, technically sound, environmentally responsible, and economically feasible" (Nuclear Waste Management Organization, 2003, p. 10). Ostensibly based on the consultation, the NWMO adopted a principle of "adaptive phased management" to guide the ongoing storage of high-level nuclear waste, which incorporated storing it on site in the short term, gradually pursuing a permanent site for geologic disposal, and leaving options open in the meantime to incorporate further scientific and social developments (Fuji Johnson, 2008, p. 32). However, environmental policy actors objected to this conclusion on grounds that it paved the way forward for a DGR (p. 32). Nonetheless, the NWMO has since initiated a siting process leading to the self-nomination of a dozen towns for nuclear waste disposal, some of which are located in the granite Canadian Shield in Northern Ontario and Saskatchewan, while others are located in the Ordovician shale and limestone geology of Southern Ontario. The latter geology—which is also in consideration for the OPG DGR — has been less studied than Canadian shield granite, but theoretically demonstrates favourable characteristics such as long-term stability, low porosity, and low permeability, while reducing distances to transport nuclear waste produced in Southern Ontario's reactors (Jensen et al., 2009).

\subsection{The OPG DGR}

Canada's low-level nuclear wastes - including experimental and medical waste from the post-war period onward and nuclear waste since the first reactor was launched in 1965-are in the meantime stored above ground by their producers (Kemp, 1992, p. 146). Much of this waste is currently stored in the Western Waste Management Facility (WWMF) near the Bruce Nuclear Power Plant in the Municipality of Kincardine, on the shores of Lake Huron. Shortly after the passage of the Nuclear Fuel Waste Act in 2002 that legislated the responsibility of corporations for low and intermediate level nuclear waste, Kincardine town council approached OPG and 
requested a long-term solution for disposal of waste currently stored in the WWMF (Ontario Power Generation, 2016a). OPG subsequently contracted an independent study to investigate a range of approaches to longer-term management that settled on a DGR as the safest option (Ontario Power Generation, 2016a). Thereupon OPG initiated an environmental impact assessment (EIA) of a DGR project sited on land they own adjacent to the Bruce Power Plant and near the WWMF (Ontario Power Generation, 2016a). In 2015, after two years of hearings, the DGR proposal achieved a favourable environmental review and licensing application from the Canadian Environmental Assessment Agency (CEAA) and the Canadian Nuclear Safety Commission (CNSC), respectively. If built, the OPG DGR will be the first DGR in Canada.

The social acceptability of the DGR in Kincardine, a town that already hosts a power plant, is congruent with the relative degree of ease that has been observed internationally in siting nuclear waste facilities near nuclear plants, where "basic understanding and trust may be most easily achieved" due to the community's familiarity with and economic involvement in nuclear activities (Kemp, 1992, p. 31). Easterling and Kunreuther (1995) likewise describe the existence of a "doughnut effect" with respect to nuclear waste projects, whereby communities closest to projects tend to view them favourably, while communities in the wider regions of these projects are often averse to these projects because they regard themselves as receiving risks but no benefits from them (pp. 153-163). In keeping with this logic, community action groups comprising citizens from municipalities adjacent to Kincardine have been the source of strongest opposition to the OPG DGR. These include the Inverhuron Committee, which incorporated in late 2012 specifically to oppose the OPG DGR (Inverhuron Committee, 2013), the Bluewater Coalition against the DGR, made up of citizens' groups from Bruce, Grey and Huron counties (McPhee, 2012), and Huron-Grey-Bruce Citizens on Nuclear Waste. Save Our Saugeen Shores, 
founded by some residents of the town of Saugeen Shores in early 2012 after they learned of their town council's plan to include the town in the NWMO's site selection process for a used nuclear fuel repository, also opposes the OPG DGR project (Save Our Saugeen Shores, 2016). ${ }^{2}$ These groups have established links with wider national environmental and social justice groups opposed to nuclear energy, including the Canadian Council for Nuclear Responsibility, The Sierra Club, The David Suzuki Foundation, The Council of Canadians, Northwatch, and Great Lakes United, amongst others (McPhee, 2012; Inverhuron Committee, 2013, p. 2).

Stop the Great Lakes Nuclear Dump (STGLND) is a community action group that splintered off other local opposing community groups in 2013 with a focus of rallying wider national as well as international opposition to the DGR project (Inverhuron Committee, 2013, pp. 2-3). STGLND, which has been particularly adept at attracting attention to concerns around the OPG DGR from the population at large and on an international scale, appears to be driven by the commitment of one married couple, Beverly and Frank Fernandez. As of July 20, 2014, STGLND had solicited and obtained signatures on a web petitions from over 64,000 people, $67 \%$ of them from Ontario or the Great Lakes region (Stop the Great Lakes Nuclear Dump, 2014, p. 21). ${ }^{3}$ By November 2015, STGLND had also played a part in eliciting statements of opposition to the OPG DGR from 159 town and city councils around the Great Lakes, including Chicago, Milwaukee, Toronto, Kingston, Windsor, and Sarnia, and triggering several U.S. Congressman and Senators to submit resolutions upon the issue to their respective legislatures, on the grounds

\footnotetext{
${ }^{2}$ Save our Saugeen Shores (2016) has most recently "rebrand[ed] and expand[ed]" into the pithier SOS, with a new focus on helping communities around the Great Lakes stand up against the OPG DGR, much like that of Stop the Great Lakes Nuclear Dump.

${ }^{3}$ As of November 2016, the number of signators on the petition had topped 94,000.
} 
that the DGR violates international treaties to secure the water quality of the Great Lakes (Stop the Great Lakes Nuclear Dump, 2016). ${ }^{4}$

According to Kemp (1992), regional opposition to nuclear waste projects can become exacerbated if perceptions circulate that the siting process was less rigorous than it should have been or that the DGR was sited based on convenience rather than of optimal geology (pp. 31-32). Unfavourable perceptions such as these have taken root in the case of the OPG DGR, in part because Southern Ontario's Ordovician geology has been far less extensively studied for nuclear waste than the granite geology of Northern Ontario's Canadian Shield. The move to consider a Southern Ontario site for nuclear waste disposal has been called "speculative" and "expedient" by scholars opposed to nuclear energy (Murphy \& Kuhn, 2009, p. 157) and has raised suspicions that the OPG DGR is a "Trojan Horse" intended to set a precedent for NWMO to site Canada's DGR for long-term nuclear waste in the same geology (Stop the Great Lakes Nuclear Dump, 2016a). The prospect of opening up Southern Ontario geology for consideration may indeed seem attractive to proponents, due to the opportunity it presents to shorten transport routes for nuclear waste material, which would likely raise concerns in communities along routes. A Southern Ontario site for nuclear waste disposal may also be attractive due to its ability to counter settle accusations of environmental injustice levied by Northern Ontarians, whose Canadian Shield geology has long been expected to host nuclear waste produced for the benefit of energy customers in the southern region of the province (Murphy \& Kuhn, 2009, p. 156). As an example, the community action group Northwatch (2012) formed itself in 1988 to "prevent

\footnotetext{
${ }^{4}$ This claim has, however, been countermanded by the approval given by the Michigan Department of Environmental Quality as well as the U.S. Environmental Protection Agency in 2012, with the former explicitly observing that they have "no technical objections" to evidence in favour of the project put forth in OPG's Environmental Impact Statement, and the latter indicating that the DGR design is more than adequate to keep the waste "isolated from surface and drinking water" (McKay, 2013).
} 
northeastern Ontario from becoming the receiving ground for foreign wastes, whether it's Toronto's garbage, Ontario's biomedical waste, [or] Canada's nuclear reactor fuel waste.”

The movement against the OPG DGR project arrives in the wake of two decades of regional and national opposition to perpetuation of nuclear activity in Canada. Numerous nongovernmental organizations (NGOs), including the Canadian Coalition for Nuclear

Responsibility, Energy Probe, the Pembina Institute, Northwatch, as well as Canadian branches of international organizations such as Greenpeace Canada and the Sierra Club, have been lobbying for a Canadian phase-out of nuclear power for several decades, with many acting as intervenors in the OPG DGR environmental assessment (see Figure 1: Policy Map [in Section 3.3]). On an international front, the Nuclear Free Great Lakes Campaign, based in Illinois, has acted as a coalition of groups lobbying to remove nuclear power from both sides of the Great Lakes border since 1999. This longstanding concern from national environmental pressure groups against nuclear power generation in Ontario has laid the groundwork for opposition to new nuclear facilities such as OPG's proposed DGR.

\subsection{Public Consultation on Nuclear Waste Disposal}

Questions regarding "who" makes decisions about nuclear waste have consistently been raised over the same period as the technical questions about nuclear waste disposal. Nuclear waste was entirely managed by its producers in the inter-war and post-war period. Only subsequently, in the 1970s and 1980, did nuclear waste management come to be regulated by governments (Lochbaum, 1996, pp. 85-86). During this period, governments typically tried to site repositories in what they believed to be optimal locations, an approach that in many cases aroused local resistance that led to the tabling of these projects (Berkhout, 1991, pp. 69-81). Since the 1980s, questions regarding nuclear waste management and siting have accordingly 
enlarged to encompass not only "what is to be done, but also how we decide what is to be done" (p. 4). During the 1990s, the OECD Nuclear Energy Agency observed that progress in nuclear waste disposal was being impeded by poor public confidence in nuclear waste management institutions and processes and recommended that these could prospectively be improved through greater public involvement (Brown \& Letourneau, 2001, p. 123). Also in the 1990s, a broadbased international norm of public participation in environmental decisions such as nuclear waste siting was further enshrined in Principle 10 of the UN's Rio Declaration on Environment and Development, which held that "[e]nvironmental issues are best handled with participation of all concerned citizens" (United Nations Environmental Programme, 1992).

Much attention over these past two decades has been given to the issue of how to improve public involvement in decision-making around nuclear waste management, with the understanding that "[f]ormal and substantive involvement in the decision-making process enhances acceptance" of nuclear waste projects in addition to promoting environmental justice (Flüeler, 2006, p. 48). Gradually staged, widely consultative, analytic-deliberative processes that treat the public respectfully, integrate technical and lay knowledge, and adapt to inputs from public engagement processes are now widely recommended in pursuit of both these ends (Rosa et al., 2010, p. 763). Further work on how to make decisionary processes concerning nuclear waste management more democratic and acceptable has been pursued by Easterling and Kunreuther (1995), who see the achievement of consent-based, consensual outcomes in which all affected stakeholders "feel their concerns have been met" (p. 168) as a gold standard. They call for democratic siting approaches that prioritize fairness, legitimacy, and integrity and offer communities influence over the shapes of projects, veto rights, and authority to shut down facilities (Kunreuther, Easterling, Desvousges, \& Slovic, 1990). A more recent study produced 
for the U.S. Department of Energy anticipated consent-based processes will be able to obtain "substantially greater support than traditional, single-function facilities employing top-down siting strategies" (Jenkins-Smith et al., 2013, p. 57). Evidence on behalf of the consent-based approach is provided by the DGR siting that has held most closely to this principle: the Östhammer repository in Sweden, which is widely seen as having been successful and as being acceptable to the local community (Metlay, 2013). Consent-based siting is the general formula for the NWMO's current process to site high-level nuclear waste in Canada (Metlay, 2013). Nonetheless, Yim observes that successful consent-based siting requires the presence of favourable public attitudes, including an acceptance that "the problem [of managing the nuclear waste] belongs to society" that benefits from nuclear generation (Yim, 2009).

Canadian analysts of nuclear waste management decision-making processes tend to support the types of consultation processes undertaken by the NWMO, but disagree about what their scope should be as well as what outputs should look like. On the one hand, Brown and Letourneau (2001) agree a fulsome discussion of the ethical issues involved is necessary, but believe that such a discussion should not be so protracted as to hold up progress in the direction of a long-term disposal solution, since "a time may arrive when present storage methods are no longer considered safe" (p. 124). By contrast, Fuji Johnson and Durant (2009) call for yet more exhaustive processes of public deliberation around nuclear waste that would allow citizens with technical expertise, those with other types of expertise, and citizens with relevant "life experience, cultural practices, [and] orally transmitted knowledge" to consider amongst themselves "the reasons for and against perspectives" and to seek an agreement that is respectful of the diversity of these viewpoints and the reasons behind them (p. 84). They believe that in the case of the NWMO consultation these conditions were not met, with the NWMO "dismissive of 
important perspectives" in its ultimate recommendation, which they see as sidelining the input of civil society groups and favouring nuclear energy producers (Fuji Johnson, 2008, p. 38; Fuji Johnson \& Durant, 2009, p. 30). Fuji Johnson (2009) observes that recommendations published by the overseeing body excluded mention of concerns relating to "personal and collective autonomy, matters of fairness in the distribution of risks and benefits, as well as cultural, religious, and 'metaphysical' values" (p. 99). She also criticizes the NWMO's mandate of "public consultation" as involving no legislated requirement that policy outcomes be reflective of what happens in the deliberations, which she sees as necessary for political justice (p. 100). ${ }^{5}$ One can conclude that Durant and Fuji Johnson seek a highly different outcome from deliberative processes around nuclear waste than Brown and Letourneau do, prioritizing not the greenlighting of a concrete disposal solution, but rather an ultimate consensus that is acceptable to all participants.

Yet the way Fuji Johnson describes that consultation suggests that such a nuclear waste management solution would have been impossible to achieve, with some groups testifying that a resolution to pursue a certain nuclear waste solution should only have been made amidst, or after, a public debate on the role of nuclear energy production in Canada (Fuji Johnson, 2008, p. 99; 2009, p. 105). Based on their public profiles, however, virtually all the groups who opposed the DGR would have voiced strong opposition to the continuation of nuclear energy, while the groups who supported the DGR would have voiced a position of strong support for extending nuclear production. A process designed to ensure full airing of the nuclear energy issue alongside

\footnotetext{
${ }^{5}$ Fuji Johnson's ideal of determinative public deliberation is notably at odds with the present legislative requirements of public participation in Canada, which is designed not to elicit citizens' approval of projects but rather to elicit knowledge they have regarding the potential effects of projects. The standard invitation that the Canadian Environmental Assessment Agency (CEAA) issues on projects is accordingly for the public to "help inform this decision" by providing "comments ... on the project and its potential effects on the environment" (Canadian Environmental Assessment Agency, 2016).
} 
the nuclear waste disposal would likely have further delayed and complicated the discovery of a consensual solution. For Fuji Johnson (2008), deliberative policy processes "constitute a framework in which policy actors can fairly work through their different perspectives on their values, interests, and needs at stake" (p. 111). However, as Fuji Johnson (2008) reported, little working through appears to have happened at the NWMO consultation, as most participants "walked away with their fundamental positions unchanged" (p. 102).

Despite Fuji Johnson's aspirations for fair and successful democratic deliberation on nuclear waste, therefore, her account of the NWMO consultation affirms that when it comes to longstanding polarized risk issues like nuclear waste disposal, processes of public consultation and democratic deliberation are unlikely to forge new and genuine consensuses. Flüeler (2006) agrees that current models for deliberative processes concerning risk issues typically lead to "sub-optimal decision making," due to the inability of these processes to coordinate "“absolute' statements" regarding risk that are put forth in the proceedings (p. 167). Jasanoff (2003) likewise finds that in the public participation component of regulatory processes, arguments are generally made not to advance mutual understanding of the issues, but rather to advance political agendas by entities "challeng[ing] scientific points on political grounds" (p. 237). Even Fuji Johnson (2008) acknowledges that her deliberative ideal is also not aligned with that of the stakeholders that tend to participate in these processes, since "people with a history of activism or with direct stakes in a given policy area" are typically uninterested in "reasoning towards a shared interest" (p. 109). Fuji Johnson accordingly recommends deliberative procedures that more greatly favour the participation of "unaffiliated participants" (p. 109). Yet a recent citizen jury held in November 2016 on nuclear waste disposal in South Australia demonstrates the difficulty of mounting a successful deliberative process on the subject involving supposedly unaffiliated 
citizens. In the observation of one expert witness, "many jurors arrived with their minds already made up for the negative and worked assiduously to that end" by "drowning out debate," "gaming" the system to exclude experts who would give voice to certain arguments, and ultimately producing, in the words of another expert witness, "the most biased process [he had] ever seen" (Manning, 2016).

As we will see in Chapter 2, there are persuasive theories as to why such deliberative processes fail to produce agreements on heavily polarized issues. As Schön and Rein (1994) argue, certain types of policy controversies tend to persist over long periods of time, with the surfacing of yet more facts or arguments not leading to the production of rational policy decisions; as "[r]eason ends up taking sides rather than building rational bridges of persuasion from one side to another" (pp. 8-9). An underlying syndrome in such controversies, as Kahan and colleagues have observed, is that people tend to only credit information put forward by experts who support positions they already hold, obstructing the prospect of perspectival change that could follow from the integration of new information (Kahan et al., 2011). Yet as will be suggested in Chapter 7, it may be possible to reconfigure the concept of public deliberation to produce more widely acceptable and "societally robust" (Flüeler, 2006) outcomes if participants can be found who are willing to attend open-mindedly to each other's evidence, and to be facilitated in dedicated ways that move them beyond their cultural narratives into sites of common ground that can be shared by diverse policy actors (p. 263).

\subsection{Public Consultation on the OPG DGR}

The OPG DGR public consultation occurred in stages and was administered by a number of different policy actors: OPG itself; the Municipality of Kincardine; and the Government of Canada's CEAA. As OPG (2005) describes, its engagement activities began in 2002 and 
included providing information and opportunities for input to members of the public and stakeholder groups. Its process of soliciting public input proceeded by several means:

- the maintenance of a Community Consultation Centre in Kincardine;

- ten open houses held in five nearby municipalities, cottage communities, and local First Nations and Métis communities; and

- distribution of fact sheets and presentations to community groups.

OPG claims to have incorporated public and stakeholder input into their original determination of the DGR as a preferred technology from a range of four options, consisting of a DGR, the continuation of the status quo, and the construction of either surface or shallow concrete vaults. It also claims to have incorporated public input in the identification of valued ecosystem components; and in the orientation of the DGR project relative to Lake Huron.

In addition, a market research firm contracted by OPG conducted a public opinion survey in January 2005 in which they asked Kincardine residents the question: "Do you support the establishment of a facility for the long-term management of low and intermediate level waste at the Western Waste Management Facility?" (Ontario Power Generation, 2005, pp. 83-89). According to OPG (2005), the poll reached nearly three-quarters of all households in the municipality, both permanent and seasonal, and was subsequently evaluated by a third-party auditor. The results showed that $60 \%$ of respondents supported the idea of a long-term management facility for the waste, $22 \%$ were opposed to the idea, and 35\% did not have an opinion or were neutral (pp. 83-89). The generally strong level of public support and the endorsement by Kincardine town council reportedly led OPG to determine that it was proceeding with "community acceptance" (pp. 90-91). However, the communication action group Stop the Great Lakes Nuclear Dump (STGLND) (2013) argues that the survey question was too vague, 
the consultation region was too small, and the process too perfunctory for the results to genuinely reflect or represent "community acceptance" (pp. 5-6). They claim the poll failed to tap into the views and attitudes of individuals and communities beyond the limits of the municipality who could be affected by a release of nuclear waste into the Great Lakes to which the DGR would be proximate (pp. 5-6). They further aver that many Kincardine residents produced an affirmative response to the question because they are OPG employees or retirees and thus depend on the corporation for a salary or pension, placing them in a "conflicts of interest" (p. 6).

Finally, the Joint Review Panel (JRP) review, which conjoined an environmental assessment of the DGR project conducted by the CEAA with a licensing application to the CNSC, held approximately one month of public hearings for the project in the fall of 2013 as well as two additional weeks of hearings in the fall of 2014. A panel of experts nominated by these two agencies oversaw the JRP review, thereby helping to prevent "regulatory capture." ${ }^{\text {In }}$ my observation of several of the additional hearings on the OPG DGR held in 2014, the JRP undertook their commission to review the environmental assessment and licensing application with seriousness and rigour, as demonstrated in how they called for extra hearings in 2014 on the grounds that unresolved questions still remained, or had arisen, after the 2013 hearings. In keeping with the Canadian Environmental Assessment Act of 1995 (CEAA 1995), which legislated that environmental assessments permit the participation of "interested part[ies] among the public," these hearings were open to the public and provided time for any citizen or interest group who wanted to speak to a topic in consideration. ${ }^{7}$

\footnotetext{
${ }^{6}$ Regulatory capture is a term describing a regulator whose decisions are excessively beholden to the interests of the corporations it is supposed to be regulating. As Hempling (2014) describes, regulatory capture is "evidenced by a body of commission decisions or non-decisions - about resources, procedures, priorities, and policies, where what the regulated entity wants has more influence than what the public interest requires."

${ }^{7}$ Regrettably, future environmental assessments may be less liberal in their consideration of interested parties, as CEAA 1995 has since been superseded by the Canadian Environmental Assessment Act of 2012 (CAEE 2012), which defines an interested party more narrowly and explicitly as a person who is "directly affected by the carrying
} 
The hearings were also designed to be somewhat interactive, in keeping with JRP's description of their view of public engagement as "an interactive and iterative process of discussion among citizens that contributes meaningfully to decisions" (Swanson et al., 2015, p. xiii). The procedural decision most amenable to the interactive character was that the review did not feature designated days on which members of the public spoke, and others on which professional and other interested bodies spoke, as has been the case in other JRP assessments. ${ }^{8}$ Each day of the hearings would involve the consideration of a broad issue, and representation on that issue would be made by the proponent OPG and the regulator, the CNSC, followed by representatives of other government departments and ministries; of municipal councils and First Nations tribal associations; of professional associations and labour unions; of national, regional, and local organizations, including environmental organizations and clubs; as well as by individual members of the public. The result of this schedule was that all participants on each day could hear what all the others had to say; as one intervenor disclosed in an interview, "this is the only place where people are forced to listen to each other" (S. Greer, personal communication, September 9, 2014). Further in keeping with the JRP's commitment to interaction, members of the JRP frequently directed questions at people who gave oral statements and permitted other people in the room to direct questions at them. The panel would also at times direct points that a citizen had raised to the proponent or the regulator and oblige them to respond, either on the spot or the next day. Finally, any citizen in attendance could sign up to ask

out of the designated project or ... has relevant information and expertise." Gibson (2012) hypothesizes this could "exclude at least some members of the public and public interest organizations" (p. 184). Additionally, while according to CEAA 1995 an environmental assessment would be triggered automatically by "the definition of the project and its potential impacts," according to CAEE 2012, the relevant ministry and the CEAA may decide whether a project warrants an environmental assessment on a case-by-case basis, which could lead to fewer public reviews (Doelle, 2012, p. 15).

${ }^{8}$ The Joint Panel Review for the Northern Gateway Pipeline, for instance, held designated days for large numbers of citizens who made oral presentations to the panel in quick succession and with generally no interaction. 
questions of any other person or institution who had testified through the day, and members of the JRP would occasionally help citizens clarify their questions to obtain a precise answer.

On the negative side, the hearings were conducted in Kincardine, Ontario, a two-to-threehour drive from the nearest cities of London and Toronto, so that even though interested Canadians were invited to provide comments, it was not convenient to do so in person. Further, the hearings were organized in a way that placed the proponent, OPG, at the front of the room alongside the regulators and government officials, whereas members of the public were required to sit in chairs towards the back of the room, derogating intervenors beneath the status of the proponents. As one anti-nuclear intervenor told me, the process constituted them as "underdogs" amidst a clear power differential where representatives of OPG would "go to their own washrooms [and have] meals catered" (A. Tillman, personal communication, September 9, 2014). That same participant pointed out unfair features of the hearing: “[W]e [couldn't] ask questions until after [OPG/other institutional actors] ask questions" and "they [could] get back to us later" with answers whereas "we [had] to know every single word," i.e., the intervenors did not have the same opportunities to defer or correct their answers to questions as the proponent did.

Despite these unbalanced features of the public hearings, however, it was clear that a significant effort was made by the JRP to ensure the public hearings and other forms of input and oversight of the OPG DGR decision were fulsome, interactive, and meaningful, presumably in part so that their decision would be seen to have legitimacy. Yet the social divisions around the DGR do not appear to have been remedied by these efforts, as STGLND and other organizations opposed to the DGR have since voiced their displeasure at the JRP's decision to conditionally recommend the project and have called on the government to defeat it (Battagello, 2015). 


\subsection{Social Divisions around Nuclear Waste}

Numerous scholars have attempted to anatomize the social and political divisions around nuclear waste. The most comprehensive studies are Kemp's (1992) description of the politics of radioactive waste disposal in the United Kingdom; Slovic (1993) and Slovic and Peters's (1996) account of divisions in risk perception relating to nuclear waste; Easterling and Kunreuther's (1995) research on nuclear repository siting in the United States; Berkhout's (1991) intersectional analysis of nuclear waste policy processes across Europe; Flüeler's (2006) discourse analysis of the Swiss experience of siting a nuclear waste repository; and Fuji Johnson's (2008) case study of the Nuclear Waste Management Organization's public consultations around high-level nuclear waste disposal in Canada.

On balance, these scholars tend to see the fundamental schism in the controversy as falling between an elite conjunction of governmental and corporate proponents of nuclear waste expert, on the one hand, and the lay public, on the other. For example, Slovic (1993) describes how public attitudes to nuclear and chemical risks are sensitive to "technical, social, and psychological qualities of hazard that [are] not well-modelled in technical risk assessments by experts, ensuring that the risk analyses of the latter have little influence over those attitudes" (p. 675). Flynn, Slovic, and Mertz (1993) similarly observe a distinctive difference between the public and nuclear professionals regarding perceptions of risk from a high-level waste repository (p. 646). In the words of Beck (1988), addressing divided social perceptions about technological risk, citizen and expert groups "talk past each other ... [s]ocial movements raise questions that are not answered by the risk technicians at all, and the technicians answer questions which miss the point of what was really asked and what feeds public anxiety" (p. 30). 
Moreover, according to these scholars, it is not merely the nuclear materials themselves that many lay people distrust, but also the scientists and engineers whose expertise underlies their construction (Berkhout, 1991, p. 2). As Wynne (1996) details in a case with specific reference to the nuclear industry, citizens with practical, lived experience frequently express scepticism of the safety practices touted by institutions and regulatory bodies. Owens (2000) elaborates that "[1]ay people may not understand the complexities of the science ... but they are aware of commercial imperatives, sceptical about politics, and distrustful of the competence and impartiality of regulatory frameworks" (p. 1142). Given the long epochs in which nuclear waste remains radioactive, claims by nuclear engineers that they can design a DGR that will function as a permanent solution is observed to be considered audacious, arrogant, and even fraudulent—a tactic of "abandon[ing]" responsibility for the waste passed off as a viable management strategy (Flüeler, 2006, p. 61; Murphy \& Kuhn, 2009, p. 153; Edwards, 2015).

Public distrust in the science of nuclear waste management is also observed to manifest more broadly as suspicion in the motives, practices, and ultimate ends of the types of large institutions involved. Kasperson, Golding, and Tuler (1992) have observed that, "intense public opposition and protest in hazardous facility siting" is based in part on "a broad-based loss of trust ... in institutions . . . over the past three decades" (pp. 172-174). Scholars such as Winner (1980) have proposed that technologies like nuclear power are inherently untrustworthy due to the centralized, secretive, and non-transparent institutions required to maintain them (p. 71, 159). By contrast, Winner cites an argument by Hayes (1977) that "dispersed solar sources" are "more compatible ... with social equity, freedom and cultural pluralism" (p. 159). The cultural affinity between a preference for decentralized forms of power-such as solar, wind, and small-scale hydro development - and a concern for social democracy can be found in the new Leap 
Manifesto, which identifies these causes with each other (Leapmanifesto.org, 2016). ${ }^{9}$ Invoking a similar range of political concerns, Fuji Johnson observes that "those articulating concerns for social and environmental justice and participatory democratic legitimacy" at the NWMO hearings bore a challenge to "faith in scientific, technological and economic development" (p. 11).

Yet, while many scholars attribute this distrust of nuclear power and its associated scientific, governmental, and capitalistic institutions to 'the public,' it is questionable whether it actually does represent the public as such or rather a specific socio-cultural cohort of it. Voting patterns and surveys do not support the claim that most of the public lacks faith in scientific, technological, and economic development or, to an overwhelming extent, distrusts nuclear power. In Canada, acceptance of nuclear power runs at roughly 40\% (Hanaina, Jenden, Lloyd, \& Donev, 2015) and 54\% in Ontario, the province in which most of the country's nuclear power plants are located (Canadian Nuclear Association, 2012). In the United States, public faith in scientific institutions has also held steady at approximately $40 \%$ since the early 1970 s (Sense About Science USA, 2016), while 70\% of Americans say the benefits of science and technology outweigh the adverse effects (Funk, Kennedy, \& Podrebarac Sciupac, 2016). These numbers point to the existence of a broad swath of citizens who do not subscribe to the anti-institutional and anti-science attitudes of the NWMO's anti-nuclear stakeholders. As such, Fuji Johnson's (2008) description the Canadian controversy around nuclear waste as pitting a "historically

\footnotetext{
${ }^{9}$ The Leap Manifesto is a petition issued in 2015 by several dozen well-known Canadian activists, public intellectuals, and artists - including Naomi Klein, Charles Taylor, and Leonard Cohen, among numerous othersand subsequently adopted by the New Democrat Party as a discussion paper. The Manifesto expressed 15 "demands" for societal changes with a view to both preventing climate change and addressing other industrial and social concerns it portrays as related. These demands, which cover a wide swath of left-wing policy goals, include a shift to $100 \%$ renewable energy, an end to all long-term extraction projects, the introduction of robust "energy democracy," an emphasis on local and ecologically based agriculture, as well as finance policy changes such a reversal of trade deals, cuts to military spending, and a hike in income taxes upon the rich.
} 
dominant coalition of government and industry officials...on the other hand, a historically looser grouping of actors from environmental and religious NGOs, as well as aboriginal nations" elides the position of citizens who do not distrust science, technology, capitalism, or nuclear waste and so do not normally agitate at these types of events (pp. 27-28). Further indication that antinuclear actors do not accurately represent the attitudes and self-perceived interests of the Canadian public as a whole can be found in the range of social and civil society organizations that came out in support of the OPG DGR during the public hearings, which included unions, sporting clubs, pensioner's associations, and even a conservation authority (see Figure 1: Policy Map).

All considered, these indications suggest that in Canada and likely elsewhere, the division that is often made among experts and lay people when it comes to characterizing pro- and antinuclear sentiment is not completely accurate. Rather, it suggests that a more precise opposition ought to be made between a substantial community of meaning opposed to nuclear waste generation and disposal and distrustful of its associated institutions; and another community of meaning that is not especially opposed to and distrustful of these processes and institutions and includes both experts and other citizens.

\subsection{Gaps in the Nuclear Waste Controversies Literature}

Two major gaps emerge in the literature on nuclear waste controversies. First, studies on opposition to technologies such as DGRs tend to describe opposition to these technologies as issuing from "the public." Yet, as I will argue in Chapter 2, the cultural theory of risk suggests that the major opposition to nuclear developments such as the DGR expresses the view of a specific segment of the public standing in opposition to another segment that is relatively comfortable with the ability of technical experts to manage nuclear energy and waste. This 
dissertation is limited in its ability to determinatively settle this question of the existence, size, and constitution of such a socio-cultural segment of the public at large. Still, it can at least illuminate a range of prevailing attitudes to nuclear waste management among the public, as well as among experts, by analyzing pro- and anti-DGR frames of OPG and STGLND as well as their underlying stories more fully.

Secondly, as we have seen, discourse around nuclear waste disposal is permeated with cultural attitudes about technology, science, capitalist institutions and the environment. Yet, few scholars of nuclear waste management controversies have fully considered the socio-cultural character of these attitudes and how they support polarized views of the risk of nuclear waste and what ought to be done about it. As the dissertation will show, a narrative analysis of this policy issue can help develop this understanding by revealing how underlying socio-cultural narratives diverge on key questions about nuclear waste, including what ethically responsible decisions about the risks of nuclear waste look like and who ought to make them. As the dissertation attempts to demonstrate, an analysis of the cultural symbolism animating different answers to these questions can prospectively help pave the way towards creating more constructive and practical consensus on this issue, as well as on similar and related ones that are becoming increasingly urgent. 


\section{Chapter 2: Theoretical Framework}

\subsection{Overview}

Whereas Chapter 1 explored how nuclear waste management has historically emerged as a policy controversy that is divided in relation to technical as well as social questions pertaining to risk, this chapter considers this conflict in theoretical terms, in terms of the roles played in these types of controversies by policy frames and the narratives that underlie them. It draws on narrative theories of policy, policy frame theory, and cultural theories of risk to describe how social cultures reproduce unconscious symbolic narratives about policy issues and maintain extensive and rigid normative and epistemological discourses anchored in these narratives. Finally, the chapter describes theories of communicative rationality and communicative competence (Habermas, 1990; Webler, 1995), proposing that these are essential ideas for fomenting a societal shift beyond currently paralyzing policy narratives on risk issues towards more constructive and collaborative culture-spanning deliberation on such issues. While the barriers presented by culture to successful deliberation on issues relating to technological and environmental risk are high, the dissertation ultimately finds evidence to suggest that focussed deliberative processes geared to evidence-based claims-making and claims-challenging can prospectively help citizens overcome the divisive impact of cultural frames and storylines and achieve more societally acceptable and stable decisions in these policy areas.

\subsection{Narrative Theories of Policy}

Discursive approaches to policy hold that policies and policy proposals obtain traction among constituencies by resonating with particular social meanings and ideological frameworks (Fischer, 2003, pp. 141-142). As Yanow (2000) describes, policies can be understood and analyzed in terms not merely of what they are meant to achieve, but of how they express social 
meanings such as ideals, beliefs, and feelings that make them acceptable and resonant amid social cultures (p. 6). Hajer (1993) describes how "discourse coalitions" conceptualize issues in socially shared ways that provide new handles for seeing them through their selection of discourse, which he defines as "ensembles of ideas, concepts, and categories through which meaning is given to phenomena," and which may include ethical and analytical approaches, historical references, and references to common myths (p. 12). Narrative theories of policy have similarly arisen to explain the way perspectives on issues and policies are structured around stories that give them discursive significance and power. Narratives are understood as a cognitive resource that enables individuals and groups to understand problematic situations by bringing together elements of reality that might initially seem unconnected and providing structures for understanding them coherently (Fischer, 2003, p. 140).

As Yanow (2000) points out, discourse analysis of policy narratives can be alternatively oriented towards the "purposes of argument and claims-making (the analytical approach of political science)" or towards "the expression of individual identity (a more psychological approach)" (p. 58). As an example of the former, Hajer (1993) describes policy narratives, or "story lines," as discourse-structuring devices that policy actors use to combine various policyrelated discourses "into a more or less coherent whole" that "imposes their view[] . . suggests certain social arrangements, and criticize[s] alternative social arrangements" (p. 47). In Hajer's (1993) view, what is most important about such story lines is how they compete with others in a "struggle for hegemony" to become embedded in institutions (pp. 53, 48). For Roe (1994), who emphasizes the epistemological character of these struggles,

policy narratives can be defined as those stories — scenarios and arguments— that are taken by one or more of the parties to the controversy as underwriting (that is, 
establishing or certifying), and stabilizing (that is, fixing or making steady) the

assumptions for policymaking in the face of the issue's uncertainty, complexity,

or polarization. (p. 3)

In the vein of Roe, this dissertation is concerned with how policy narratives make sense of policy situations for actors in a socio-psychological fashion, in keeping with the values and worldviews to which these actors subscribe.

Looking at the wider importance of narratives in culture helps to explain the source of the narratives that sustain policy frames at the level of both individual and group identity, and indicates some ways in which narratives are both productive and problematic in these respects. Anthropologists such as Clifford Geertz (1973) have described humans as "symbolizing, conceptualizing, meaning-seeking” animals (p. 140). Robert Fulford (1999) explains how narrative is a particularly compelling means of giving order to experience, as it reconstructs its linear character of transformation through time and thus seems to "to be rooted in reality" ( $\mathrm{p}$. 16). Yet the way narrative reproduces reality is selective and can be deceiving, Fulford warns, "persuading us that we understand more than we do" (p. 152). While strongly social constructivists' approaches to policy narratives, such as Hajer's (1993), assume that narratives are an inevitable feature of human efforts to grasp and contend over reality, realist approaches to narratives also highlight how narratives can frame reality in misleading and even deliberately distorting ways..$^{10}$ As Fulford (1999) holds, narratives be can politically dangerous,

\footnotetext{
${ }^{10}$ Social constructivists understand the world as only graspable through human ideas about it, while realists believe that humans have means to grasp reality in itself apart from conceptions about it, and so hold that distinctions can be drawn between more and less accurate conceptions of that reality (see Dempsey, 2000). A middle ground described by Best (1993), contextual constructivism, distinguishes between the kinds of things people typically believe, which are likely conditioned through social processes, and the glimpses of reality that can be obtained through robust processes of inquiry, for instance ones that are scientific and/or deliberative. This position best describes several the central scholars in this dissertation, including Schön and Rein (1994), Habermas (1990), and Kahan (2015b), as well as the assumptions of the dissertation itself.
} 
"manipulating our consciousness," as when they establish metaphorical correlations that transfer qualities from a person, object, or cause to another that does not actually express them (p. 152). Cognitive linguists George Lakoff and Mark Turner (1989) agree that metaphors have "power over us" because people are so used to thinking with them that they are unlikely to notice when they are being introduced, and are "predisposed to accept [their] validity" (p. 63).

The power and danger of policy narratives are further characterized in policy frame theory. The idea that frames underpin policy narratives draws conceptually on Goffman (1971), who defined frames as structures "which govern the subjective meaning we assign to social events" by prioritizing some parts of reality and excluding others (pp. 10-11). Urban Planning scholars Donald Schön and Martin Rein (1994) adapted the idea of the frame to policy sciences, proposing that policy options are defended through frames that highlight some aspects of reality and subordinate others (p. 26). In this regard, policy frames express underlying theories of "the way things are," "what is to be done," and "by whom" (p. 143). Further, they observed that policy frames are typically "tacit, which means that they are exempt from conscious attention and reasoning" and grounded in unconscious socio-cultural assumptions (Schön, D. and Rein, M., 1994, p. 23). Yanow (2000) affirms that the "meanings" that underlie policy discourses include "values, beliefs, [and] feelings" that are "hard to access directly" (p. 20). Schön and Rein theorize that policy frames are largely grounded in unconscious "generative metaphors" that diagnose social and material problems and implicitly narrate prescriptions of what is to be done about them (pp. 26-28). For example, a common generative metaphor, "disease and health," carries the technocratic sense that what is left to its own devices will often become degraded and require expert-driven fixes; another, "decline and fall," reflects the Romantic view that natural conditions are best and that degenerated entities need to be restored to their original conditions 
(Schön \& Rein, 1994, pp. 26-28). Political scientist Deborah Stone (1989) likewise describes how policy actors strategically use policy metaphors that emphasize either natural or mechanical causation and imply that either technological fixes or reparative social changes are required.

Further, policy frame theory indicates that policy frames and metaphors are embedded in social cultures, which are not necessarily ethnic or religious, but reflect clusters of people aligned with certain norms and beliefs amidst pluralist societies. The ways that policy frames derive from "culturally shared systems of belief" makes it especially difficult for people to think outside of these cognitive schemata (Schön, D. and Rein, M., 1994, p. 33). Hajer (1993) likewise describes how discursive constructs "predetermine the definition of a problem" for members of discourse coalitions, an effect he calls "discourse structuration" (pp. 45-46). Yanow similarly hypothesizes that policy meanings are derived from the experiences and backgrounds of communities and internalized by the community's members through forms of thought and language the community sustains to "promot[e] internal cohesion as an identity marker with respect to other communities" according to an "us-them" logic (pp. 21, 10).

As Schön and Rein (1994) further convey, the ways that frames and their underlying narratives reinforce divisions amid controversial policy issues make "public learning" difficult to achieve and ensure that society as a whole does not often come to agreement on these issues ( $p$. 8). A more typical outcome than resolution is "institutionalized policy contention leads either to stalemate or to pendulum swings from one extreme position to another, as one side or another comes to political power" (p. 8). Schön and Rein (1994) link their theory of policy frames with Thomas Kuhn's (1962) theory of scientific paradigms advanced in The Structure of Scientific Revolutions, which observed that holders of one paradigm are highly unlikely to embrace a conflicting one even when incoming evidence disproves their own, and that generational die-offs 
are generally required for new paradigms to succeed older ones (in Schön \& Rein, 1994, p. 47). Kuhn hoped the evolution of paradigms could be hastened through processes of translating and synthesizing knowledge, but Schön and Rein (1994) doubt such measures are effective, seeing few incentives for these types of translators to emerge and be accepted in communities (pp. 4748).

Schön and Rein (1994) see a more promising solution in forums in which participants "co-design" specific solutions for "situated policy controversies" (p. 175). As they describe, it is possible that during such practical forums focused on observing and mitigating the details of real situated problems, "the sponsors of conflicting metacultural frames may . . . be struck by similar perceptions of their policy situation" (p. 175). While such solutions may hold promise for certain local policy controversies, they seem less likely to work in nuclear waste controversies, however, which, as we have seen, are typically implicated in wider conflicts about energy policy that reach across larger regional, national, and even international scales.

\subsection{Cultural Theories of Risk Perception}

The problem of rigid policy frames that Schön and Rein (1994) describe is in some respects reiterated in cultural theories of risk perception. These theories raise challenges for the major ways that risk perception has been studied and understood over the past three decades, the most prominent of which has been the 'psychometric paradigm,' developed to explain the divergences between expert and lay assessments of risks. Early psychometric research by Starr (1969) sought to understand why lay perceptions of the risks associated with technologies varied so widely from the empirical accountings of the fatalities associated with them. Fischoff, Slovic, and their extended research teams $(1978,1988,1990,1993,1996)$ continued to probe the same questions, applying the idea of heuristics, or cognitive shortcuts, from decision theory to explain 
why lay risk perceptions are inflated by symbolic or emotional factors that do not bear on relative levels or likelihoods of harm. Another factor widely observed to elevate lay risk perceptions is sensationalist coverage of isolated incidents in the mass media, which was seen as leading to "social amplification" of certain risk concerns over and above the threats that they pose in probabilistic terms (Kasperson et al., 1988).

A sociological approach developed by Beck (1988), Wynne (1996) and Fischer (2000) emerged to challenge several key assumptions of the psychometric paradigm. Beck (1988) held that science, far from generating an authoritative view of risk that should be used as a benchmark against which public views are measured, is "incapable of reacting adequately to civilizational risks, since [it is] prominently involved in the origin and growth of those very risks" (p. 55). He proposed that instead of using science to perform risk assessments, society needs to re-orientate around "social rationality," which, while lacking the precision of science, is more capable of achieving a realistic overview of the cumulative detrimental character of technological risks ( $\mathrm{p}$. 7). Wynne (1996) made an highly influential intervention in favour of crediting local knowledge as more likely to be in touch with relevant risk factors that expert knowledge overgeneralizes and excludes. Fischer (2000) similarly argued for taking seriously the "cultural rationality" of lay citizens concerning technological risk on grounds that it features a more realistic sense of human fallibility and corruptibility than scientific risk assessment (p. 136).

These critical sociological approaches to risk have been important for counteracting excessive levels of credulity towards expert risk analysis and for bringing citizens into policy conversations around risk. Yet a problem with these sociological analyses of risk is that they provide little specific guidance for policy-makers and others on how to weigh or balance different risk perspectives when they are in tension. The sociological paradigm typically 
presupposes a constructionist epistemology, according to which there is no legitimate basis for evaluating frames and storylines other than on the grounds of whether the actors who present them are more, or less, powerful. Fischer (2000) accordingly cites Foucault's call to disrupt regulatory discourses that "produce" dubious "truth" wedded to elite power as a reason to elevate cultural rationality in policy discourse around risk (p. 25). For Beck (1988), the accuracy of social perceptions of "omnipresent pollutants and toxins" is less relevant than how these suspicions can help to reverse the destruction to which science and technology are dooming us (p. 73). Yet, it has become increasingly clear in recent years that elevating non-expert views on technologies such as vaccines to the same level of those of scientists can raise serious dangers for public health (Dubé et al., 2013; Greenberg, Dube, \& Driedger, 2017). In such contexts, whether policy actors have more power or less bears little on whether their policy prescriptions are functional in averting threats. In a similar regard, there is a growing understanding that cultural fears of radiation can lead to policies that raise risks across the board, for example in Germany, Japan and California, where nuclear plant shut-downs sought by Green parties and groups have led to elevated risks to health and climate as the electricity they had provided has been, for the most part, replaced by fossil fuel generation (Ropeik, 2016; Sarmadi, 2015). While sociological accounts of risk perception have provided useful insight into how more and less powerful policy actors contend with each other over risk decisions, it has not reckoned with questions of how to anticipate when the crediting of social rationalities stands to do more harm than good.

The cultural analysis of risk was an attempt to challenge the assumption that social divisions around risk are arrayed along a class-type hierarchy of "elites" versus "the people" (Peters \& Slovic, 1996). Instead, the cultural analysis of risks observes the most significant divisions around risk perception to abide between socio-cultural communities that are beholden 
to diverse worldviews and that include both experts and lay citizens. As cultural theorists of risk argue, worldviews develop amidst the life experiences of different communities, creating social identities and helping individuals with those identities interpret experiences according to consistent "system[s] of beliefs and moral codes" (Peters \& Slovic, 1996, p. 1437). Research on the impact of cultural worldview on risk perception was conducted through the 1980s and 1990s by Douglas and Wildavsky (1982), Dake (1991), and others. Douglas and Wildavsky (1982) argued that in contemporary society, risks function like tribal taboos, in accordance with EvansPrichard's anthropological observation that "the test of a dominant worldview ... [can be observed in that to which] people attribute dangers" (1937, in Douglas \& Wildavsky, 1982, p. 26). Individuals with hierarchical worldviews focus on risks of social disorder and immigration, individuals with egalitarian worldviews focus on the environmental risks of technology, and individuals with individualistic worldviews focus on risks of economic downturns, with little indication that any of these habitual risk concerns are more substantively harmful than any others (Douglas \& Wildavsky, 1982, p. 187). Verweij et al. (2013) accordingly call for policy-makers to avoid choosing among worldviews and their associated risk concerns and instead to chart a course between the risk concerns of plural worldviews through "clumsy solutions" amenable to several of them at the same time (p. 169).

Dake (1991) elaborated upon Douglas and Wildavsky's (1982) work by focussing on socio-technological worldviews, proposing that these worldviews "represent more-or-less integrative way[s] of responding to the complex issues raised by the protagonists in public controversies over technology" (1991, p. 65). As he noted, several researchers had observed a binary set of comprehensive worldviews concerning nature and technology taking shape during the 1980s (Cotgrove, 1982; Dunlap, 1983, in Dake, 1991). One worldview regarded nature as a 
“cornucopian" resource for humans and technology as a relatively reliable and manageable means to maximize that resource, while the other saw that view as impelling humanity towards environmental catastrophe and called for a shift to a more unintrusive relationship with nature (Cotgrove, 1982, in Dake, 1991). Dake (1991) further observed the former worldview correlating with hierarchical and individualistic attitudes and a focus on the benefits of technologies and the latter worldview correlating with egalitarian and fatalist attitudes and fears of the risks of many technologies, including nuclear generation (pp. 70-72). Buss, Crake, and Dake (1986), who also explored these two sets of attitudes, called the former "Worldview A" and the latter "Worldview B", and found Worldview A holders to hold favourable views of most technologies including nuclear power and Worldview B holders to be favourable to no technologies other than solar

\section{Worldview A}

- A high-growth, high technology society provides the best hope for raising the poor to a high state of material and social well-being.

- The ability to achieve human goals has been and will continue to be made possible through economic growth and technological progress.

- Hard-headed rationality should be the basis of decision making in society.

- Although centralization may cause some problems, it is needed in our society for efficient production and management.

\section{Worldview B}

- The social and environmental costs of continued technological growth and rising per capita energy consumption are intolerably high.

- The "new scarcity" (of physical resources, waste-absorbing capacity of the environment, and resilience of planetary life support systems) is qualitatively different from the scarcity problems "solved" by modern industrial production.

- Decision making in our society should be made as participative as possible and guided more by humane criteria.

- Decentralization of technology and of population is necessary if we are to have a just and free society.

Excerpted from a table by Buss, Craik, \& Dake, 1986, pp. 99-100

Table 1: Buss, Craik \& Dake's (1986) overview of socio-technological worldviews (summary), pp. 99-100. 
panels (pp. 107, 116); see Table 1. Other researchers also observed that these socio-technological worldviews correlated with starkly different framings of the risks of nuclear power, with Worldview A holders envisioning more positive imagery in response to the term "nuclear waste repository" and expressing higher trust in government decisions about technologies than Worldview B holders (Jenkins-Smith, 1993, in Peters \& Slovic, 1996, p. 1431; Peters \& Slovic, 1996). Finally, Worldview A holders were observed to favour cost-benefit analysis as a policy measure for decisions about technology, while Worldview B holders favoured public consultation (Buss, Dake, \& Craik, 1986, pp. 107, 116).

The most prominent current researchers investigating the relationship of cultural worldviews to risk attitudes are Dan Kahan and colleagues at Yale University's Cultural Cognition Project. The Cultural Cognition Project studies how culturally divided perceptions of risks are perpetuated within contemporary society and how "society can resolve culturally grounded differences in belief about risk" that are not especially susceptible to alteration through more information (Cultural Cognition Project, n. d.). Kahan and colleagues claim psychometric theories of risk perception as dividing between the public and experts fail to account for the range of risk perceptions across both the public and scientific communities (Kahan et al., 2015a, 2011). To capture these effects of divided cultural cognition, Kahan et al. (2011) studied the responses of laypeople to concocted pieces of writing by fictitious experts on nuclear waste management. They observed that laypeople did not generally distrust experts so much as they distrusted experts who disagreed with their worldviews. People holding egalitariancommunitarian worldviews believed experts who proposed nuclear waste was risky and difficult to manage were more "trustworthy and knowledgeable" than experts who proposed nuclear waste presented low risks; people who held hierarchical-individualistic worldviews conversely 
came to the opposite conclusions (p. 25). This research suggests that when issues are culturally polarizing, people do not so much distrust experts as find experts to trust whose findings and arguments align with their worldviews. In this dynamic, "factual issues become entangled in antagonistic cultural meanings that transform positions on them into badges of loyalty" to sociocultural communities (Kahan, 2015b, pp. 6-7). Kahan et al. (2011) advanced a theory of "expressive rationality" to explain how individuals form "beliefs that convey their affinity to those with whom they share cultural attachments" through "appropriate calibration and unconscious activation of emotional sensibilities" to match those of the groups to which they belong (p. 12). Like Schön and Rein (1994), Kahan et al. (2011) find the unconscious dynamics that reinforce polarization concerning, seeing them as leading to a "tragedy of the risk perception commons," in which relevant information is unlikely to cross cultural boundaries and policy controversies are unlikely to be resolved in rational ways.

A remedy Kahan (2015a) proposes for overcoming rigid polarizations among groups on risk issues is for science communicators to "craft[] messages to evoke narrative templates that are culturally congenial to target audiences," thereby "assur[ing] that the content of the information they are imparting receives considered attention across diverse cultural groups" (p. 31). Such messaging, they hope, can facilitate individuals with different worldviews to consider information more "open-mindedly" and potentially to support more "enlightened democratic policymaking” (p. 31). Another remedy the Cultural Cognition Project proposes for overcoming social polarization around risk calls for deliberative processes that facilitate pragmatic thought among local citizens on "what should we do with what we know" and "how to use scientific knowledge to address ... practical, everyday needs" in their communities (Kahan, 2015b, p. 78). Such processes would avoid triggering identity-oriented questions such as "who [citizens] 
are, whose side they are on," and what they believe, through strategies of "disentangl[ing] knowledge and identity" (pp. 7-8). But as with Schön and Rein's (1994)'s co-design process, it is uncertain that this locally-grounded approach could work in arbitrating nuclear waste cases, given wider regional and national questions that such discussions inevitably raise concerning nuclear power generation, which is yet another issue with which socio-cultural identities and worldviews are invested.

\subsection{Theory of Communicative Rationality}

As we saw in Chapter 1, the usual remedy proposed for settling thorny risk issues concerning technology are more public consultation for determining policies and for making regulatory decisions about which specific projects go ahead. Exactly what types of consultative processes would help to advance the conversation around polarized risk issues is a question that remains, however, in dispute. As we have seen, such proposals typically advocate for more deliberation amongst different types of stakeholders and/or members of the public (Webler, 1995; Jasanoff, 1995; Stern \& Fineberg, 1996; Fischer, 2000, 2003; Fuji Johnson, 2008). Yet how researchers conceptualize the necessary forms of deliberation depends on how they view these risks and the social divisions that surround them. Scholars who see these divisions as abiding between experts and the public regard the primary goal of deliberation as empowering the public so it can have a say in policy areas where decision-making has been overly monopolized by elites (Beck, 1988; Fischer, 2000; Fuji Johnson, 2008, pp. 17-18). For these scholars, improvements to deliberative processes would render them more open to public access and to common public modes of discourse such as storytelling, in keeping with Young's (2000) advocacy for the mode of narrative to be permitted within democratic deliberation to reduce barriers and impacts of educational inequity and cultural difference. These improvements would 
eschew standards for discourse that could be considered to re-enforce elitism, such as of reasoned argumentation and the use of evidence. Fischer (2000), who is concerned with the need for public deliberation on policy issues to "coordinat[e] multiple discourses," holds that citizens must be permitted to use narrative, their "primary means of giving meaning to complex social phenomena" (pp. 200, 253).

However, scholars such as such as Webler (1986) and Flüeler, who see the main requirement of deliberation as coordinating polarized cultural views on policy issues, tend to recommend at least a partial return to Habermas's original deliberative standards of reasoned claims backed up by valid evidence (Habermas, 1984, 1990). Such a turn to Habermas by researchers more concerned with cultural polarization than power imbalance might seem paradoxical. Habermas (1984b) was, like sociologists Fischer and Beck, intensely concerned about power imbalances manifesting due to complex technologies such as "nuclear power plants [and] atomic waste" (p. 394). However, Habermas (1990) was also concerned with how modernity had led to reason being "differentiated" in our pluralist societies (pp. 3-4). He judged that the only way the public could obtain an accurate enough sense of reality to support democratic decision-making was through procedures of "communicative rationality" to bring fragmented perspectives together (Habermas, 1984a, p. 14). Only such procedures could permit people with different perspectives to achieve a sound consensus grounded in "the unforced force of the better argument" (Habermas 1992/1996, p. 541, n. 58). Further underpinning Habermas's (1990) idea of communicative rationality was the conviction that exchanges of argument, and not narrative, are appropriate for deliberation. Only argumentative exchanges are "speech situation[s] immune to repression and inequality," as only arguments are susceptible to being evaluated according to standards of logic and evidence that are independent of the statuses and 
affiliations of the persons who make them (p. 88). By contrast, narrative and rhetoric are not subject to formal standards and thus harder to interrogate and challenge.

Building on Habermas, Webler (1995) describes how functional environmental deliberation requires procedures of "communicative competence" to help participants with different perspectives achieve a working consensus around the interpretation of a problem and an appropriate response to it (p. 75). One of the principles he outlines is that deliberators should trade primarily not in expressive and normative types of speech acts, which are especially prone to subjective biases, but in "constative speech acts" that purport "to represent something in the objectifiable world of nature or society" supported by a "claim to truth or correctness" (p. 78). One might argue that constative speech acts can also introduce bias-for instance, scientific evidence might be specifically contracted to support a proponent's position. Nonetheless, at least such speech acts offer scope for interrogation according to established community standards designed to ensure that erroneous and fraudulent claims are not left standing. To help participating individuals arbitrate among conflicting claims, meanwhile, Webler (1995) calls for deliberating bodies to adopt "procedures that society has developed over time for reliably selecting knowledge" (p. 74), such as giving the most credence to claims made by well-respected and disinterested professionals using widely accepted best practices. Webler (1995) defends standards for assessing and corroborating evidence on the grounds that, for Habermas, an individual's knowledge does not exist in a vacuum, but is always formulated against a "background consensus" of understandings that his or her society has already gathered (Habermas, 1984a, p. 70).

Both Habermas's and Webler's conditions for public deliberation are exacting from a standpoint of citizen deliberation, flying in the face of a recent turn in deliberative democracy 
theory towards less stringent expectations of rationality and empiricism for participation in democratic forums. As Mansbridge (2016) proposed in a recent roundtable on the evolution of democratic deliberation, expectations have shifted during the past two decades from expecting participants to offer "reasons" for positions to a more lenient acceptance of "rational and emotional considerations." Nonetheless, as will be discussed in Chapter 7, the literature on deliberative regulatory procedures suggests that a willingness amongst participants to agree on common standards for evidence is in fact preconditional for diverse groups to find common ground upon which to forge a workable consensus. As such, while expectations of rigorous claims-making may be exacting, they may also be necessary for producing successful deliberative outcomes on complex technical issues such as nuclear waste.

\subsection{Conclusion}

Considering how the discourse around the OPG DGR for nuclear waste is underlain by divergent framings and storylines, and beyond that by dichotomous cultural worldviews, leads to deeper understanding of why policy discussions around technological risk often break down into intractable policy controversies. Policy frame theory makes comprehensible how policy controversies resist resolution through appeals to either facts or norms, by explaining how holders of diverse frames disagree both about the relevance and significance of facts and about appropriate norms as well as policy processes for decision-making. Policy frame theory also indicates that underlying these frames are culturally resonant storylines about nature and technology that help cultural groups orient themselves in a complex world. Cultural theories of risk add insight into how frames and storylines function to make group identity resistant to dissonant information, heightening polarization and rendering social learning through deliberative processes difficult to achieve. Yet Habermasian (1990) theories of communicative 
rationality and communicative competence that favour the exchange of argument over narrative in deliberation provide some conditions for how participants in deliberation on these issues may collaborate in the production of more widely acceptable outcomes on risk issues.

In light of these insights, the following chapters characterize the policy frames within the discourse around the OPG DGR controversy and identify the cultural symbols, or "generative metaphors," that underlie them. In turn, they describe how these generative metaphors root policy frames in longstanding socio-cultural worldviews concerned with technology and the environment, making these policy frames especially hard to mediate. The subsequent chapters propose interpretive and deliberative procedures for shifting the policy discussion at least partially beyond the grip of these cultural frames and narratives, into a deliberative space where problem-solving could become more feasible. 


\section{Chapter 3: Methodology}

\subsection{Overview}

This dissertation applies interpretative policy analysis to better understand the impact of cultural narratives on the OPG DGR. As Fischer (2003) describes, interpretive policy analysis is a form of "case study research" with "an emphasis on the social meanings held by the actors under investigation" (p. 139). These social meanings are identified through an analysis of frames, narratives, metaphors, and other discursive devices through which positions on the controversy are expressed (p. 143). The purpose of interpretive policy analysis is explained by Fischer (2003) as threefold. First, it can identify and account for the different frames brought to particular policy controversies or debates. Second, it can enable those who hold different views on a policy topic to understand their own perspectives and those of others. Third, it can allow policy-makers to better anticipate the nature and tone of policy controversies to make decisions that can mediate such controversies more successfully. In this case, an interpretive policy analysis of texts relating to the OPG DGR was useful for understanding how the texts of the actors concerning this project incorporate norms, beliefs, and narratives that resonate with larger communities of meaning, thereby connecting this project with the worldviews of these communities. Subsequently, a narrative policy analysis was performed to identify an additional, adjacent narrative that could serve as a starting point for rebooting the policy conversation on grounds that are more likely to be simultaneously acceptable to both policy communities. This chapter will explain and justify these methodological choices, first characterizing the method of selecting the case study, and second, the specific methods of analysis. 


\subsection{Choosing the Case Study}

To answer the dissertation's research questions about what, exactly, divides communities and societies facing risk issues such as nuclear waste, and whether anything can be done to remediate these divisions, I conducted an interpretive policy analysis of materials relating to the debate over the OPG DGR project. The OPG DGR project was chosen as a case study because of its prototypical as well as significant character as a nuclear waste disposal controversy over a leading-edge contender for DGR approval in Canada. As a project that has come to fruition quickly, and that is engaged with low and intermediate level waste, the OPG DGR has received little scholarly attention compared with other nuclear contemporary waste siting projects in Canada and abroad. ${ }^{11 .}$ Further, the OGP DGR case condenses a number of critical and potent regulatory issues around how to site DGRs and other hazardous waste facilities, as well as how to identify, and engage, communities that are affected by these siting decisions. Finally, the OPG DGR case was attractive as a subject as, given the relatively timespan in which the project has moved from conceptualization to review, I was able to complete a comprehensive analysis of the entire process within the scope of this dissertation project.

\subsection{Choosing the Communities}

To guide my study of this issue, I developed a modified approach to Yanow's (2000) four-step process for interpretive policy analysis. My analysis did not begin with Yanow's (2000) first step, to "identify the artifacts (language, objects, acts) that are significant carriers of

\footnotetext{
${ }^{11}$ Waste Management Organization's extensive consultation between 2004 and 2005, which was analyzed and assessed by Fuji Johnson (2008) in Deliberative Democracy for the Future: The Case of Nuclear Waste Management in Canada, 2008; and the attempt to site a geological repository for nuclear waste under Yucca Mountain, Nevada, which is the subject of a book edited by MarFarlane and Ewing (2006), Uncertainty Underground: Yucca Mountain and the Nation's High-Level Nuclear Waste, as well as one by Walker (2006), The Road to Yucca Mountain.
} 
meaning for a given policy issue, as perceived by policy-relevant actors and communities of meaning," as it seemed important to settle on the relevant actors before gathering their artifacts (p. 22, see Table 2). As Yanow (2000) herself writes, "steps 1, 2, and 3 are typically done at the same time" (p. 22). When it came to selecting communities of meaning, the most vocal elements of the field were broadly divided into pro- and anti-DGR positions (see Figure 1: Policy Map). Pro- and anti-DGR policy actors also tended to be pro-nuclear and anti-nuclear, respectively, for reasons outlined in Chapter 1, and more broadly tended to align with the views of larger communities of meaning holding generally techno-optimistic and techno-pessimistic worldviews.

As such, numerous other agents in this policy controversy in the pro- and anti-DGR camps, could also, or alternatively, have been included in my study. As Figure 1 shows,

\section{Steps in Interpretive Policy Analysis}

1. Identify the artifacts (language, objects, acts) that are significant carriers of meaning perceived by policy relevant actors and interpretive communities

2. Identify communities of meaning that are relevant to issue at hand

3. Identify the specific meanings being communicated through the specific artifacts and their entailments

4. Identify the points of conflict that reflect different interpretations by different communities.

Interventions/Actions (not required, but you may want to take it this extra step)

5a. Show implication of different meanings/interpretations for policy formulation and/or action.

$5 b$. Show that differences reflect different ways of seeing

$5 \mathrm{c}$. Negotiate/mediate/intervene in some other form to bridge differences.

From Yanow, Conducting Interpretive Policy Analysis, p 22

Table 2: Yanow's (2000) “Table 1.1: Steps in Interpretive Policy Analysis” (p. 22). 


\section{Favorable to DGR Conditionally favourable to DGR Opposed to DGR}

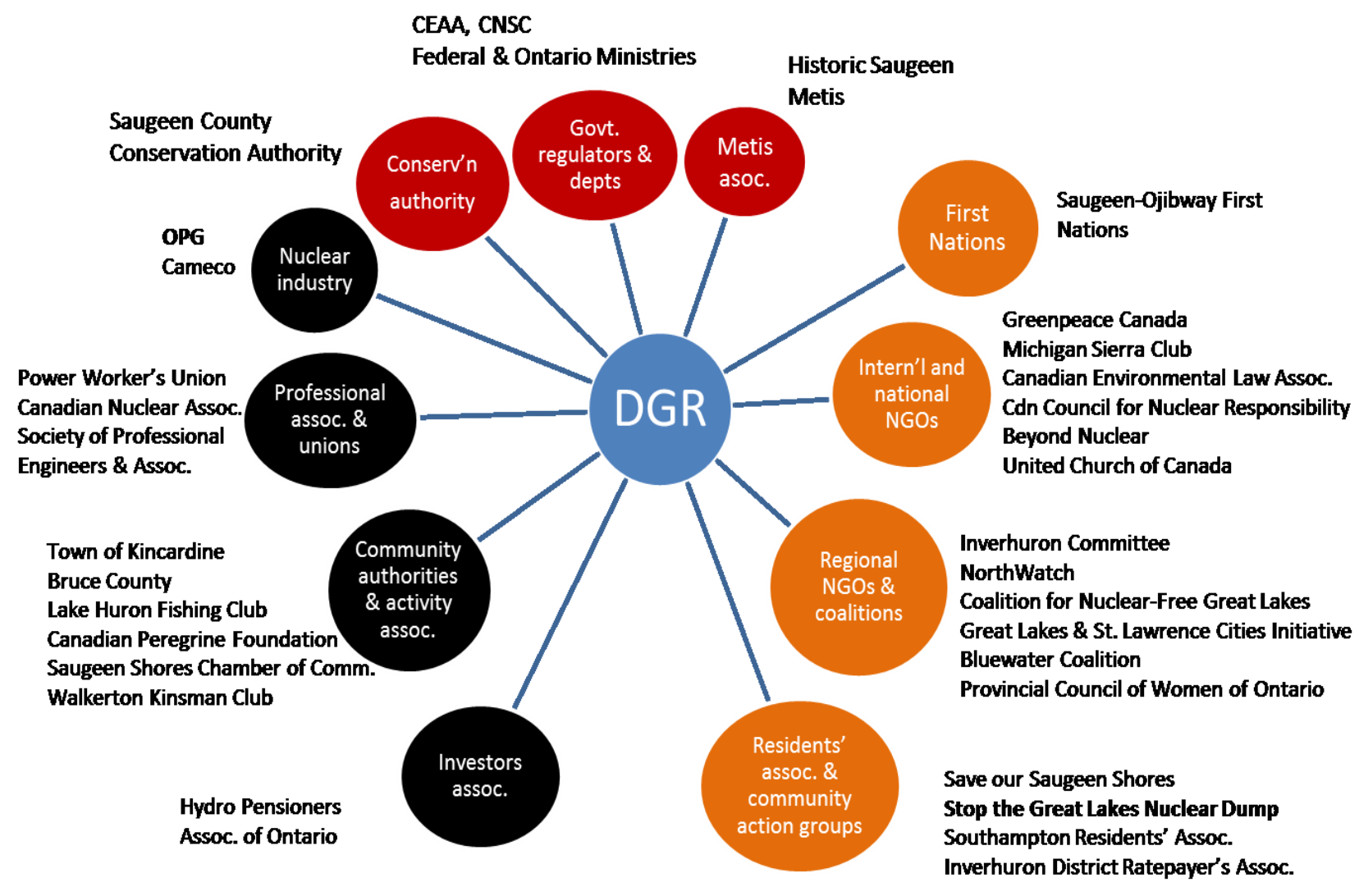

Figure 1: Policy map created by the author indicating whether intervenors in the OPG DGR environmental assessment were favourable to the project (black), conditionally favourable (red/medium grey), or opposed (orange/light grey), based on CEAA's record of oral statements to the hearings, August-September 2013.

the pro-DGR policy community in this case consisted of organizations that accepted the DGR as a solution for nuclear waste and affirmed the acceptability of the project site and design. It included the proponent and other members of the nuclear industry, as well as professional associations and lobby groups of engineers and nuclear energy workers, who formally lent their support to the project. In an in-between position were the regulators - the CNSC and the CEAA — whose JPR panel found the OPG DGR design project to be conditionally acceptable; numerous government departments at the federal and provincial levels; and the Historical 
Saugeen Metis, all of whom accepting of the project under specified conditions. The anti-DGR policy community comprised regional and environmental organizations that oppose nuclear development projects, including Greenpeace Canada and Sierra Club Canada; community action groups such as STGLND that specifically arose to oppose the DGR; and Saugeen-Ojibway First Nations; see Figure 1 for a complete list of intervenors. ${ }^{12}$

To set clear parameters around the project, this dissertation focused on two major antagonists central to the DGR policy controversy: namely (1) OPG and (2) Stop the Great Lakes Nuclear Dump (STGLND), the most prominent community action group founded specifically to oppose the OPG DGR. The texts of OPG and STGLND were chosen for several reasons. First, these groups were frequently positioned opposite each other in media coverage. The scan of media coverage of the OPG DGR between 2012 and 2015 found 28 articles in major outlets such as CBC, CTV, The Globe and Mail, National Post, Toronto Star, Al Jazeera, Vice, Water Canada, Huffington Post, Now Magazine, as well as smaller community newspapers. OPG's official positions and those of its spokespeople were introduced in 17 of the articles, while the public relations materials of OPG were linked or cited in 25 of them. STGLND was additionally quoted as an authoritative source in all but two of these articles. By contrast, the Canadian Council for Nuclear Responsibility was quoted three times; the Inverhuron Committee, a local anti-DGR group, was quoted in two of the articles, Save our Saugeen Shores was quoted in one, and Greenpeace was not mentioned at all in news coverage of the DGR debate. In comparison to other opposition groups, therefore, STGLND was the most visible public voice in the debate. In all these respects, media coverage of the OPG DGR issue has largely portrayed the controversy

\footnotetext{
12 The bounds of this project did not allow me to investigate fully the positions of the Indigenous groups and their relationships to each other and to the other policy groups; however, this remains an important area for future research.
} 
as a conflict between STGLND and OPG, leading to my analysis of the discursive conflict over the DGR in relation to these actors. A second justification for focusing on these organizations was that their texts were generally representative of the types of discursive production that unfolded on both sides of the issue. As will be discussed further in Chapters 4 and 5, OPGs discourse broadly reflected the technocratic approach to nuclear waste management, while the discourse of STGLND_even though it was a community group ostensibly opposing the proposed DGR site - had affinities with the discourse of environmental organizations opposed to nuclear energy more broadly.

A potential problem with focusing on OPG and STGLND as opposing voices in the OPG DGR policy controversy was that the imbalance of resources, power, and elite connections between the two sides could be judged as making a comparative discourse analysis of their respective texts unfair. In this regard, an organization such as Greenpeace Canada, which has more resources and elite connections, might have been considered a fairer selection for OPG's discursive opponent. However, as we have seen, STGLND has been far more prominent in the DGR controversy than any larger organization, and so, arguably, a focus on it is required to produce an accurate reflection of the activist ground game. Further, while STGLND has fewer institutional resources, its access to social media and ability to generate earned media attention as a community voice helped it equalize itself with the more moneyed and connected OPG in terms of "discursive power," or the ability of advocacy groups to create power through deployment of discursive strategies and relationships that bank on their "perceived legitimacy" (Fuchs, 2007, p. 82).

Another potential problem for my analysis was that STGLND portrays itself as a community organization opposed to the siting of the present DGR project rather than to DGRs 
per se. On the surface, therefore, it may seem a poorer representative of the anti-DGR/antinuclear community of meaning than a group that opposes nuclear technology in general, such as the Canadian Coalition for Nuclear Responsibility. However, as will be demonstrated in Chapter 5, STGLND's texts indicated multiple affiliations with organizations opposed to nuclear technology in general, affirming its embeddedness in the anti-nuclear policy community. As well, STGLND's highly successful use of social media to generate support for its petition led that petition being championed by groups such as the David Suzuki Foundation and the Council of Canadians, arguably embedding the group amid the broader Canadian ecology- and social justice-oriented communities of meaning represented by these organizations.

\subsection{Choosing the Artifacts}

Once the decision was made to focus the interpretive policy analysis on OPG and STGLND, I returned to Yanow's (2000) first step in her methodology: identify the artifacts (language, objects, acts) that are significant carriers of meaning for a given policy issue, as perceived by policy-relevant actors and communities of meaning (p. 22, Table 1). In fulfilling step 1, I selected web-based communications materials and media articles as objects of analysis because these served as foundational texts presenting arguments for and against the DGR project. Primary source materials were gathered through web searches, through the CEAA web archive, and from STGLND's Facebook archives. Most of the analyzed materials were published between November 2012, when STGLND launched its petition against the OPG DGR, and November 2015, when the newly elected federal Liberal government announced it was delaying its decision on the DGR for further study.

The artifacts I collected included the major submissions of the groups to the public hearings for the environmental review archived on the CEAA's website, along with public 
relations materials including brochures, FAQs, timelines, and other documents linkable through the websites of OPG and the NWMO and through STGLND's Facebook page. Media articles were identified through a Google-driven web search using the keywords "Ontario Power Generation" and "Deep Geological Repository" and in STGLND's media archive. The media from this period appeared to be well-preserved for the period in question (2012-2015). Both OPG and STGLND submitted numerous documents to the JRP, although as there was a good deal of discursive repetition among them, I chose the most substantive plain-language written submission from the 2013 hearings from each of these organizations to code. On occasion, there was a need to seek out earlier documents, such as OPG's (2005) Project Description, OPG's (2011) Environmental Impact Statement, and OPG's (2012) Responses to Information Requests, in order to clarify points in OPG's as well as STGLND's submissions to the hearings. Since these earlier documents by OPG were especially technical and lengthy they were not coded for analysis. Web materials designed for public use and quotations in media interviews reflected more curtailed versions of each policy actor's discourse than their submissions to the hearings, presumably emphasizing elements they judged as having the greatest potential to influence policymakers and public opinion. The media analysis focused on quoted statements by these organizations in key Canadian and international news sources as well as local community news media.

In all, the materials comprised two submissions to the primary set of environmental hearings on the DGR project in 2013, consisting of OPG's request for a decision from the JRP on the project; six public relations documents comprising brochures, web pages, and FAQs; STGLND's petition against the project; and 24 news articles on the project in mass and local media sources from between January 2013, when STGLND's petition against the DGR first 
gained prominence, and October 2015, when the new Canadian government formally delayed deciding on the DGR despite the favorable environmental review; see Appendix 1 for the list of documents analyzed. In addition to undertaking the discourse analysis, I attended two days of public hearings in the environmental assessment for the OPG DGR conducted by the JRP to become familiar with the hearing format and some of the key players, positions, and sentiment underlying the debate. While attending these hearings, I conducted four key informant interviews to obtain expert validation of my observations. ${ }^{13}$

Finally, in addition to the hearing-related materials and media, 407 unique Facebook posts by STGLND were captured and tagged to reveal the breadth of themes reflected in that organization's social media campaign. Some justification may be considered required for the methodological decision to look at STGLND's Facebook postings even though OPG does not have a Facebook account and did not run a Facebook campaign to which the other organizations could be compared. For STGLND, Facebook was evidently a way for a small organization to establish a more level playing field with OPG in terms of access to and influence over public opinion. As a well-resourced and connected crown corporation, OPG had financial assets to launch dedicated websites expressing its position and to create and distribute attractive promotional materials. It also had the authority and networks to present itself as an expert in nuclear waste management to the media and public and, presumably, to directly press its position with the government. In response, however, STGLND took opportunities to wield "discursive power," which Fuchs describes as the ability of less advantaged groups within conflicts to essentially create power through membership and perceptions of legitimacy (2007, p. 80). As

\footnotetext{
${ }^{13}$ I received Carleton REB approval to interview human subjects as part of my research, though I ultimately downplayed interviews as an element of my research design, both due to a shift in research focus and also because one of the major policy actors under investigation refused to be interviewed.
} 
DeLuca portrays in his book Image Politics: The New Rhetoric of Environmental Activism, discursive power is not a given for underdog environmental action groups, but depends on the effective creation and mobilization of communication strategies and networks. For STGLND, the Facebook social media platform, in conjunction with the Gopetition.com platform on which it launched its petition provided it with both communication tools and networks to communicate their position to a community of meaning sympathetic with its cause and potentially unlimited in size, equalizing their discursive power with OPG to some degree. Whether OPG could have commanded social media in a similar way to create public acceptance for their position is unknown, however their lack of a Facebook page suggests that they did not consider the social media route a high priority one for communicating about the DGR. ${ }^{14}$

\subsection{Identifying the Discourses and Their Meanings}

To investigate the collected body of material, theory-based sampling was performed to identify features of the discourse based on my guiding theories: policy frame theories, narrative theories of policy, and cultural theories of risk (Marshall \& Rossman, 2011, p. 107). More random forms of selection are not favoured in qualitative approaches to discourse analysis, as key meanings are not likely to be normally distributed through discourse (Lindlof \& Taylor, 2011, p. 109). Intensity-based sampling was also used within the databases to rank the discursive features according to the degree to which they were emphasized in the discourses of the two groups (Marshall \& Rossman, 2011 p. 111); see Table 3 and Appendix A. Ultimately the search

\footnotetext{
${ }^{14}$ Both OPG and STGLND maintain Twitter accounts, where OPG tweets on informational and public relational topics covering diverse industrial applications and relationships with a wide range of communities, and STGLND primarily amplifies its Facebook campaign against the OPG DGR. The choice was made in this thesis not to analyze Twitter as a social media tool in this controversy due to the administrative complexities involved in amassing an archive of Tweets over a lengthy time span. As well, a preliminary observation that there was much intersection and repetition between the two organizations' Twitter and other messaging, suggesting that an analysis of their Twitter campaigns would not add significantly to the picture of the debate.
} 
was considered exhaustive, with a high degree of saturation of the discursive features across the artifacts wherever the actors discussed the DGR.

The strategic and theoretical choices about how to analyze the discourse were guided by Step 3 of Yanow's (2000) interpretive policy analysis, to "identify the discourses and their specific meanings being communicated through specific artifacts and their entailments (in thought, speech, and act)" (p. 22). After the textual artifacts were chosen, an interpretive policy analysis was performed through a series of two stages. First, the texts were closely examined for instances where the policy object — that is, the DGR — was described and characterized, along with its surrounding contexts and dilemmas. In particular, I looked for and coded the following discursive elements: expressions of feelings (F), norms (N) consisting of ideals and values (Yanow, 2000, p. 20); beliefs (B) making a claim for truth on the basis of either science or “common sense" (Fairclough, 2001, p. 64); generative metaphors (GM) implying normativeprescriptive diagnoses of the policy problems and appropriate solutions (Schön \& Rein, 1994, p. 28); synecdoches (SY) mapping other contexts onto the policy problem (Stone, 1988); and storylines (S) about the policy situation (Yanow, 2000, p. 80).

All in all, my approach to narrative policy analysis adhered to the "psychological" method categorized by Yanow (2000), which emphasizes how policy narratives express individual, group and cultural identities, in contrast to "the analytical approach of political science” (p. 58). This latter approach is exemplified by discourse analysts such as Hajer (1993), for whom storylines coalesce diffuse aspects of policy discourses in ways that are significant for understanding the larger political dynamics of policy debates (p. 46). Certainly, many storylines that policy actors generated about the OPG DGR policy situation had a markedly political character. However, I ended up focussing my narrative analysis on more symbolic underlying 
narratives of the frames rather than these distinctively strategic storylines as such, finding that these symbolic narratives and narrative features offered greater psycho-social depths to be excavated. The generative metaphors, especially, were found to express rich symbolic connections with the socio-cultural roots of the policy actors and so to provide insight into fundamental risk perceptions and concerns, which while divergent, at least held prospects for mediation. By contrast, the more politically strategic storylines, or "spin," that the policy actors constructed about the issue primarily focussed on inflating themselves and denigrating their opponents and did not seem especially amenable to mediation (Dinan \& Miller, 2008). In bypassing these more divisive policy storylines, I drew on Kahan's argument (2015b) that highly politicized policy statements play a negative role in heightening cultural polarization as they induce individuals to choose one side in a conflict.

Overall, my coding process generated a fulsome menu of meanings prominent in the texts of each organization that could be used to characterize their positions. After the materials were coded, all the statements reflecting these discursive features were transcribed in two Word documents of approximately twenty single-spaced pages. Where statements straddled several categories of discursive features, a determination was made into which category they best fit. Subsequently, the statements were collated in each discursive category to reveal key themes and their intensity of reiteration (see Table Appendix A). STGLND's Facebook posts were coded differently, identifying one broad theme per post and then grouping these themes into broader categories. The decision was made to code these posts separately and differently from the other texts because of their unique features. In its Facebook posts, STGLND frequently quoted the comments of petition supporters, giving the discourse in their Facebook campaign a greater range than in their self-authored materials. Accordingly, I decided to code the Facebook posts for 
general themes rather than discursive features, to see how these themes aligned with those in the group's other materials.

There were limitations to this analytical method. First, the analysis did not reflect the positions of all the policy actors within the DGR controversy, including other environmental and community organizations, indigenous groups, the regulators, or Kincardine town council. As such, the reflection of the beliefs, norms, and ultimately of the frames of the communities of meaning for and against the DGR might have been incomplete. As well, the methodology's hermeneutic — or textually interpretive — approach did not provide scope to test inferences about objectives, strategies, and underlying worldviews motivating the frames and narratives of the policy actors and their constituents through "member checking," which is a widely recommended step for affirming the validity of a qualitative analysis such as a discourse analysis (Lincoln \& Guba, 1985, 314). However, as was described in chapters 1 and 2, a great deal of empirical surveying and interviewing of holders of different attitudes about nuclear waste and nuclear power has already been done by other researchers, informing the thesis's understanding of the worldviews of these competing policy communities.

Further, as I did all the coding of the texts myself, it is possible I introduced biases in the analysis that compromised its reliability, consisting of the guarantee that if other researchers were to analyze the same subject matter using the same methodology they would produce the same results. However, for qualitative research projects undertaken in the social sciences, and particularly those hermeneutically oriented towards discovering meanings, it is generally acknowledged that the criterion of reliability is more difficult to achieve, and ultimately less important, than validity, or the degree to which the study's conclusions provide a valid or true reflection of the situation (Seale, 2004, p. 72). Validity in a qualitative analysis is considered to 
be established in accordance with a range of criteria, including construct validity, or the degree to which the results of an analysis conform to a relevant theory (Seale, 2004, p. 73). As the results of my discourse analysis accorded with policy frame theory as well as cultural theories of risk, it could be assessed as having construct validity. Another criterion of validity is transferability, or the degree to which the qualities of the object have been faithfully transferred to the analysis (Lincoln \& Guba, 1985, pp. 124-5). To obtain transferability, I quoted the discourse frequently in my analysis and provided a thick description of the meanings that I found in them in relation to cultural and historical contexts. Additional procedures I used to lend my study validity were triangulating quantitative and qualitative approaches by producing intensity rankings of key themes; triangulating a range of different textual sources, including both formal documents and media sources; and providing a reflexive account of the research process that described how decisions were made and how conclusions were drawn (Seale, 2012, p. 80).

\subsection{Identifying the Points of Conflict and their Sources}

In the next step, the coded and recorded feelings, norms, beliefs, storylines, generative metaphors, and synecdoches of the two policy actors examined were analyzed in keeping with Step 4 of Yanow's (2000) interpretive policy analysis: "identify the points of conflict and their conceptual sources (affective, cognitive, and/or moral) that reflect different interpretations by different communities" (p. 22). To explore the conflict between the two groups more fully, as well as to reveal potential sites of overlap, the positions of the groups were counterpoised in opposite columns to reveal exactly where the two groups diverged and agreed with each other in terms of the range of discursive features that were coded; i.e.: feelings, beliefs, norms, storylines, generative metaphors, and synecdoches. Table 3 offers a counterpoised summary of the top three 


\begin{tabular}{|c|c|c|c|}
\hline \multicolumn{2}{|c|}{ OPG's three most common beliefs } & \multicolumn{2}{|c|}{ STGLND's three most common beliefs } \\
\hline Geology will contain waste & 39 & Leak will harm Great Lakes forever & 16 \\
\hline Engineering unlikely to fail & 13 & All DGRs have failed & 9 \\
\hline Ecological impacts avoidable & 6 & Nuclear waste is especially toxic & 5 \\
\hline \multicolumn{2}{|c|}{ OPG's three most common norms } & \multicolumn{2}{|l|}{ STGLND's most common norms } \\
\hline Radiological safety & 13 & Broad community acceptance & 30 \\
\hline Scientific expertise & 11 & Precautionary approach & 22 \\
\hline Producer/Consumer responsibility & 10 & Duty of stewardship over Great Lakes & 18 \\
\hline \multicolumn{2}{|l|}{ OPG's most common feelings } & \multicolumn{2}{|l|}{ STGLND's most common feelings } \\
\hline Concern to fulfill responsibilities & 3 & Indignation at $\mathrm{OPG}$ & 9 \\
\hline Confidence in project & 2 & Concern about the Great Lakes & 6 \\
\hline Certainty about site/project & 2 & Dread of nuclear waste & 5 \\
\hline
\end{tabular}

Table 3: Most common beliefs and norms expressed by OPG and STGLND regarding the OPG DGR. Numbers indicate the number of times they were expressed in the examined texts.

most intensely represented discursive features in the categories of beliefs, norms, and feelings that highlights how they were opposed. Especially highlighted in the analysis were the generative metaphors of the policy actors, which were identified as central symbolic elements of the policy actors' discourses overall. As Schön and Rein (1994) describe, a generative metaphor is a "process by which a familiar constellation of ideas is carried over ... to a new situation," causing us to interpret the features of the new situation in a given way and introducing normative guidance as to how it should be solved (p. 26). Generative metaphors are essentially "problem setting stories" that capture how a community of meaning formulates a policy problem along with its "preferred solutions" (Schön \& Rein, 1994, p. 29). A generative metaphor can also be understood, according to Yanow (2000), as a symbol that expresses "visible and tangible evidence of the values, beliefs, and feelings that a group holds, believes in, and practices" ( $p$. 15). The theoretical centrality of the generative metaphor to policy frames provided a basis for my structuring of Chapters 4 and 5, which began with discussions of the generative metaphors of the two policy actors and then demonstrated how they appeared to inform their beliefs, norms, and feelings. In this way, I performed Step 5a of Yanow's (2000) interpretive policy analysis 
methodology: "[s]how implication of different meanings/interpretations for policy formulation and/or action" (p. 22).

Subsequently, the constellations of generative metaphors, beliefs, and norms of each group were compared to Buss, Craik and Dake's (1986) bifurcated socio-technological worldviews, Worldview A and Worldview B, thereby performing Yanow's (2000) step 5b, to show "how the differences reflect different ways of seeing" (p. 22). In the worldview analyses at the ends of Chapters 4 and 5, I argue that the policy frames of the two organizations are continuous with these divergent socio-technological worldviews. I further suggest that these broader roots indicate the embeddedness of the OPG DGR policy controversy in a longstanding conflict around socio-technological fates that helps to explain why policy controversies around nuclear waste and other technologies posing environmental risks are so intractable.

\subsection{Mediating the Conflict}

The last step in Yanow's (2000) interpretive policy analysis is to "[n]egotiate/ mediate/intervene in some other form to bridge differences. In Chapter 6, a narrative policy analysis was undertaken to mediate the major storylines in this policy controversy. As Roe (1994) describes, the principle of narrative policy analysis is that a given policy situation may be so complex, with such substantial uncertainties involved, that there is no way to ultimately and convincingly determine which narrative is most explanatory (p. 3). However, in such cases, a process of narrative policy analysis can possibly identify an "intertext," or shared discourse, standing behind the two narratives; "an implicit reference without which [the narratives] would not make sense" (134). ${ }^{15}$ The intertext—a concept Roe (1994) borrows from literary critic

\footnotetext{
${ }^{15}$ In the earlier parts of Narrative Policy Analysis: Theory and Practice, Roe (1994) focusses on the prospect of finding a useful "metanarrative" for policy controversies. The metanarrative, as he describes, is a new narrative that characterizes the relationship between the circulating policy narratives and that can in turn act as a jumping-off point
} 
Michael Riffaterre-is a conceptual or discursive background found "in the wider sociolect", which Roe defines as a society's historical way of framing and understanding reality that underlies even "multiple and opposing" interpretations of a given policy issue (p. 130, 134). Because an intertext is by implication shared by all policy actors, if only in a deeply tacit way, it can provide a "way to surmount the problem" of competing understandings by "identifying another set of questions" to which policy-makers and policy actors can turn (p. 138). As Roe (1994) describes, the methodology of finding an intertext proceeds through three steps:

1) identify the polarized policy narratives in relation to an issue;

2) identify an intertext amid the broader conceptual or discursive field around the issue that reveals "how two policy narratives, each the polar opposite of the other, can both be the case at the same time";

3) determine how the intertext recasts the problem in such a way to make it more amenable to policy-analytical processes. (p. 155-56)

In the case of the OPG DGR, narratives regarding the future performance of the DGR were generalized from the generative metaphors as well as other features of the two policy actors' discourse. Out of these competing narratives, it was concluded that there may be no way to determine which storyline is most accurate for the OPG DGR situation —at least not in a way that would be broadly persuasive across communities of meaning. Nonetheless, through narrative policy analysis, an intertext of 'Responsible Geologist' was discovered that puts emphasis on the processes and capabilities associating with learning about the relevant problems involved in siting DGRs. With its exploratory, tentative, case-by-case approach to evaluating geologies, the

for ongoing policy work. However, I found that the approach he introduces later in the book, of finding the "intertext" of a policy controversy amid its broad textual backdrop, harmonized better with the discursive focus of the interpretive policy analysis methodology (pp. 129-145). 
Responsible Geologist intertext stands in contrast to the more determined narratives of other policy actors, which tend to portray DGRs as inevitably bound to be either successful or disastrous. I then go on in Chapter 7 to propose how to chart a normative and procedural path beyond the current policy controversy that draws on this more open-ended and process-focussed narrative. 


\section{Chapter 4: Interpretive Policy Analysis of OPG's Discourse}

\subsection{Overview}

In this chapter and in Chapter 5, I apply Yanow's (2000) methodology of interpretive policy analysis to identify the most prominent generative metaphors of both OPG and STGLND as well as the range of norms, beliefs, feelings, synecdoches, and storylines that are expressed in their discourse. Drawing on Schön and Rein (1994), I also show how these generative metaphors anchor the frames that bound much of each group's discourses into relatively coherent structures for understanding reality, diagnosing policy problems, and determining solutions. Finally, I suggest that the congruence of the discursive frames used by OPG and STGLND with the tenets of socio-technological Worldview A and Worldview B (Buss, Craik, \& Dake, 1986) affirm cultural theories of risk perception by demonstrating the ongoing continuity and relevance of these worldviews for policy actors.

\subsection{Features of OPG's Discourse}

4.2.1 Generative metaphor. OPG's framing of the nuclear waste issue was organized around the idea of rock as a sturdy and reliable substance, which is a symbol of longstanding cultural familiarity. The deep geological rock in which the project proposes to bury low and intermediate level nuclear waste was described by OPG (2013b) in their submission to the environmental hearing as a "blanket" and as a "cap" with "integrity" (p. 13). Its reliability and protectiveness were captured in the idea of a "seal" in media interviews with OPG representatives, who claimed that the "stable bedrock and shale would essentially seal the facility" (in Perkel, 2015a) and that "the rock is geologically stable and would provide a hermetic seal" against the nuclear waste (in Perkel, 2015b). Tom Al, a scientist contracted by OPG to perform a site characterization, described the rock covering the geological zone in which the 
DGR would be installed as a "natural barrier" that is "almost like a steel plate" which "nothing has penetrated ... for these many hundreds of millions of years" and further held that "there is no permeability of any kind," in the rock (in Kowalski, 2013). Another member of the geological team, Ian Clark, elaborated that they knew the rock was stable and impermeable because waters at the same geological level had been trapped there "since before the dinosaurs roamed the earth" (in Kowalski, 2013). An OPG spokesman similarly claimed low and intermediate level nuclear waste could be stored in the DGR "forever" (in Friess, 2015). An OPG brochure on the DGR (2013) likewise emphasized the stability of the rock, describing how "these rock barriers have remained stable through tectonic events, climate changes and several ice ages, and are expected to remain stable for at least the next few million years" (2013a, p. 3).

In sum, the OPG's signature generative metaphor was a characterization of the geology in which the DGR is proposed to be sited as a kind of vault - an impermeable vessel that can be relied upon to separate and protect entities held to be valued and precious from other entities that are potentially dangerous and disruptive (see Figure 2). ${ }^{16}$ In keeping with Schön and Rein's (1994) emphasis on the normative character of the generative metaphor, these qualities of strength and stability did not merely characterize the DGR itself. Rather, they appeared more broadly to characterize the reliability of projects launched by strong and sound institutions and to convey faith in the protectiveness of these projects and institutions against forces of disorder and dissolution. Looking back through history, myths, and religious traditions, the symbol of rock has frequently been used to convey how institutions such as churches and insurance companies

\footnotetext{
${ }^{16}$ Schön and Rein (1994) similarly describe the symbolic resonances around a federal policy undertaken in the U.S. of "immuring," or walling off, urban slums - another policy prescription that proposed to rigidly separate that which was healthy and valued from that which was potentially disorderly (p. 24).
} 


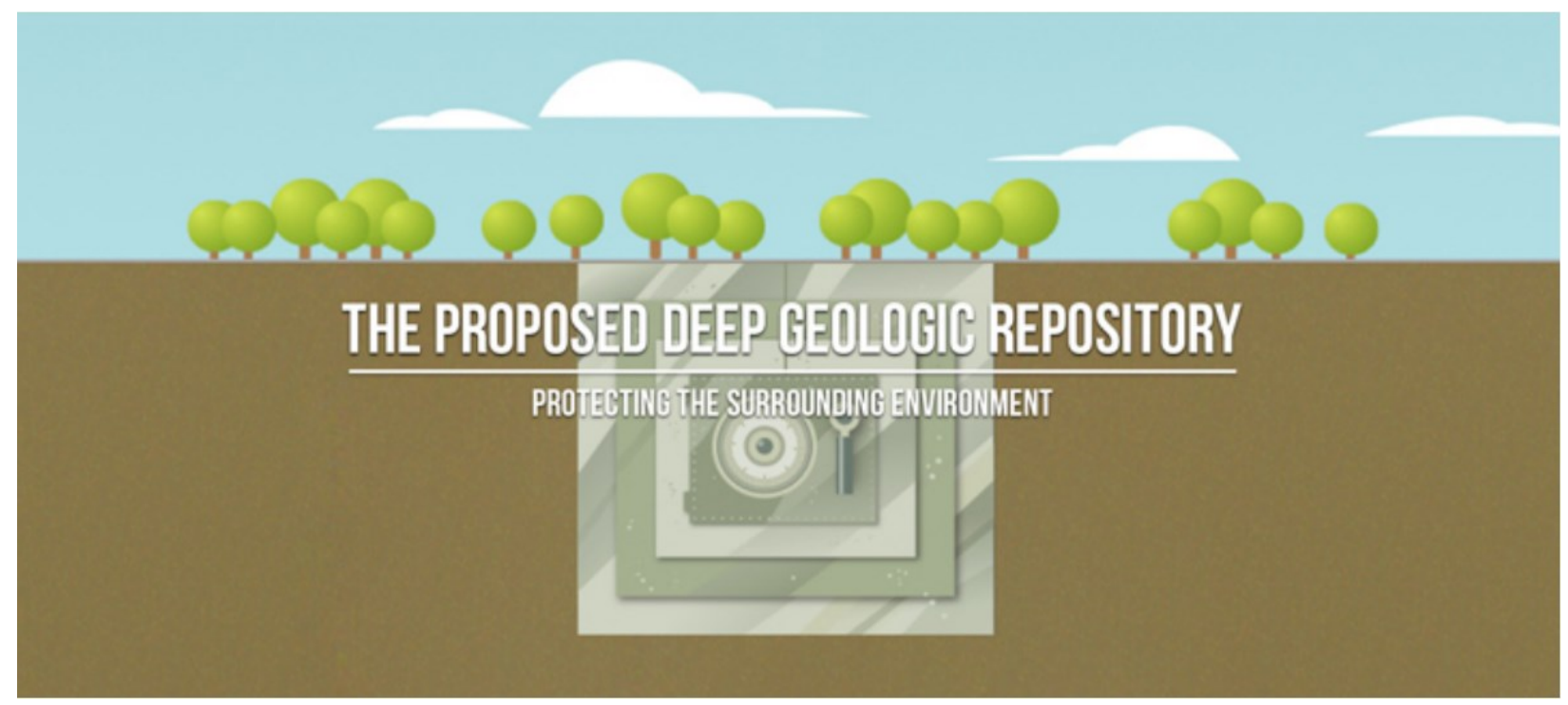

Figure 2: OPG's illustration of the DGR as a vault, from its website (Ontario Power Generation, 2016b).

are stabilizing and strong, even if humans and social ventures can be weak and unreliable. In the case of the DGR, these conservative institutional associations are affirmed in how DGRs are described as engineered to withstand a breakdown in "long-term institutional controls" that could occur if hapless communities of the future lose touch with contemporary institutional knowledge (International Atomic Energy Agency, 2007, p. 16). Under such a circumstance, organizations such as the International Atomic Energy Agency indicate that rock vaults would most capably protect humanity and ecologies from nuclear waste that could otherwise be stumbled upon or maliciously redeployed. In this regard, the imagery of the vault suggests that the DGR is not just optimal engineering, but a necessary precaution against the unpredictability of the future and the capriciousness of human civilization. This insecure vision of social futures is especially counterpoised with the more idealistic scenario captured in Edwards's (2015) notion of "rolling stewardship," which envisions future communities as having the wisdom and continuity to maintain important traditions concerning nuclear waste management while spurning nuclear generation themselves. 
4.2.2 Beliefs. OPG's faith in the protectiveness of the rock was expressed in its reflections on the site's geology, which are by far the object of the greatest number of its expressed "beliefs"; see Table 4. Promotional materials generated for the public, such as a list of FAQs (2016c), reiterated how the "geology of the site will permanently contain the waste from ecosystems and Lake Huron" and how "the 450 million-year-old rock formations are stable and will safely isolate and contain the low and intermediate level waste" (p. 3). Likewise, OPG's brochure on the DGR (2013a) portrayed that "the DGR will be isolated from surface waters" because "[1]ow permeability rock formations under and above the DGR provide multiple natural barriers to safely isolate \& contain the waste" (p. 3). As we saw in Chapter 1, the notion that a deep geology can be identified that will isolate and contain nuclear waste away from the ecosystem is widely shared in the nuclear energy community, with policy actors having consistently regarded geological burial as likely the safest method for disposing of nuclear waste and continuing to do so. Yet given the inability of current science, as characterized by DGR scientists MacFarlane and Ewing (2006), to "guarantee that a repository will not release radionuclides into the environment at some point in the future," it appears fair to say that the effectiveness of DGR technology remains a hypothesis subject to ongoing experimentation, observation, and validation (p. 3). OPG's positions on the validity of the DGR project

\begin{tabular}{|l|c|}
\hline Belief expressed by OPG & \# of times \\
\hline Site geology will permanently contain the waste & 39 \\
\hline Long-term engineering robust, disruption unlikely & 13 \\
\hline Environmental impacts can be foreseen, monitored for & 6 \\
\hline Nuclear waste for DGR is not the dangerous kind & 4 \\
\hline Public radiation doses from DGR are below reg. limits & 3 \\
\hline DGR is a relatively safe way of storing nuclear waste & 2 \\
\hline Nuclear waste is manageable & 2 \\
\hline
\end{tabular}

Table 4: Frequency of beliefs expressed by $O P G$. 
were accordingly classed as "beliefs," in keeping with the Bayesian premises of science, according to which knowledge about the future or even the present is never decisively known and can be only approached through increasing degrees of probabilities. ${ }^{17}$ In its brochure and FAQs, OPG (2013a, 2016c) echoed the probabilistic character of this hypothesis conclusion of its environmental review submission that the DGR project is merely "not likely to result in any significant adverse environmental effects.”

OPG's belief in the ability of deep geology to protect ecosystems from nuclear waste in turn allowed them to maintain several secondary beliefs about the site and about nuclear waste, all of which testified to their deep faith in the ability of science and engineering to predict and manage contingencies concerning the natural and material world in such a way as to adequately protect the environment and communities that depend on it. These beliefs held that nuclear waste is an inherently manageable substance; storage in a DGR is the safest way to deal with such waste over the long term; and the geology of the project site will effectively isolate waste that is put into it. OPG further conveyed that low and intermediate forms of nuclear waste, with their small concentrations of long-lived radionuclides, present extremely low risk to the ecosystem or humans. On such grounds, OPG (2011) expressed confidence that according to the "normal evolution scenario" of the engineering plan, the DGR would produce no adverse effects on surrounding ecosystems, including the Great Lakes, and that unforeseen accidents and other disruptions of the normal evolution scenario were highly unlikely (p. 44). For almost any credible accident or intrusion scenarios, they calculated that doses of exposure to members of the public would be vastly under levels permitted by existing regulations; at worst, the doses might

\footnotetext{
${ }^{17}$ According to the Stanford Encyclopedia of Philosophy, Bayesian epistemology entails "the use of the laws of probability as ... constraints on rational degrees of belief (or degrees of confidence) and the introduction of a rule of probabilistic inference, a rule or principle of conditionalization" (Talbott, 2008).
} 
be slightly higher, but would still pose extremely low risks to the environment or population health (pp. 41-43). Finally, they expressed belief that if disruptions from the engineering plan did occur, they could be caught through monitoring during the 300 -year period of institutional control and mitigated (p. 48).

4.2.3 Feelings. The signature "feelings" in OPG's (2013b) submission to the environmental review were the company's "concern" to fulfill their requirements as a waste producer as well as "confidence" in their project and in the scientific assessments in which it was grounded (pp. 11, 27). There is some slippage in OPG's discourse between meanings of the word “confidence," which OPG uses in some cases technically, referring to statistical probabilities that the results reflect the data, and other cases affectively, as a subjective sense of security in the robustness of the project overall. OPG's high degree of subjective confidence in the DGR was noted by a journalist who proposed that their attitude towards the DGR expressed a "rattl[ing]" degree of “certainty" (in Friess, 2015). Another feeling expressed by OPG's spokespersons is that of "good fortune" (in McCarthy, 2013) or of being "lucky" (in Rucke, 2014) in the geological formation identified for the site. This sense of luckiness was especially pronounced given the circumstances where an apparently optimal site for a DGR was fortuitously found on OPG's own property and proximate to the WWMF that temporarily stores the relevant nuclear waste. While the convenience of the site has laid OPG open to charge that it been selected for convenience, in OPG's description of the case, the idea that such fortunate discoveries are ready at hand lends its view of nature a providential cast, as bountiful and benevolently supportive of its endeavours.

4.2.4 Norms. The requirement that a DGR site be optimized to minimize radiological risks was the norm repeated with the highest degree of intensity in OPG's discourse (see Table 
5). A similar norm advanced by OPG (2013b) related to the producer's responsibility to assure that a given site will protect humans and Valued Ecosystem Components at every stage of the project by keeping radiation doses far under regulatory limits through the application of professional expertise and judgment (pp. 1, 19-23). These norms carry a broader implication of the importance of relying on expert judgement in socio-technological decision-making. As they described, their confidence in the site issues from the process whereby "a team of experts ... reviewed their plans and found that the DGR would be safe [and] in no danger of contaminating the Lake" (in Abbey-Lambertz, 2014). OPG further described the importance of expertise in their accounts of how geologists affirmed the radiological safety of the DGR through four years of stringent tests and models exemplifying expert-developed "best practices," the results of which were in turn affirmed through "peer review by both national and international external experts” (Rucke, 2014; OPG, 2016c).

A norm favoring quantitative measurement and expert modeling of tangible criteria for decision-making about projects such as the DGR is also broadly pervasive in OPG's discourse. Such a norm is embedded in the legacy of Enlightenment thought, which put faith in the ability

\begin{tabular}{|l|c|}
\hline Norm expressed by OPG & \# of times \\
\hline Radiological safety & 13 \\
\hline Scientific expertise & 11 \\
\hline Producer/consumer responsibility & 10 \\
\hline Positivist decision-making using what's knowable/measurable & 9 \\
\hline Environmental responsibility & 8 \\
\hline Meeting regulatory requirements & 7 \\
\hline Transparent and consultative process & 4 \\
\hline Social license & 3 \\
\hline Conservative approach to analysis & 3 \\
\hline Ongoing monitoring & 3 \\
\hline Respect for the views of others & 3 \\
\hline
\end{tabular}

Table 5: Frequency of norms expressed by $O P G$. 
of humans to understand and measure physical and social entities and to create rational solutions for managing them, as expressed in a quotation from Lord Kelvin (1989) that "when you can measure what you are speaking about, and express it in numbers, you know something about it." According to this spirit, in the engineering and risk assessment of a technology such as a DGR, features that are explicitly measurable must count for far more than those which are intangible. In this regard OPG described how, in their environmental impact assessment, they resisted accounting for cumulative effects of merely speculative changes such as the future siting of another DGR or calculating radiological doses from "extreme events" they considered to be "not credible," such as tsunamis and underground bombings (Ontario Power Generation, 2013b, pp. 42, 36-37). While it is understandable OPG would consider risk assessment to be a precise process that should incorporate only concrete values from and measurable phenomena, some scholars judge the positivist inclination of technocratic institutions to register only risk factors that can be quantitatively measured as one of the most problematic features of technocracy. As Fischer (2000) describes, the emphasis of technical rationality on "quantifiable impacts" leaves it without tools for understanding intangible features of "the social lifeworld" (p. 132). As neglect of social and cultural factors in their risk assessment can be observed in OPG's (2013b) resistance to incorporating possible changes to First Nations "attitudes or behaviours as a result of the DGR project regarding the fish, wildlife, and plants that they harvest for traditional purposes" because they saw no "tangible reasons" for such alterations and excluded the First Nations ecosystem concepts of "the rock of the earth" as a Valued Ecosystem Components from their environmental impact assessment because it presented no "specific measures that can be quantified and assessed" (p. 8). (p. 30). Similarly, OPG (2012) dismissed the possibility of the DGR causing a stigma to become attached to the region based on indications that property values 
in the region had previously remained stable despite the development of several nuclear power facilities (p. 33).

Finally, OPG's assurance that the geological site of the DGR can isolate nuclear waste long into the future underpinned social norms it advanced around the creation of nuclear energy and its waste products. The norm OPG (2013b) raised that nuclear producers should take responsibility for disposing of waste is grounded in the availability of a means for doing so ( $\mathrm{p}$. 4). Also grounded in the availability of means to successfully store nuclear waste is the norm that Southern Ontario power customers should be willing to bear responsibility for the externalities of the nuclear power they use "around the clock . . . to power homes, businesses, hospitals, and more" (in Rucke, 2014). As OPG reasons, "the creation of nuclear energy also creates a needand by implication, a responsibility_to dispose of the resulting nuclear wastes" (in Rucke, 2014). Nuclear physicist Alvin Weinberg (1995) once described nuclear power as a "Faustian bargain" as the "price that we demand of society for this magical source is both a vigilance and a longevity of our social institutions that we are quite unaccustomed to" (p. 1). It may be that only those inclined to regard the use of natural features such as underground rock for nuclear waste storage as morally acceptable as well as safe over the long term will regard this as a responsibility worth assuming.

4.2.5 Synecdoches. Stone (1988) argues that synecdoches are valuable in the making of policy stories, as they use parts of objects to characterize them as a whole, or individual objects to characterize an entire field (p. 117). Like narratives, synecdoches are potent rhetorical devices that play to the human inclination for pattern-making, or what Geertz (1973) calls "meaningseeking" (p. 140). Indeed, the scientific method privileged by OPG can be largely described as a 
use of synecdoches that extrapolates conclusions about what is not known from what is known. ${ }^{18}$ As meaning-seeking tropes, however, synecdoches, like metaphors, frequently call for interrogation as to how applicable one set of conditions really is to another. For example, OPG (2016b) claimed in its website that the DGR site is "located in a seismically quiet area comparable to the Canadian Shield," although the site is located in a distinctly different type of rock from the Canadian Shield; i.e., in sedimentary sandstone limestone as opposed to granite. This comparison, while potentially persuasive, calls for deeper examination about the similarities and differences between these rock formations, the degrees of similarity and difference, and the significance of these degrees. OPG describes how a team of contracted geologists who analyzed core samples to investigate the permeability of the geology of the proposed site found that "the groundwater isn't moving, [so] there's really no way for the waste to escape" (Kowalski, 2013). Yet, these core samples were drawn from specific locations around the site (Ontario Power Generation, 2013b, p. 32), and there is no definitive (vs. probabilistic) way of knowing that other samples drawn from other locations would not have revealed different phenomena. Further, the fact that the groundwater does not appear to have moved for a long time does not guarantee that this condition will persist far into the future, which is another synecdoche that extrapolates

\begin{tabular}{|l|c|}
\hline Synecdoche expressed by OPG & \# of times \\
\hline Extrapolations onto the site based on other places and times & 6 \\
\hline Environmental responsibility & 5 \\
\hline Meeting regulatory requirements & 8 \\
\hline Storyline expressed by OPG & \# of times \\
\hline Rigorous independent science backs project & 8 \\
\hline Collaborative bottom-up development of project & 6 \\
\hline Those opposing project are in minority & 2 \\
\hline The DGR will be carefully engineered and monitored & 2 \\
\hline
\end{tabular}

Table 6: Frequency of synecdoches and storylines expressed by OPG.

\footnotetext{
${ }^{18}$ I have extrapolated this usage of synecdoche from literary analysis to scientific thought.
} 
conditions from one circumstance into another. Such equivalences and extrapolations made through the application of synecdoche, be they scientific or rhetorical, involve judgements that call for interrogation and challenging in terms of their accuracy and adequacy. I accordingly propose in Chapter 7 that synecdoches should not be left standing as discursive endpoints but ought to be challenged through competent deliberative procedures of taking them up.

4.2.6 Storylines. I found that in both the discourses of OPG and STGLND, the primary storylines made by the actors were political claims about themselves and other groups that legitimized their own conduct and status and vindicated the conduct and status of others; see Table 6. OPG's most common storylines, for instance, described how as they had designed the DGR project "in collaboration with the local community," those who did not accept the project were members of a "vocal minority" who had presumably not "learned about all the research that has gone into the DGR" since "most people change their minds once they learn about all the research that has gone into the DGR" (in Rucke, 2014). This characterization of the resistance to the OPG DGR statements gave short shrift to the substantial opposition to the DGR that has arisen around the region, as testified by the many resolutions against the project that were passed by local governments around the Great Lakes. The contention that those in opposition to the DGR are merely a "vocal minority" is also unverifiable, given that OPG only surveyed one municipality in the region.

More broadly, statements attributing resistance to the DGR to a lack of information do not acknowledge the broad-based and deeply entrenched character of that resistance in certain socio-cultural communities of meaning dispersed through contemporary societies; in this regard, resistance to the DGR is more expressive of a cultural attitude than an information gap. As Kahan (2014) has demonstrated, when holders of a cultural worldview are presented with 
scientific evidence relating to questions such as "is it safe to store nuclear wastes deep underground?" they will "selectively credit or dismiss that evidence depending on whether it is consistent or inconsistent with their cultural group's position" (p. 17). Moreover, Kahan has found that the biasing impacts of cultural worldviews on risk perceptions in relation to controversial issues such as nuclear waste management is highest amongst those who are most informed about science (2015a). Thus, encountering more information would have been unlikely to defuse the distrustful views of those opposed to the DGR.

As Kahan (2014) observes, meanwhile, accusing individuals of being anti-science or uninformed tends to exacerbate polarization in risk controversies, raising defensiveness around socio-cultural identity. As he elsewhere describes, "when communication about a risk turns on the question of 'who are you?' or 'whose side are you on?' . . this style of reasoning is collectively disastrous" reinforcing polarization around risk issues by slotting people into us/them configurations that further undermine scope for trust across cultural divides (Kahan, 2015b, p. 14). As such, I chose to bracket these types of storylines in my narrative analysis of the OPG DGR case in Chapter 6. Instead, my analysis examines the underlying narratives indicated by the generative metaphors of the two groups based on the view that they have greater potential to lead to substantive understanding about the two policy actors' understanding of risk and, in turn, to create common ground on the subject.

\subsection{Worldview Analysis}

Fischer (2000) has described how the technocratic attitude towards modern technology views it as primarily beneficial, "provid[ing] the means that enable humans to achieve their desires" (pp. 12-14). OPG's statements on how nuclear power provides electricity "around the clock, used to power homes, businesses, hospitals, and more" exemplifies this technocratic view 
that the low-probability risks of nuclear waste disposal technologies such as DGRs should be tolerated for the sake of the profuse supply of goods they enable (in Rucke, 2014). OPG's normative preference for positivist bases on which to assess these risks likewise demonstrates the other major feature of the technocratic attitude towards technology described by Fischer (2000), which is that technology requires only "amoral, objective process[es] of evaluation and adjustment" to ensure it continues to match human desires (p. 16). All things considered, it is safe to conclude based on these types of statements and positions that OPG is a consistent and thoroughgoing exemplar of technocratic reason and values.

It also seems safe to conclude that OPG's subscription to technocratic norms and beliefs stems from its membership in a community of meaning that continues to bear strong affinities with Buss, Craik, and Dake's (1986) Worldview A. While OPG is a corporation and not an individual, this interpretive policy analysis presumes it is possible to study corporate discourse through the lens of worldview analysis, on grounds that corporate discourses share continuity with social worldviews. Buss, Craik, and Dake (1986) anatomize Worldview A as a coherent set of convictions in the ongoing prospect for material growth through use of natural resources, and in the human ability to apply science and technology to create new resources and control pollution, which OPG evidently expresses (pp. 99-100). Norms and beliefs expressed in OPG's discourse are extensively congruent with those that Buss, Craik, and Dake. (1986) attribute to Worldview A, in particular: the value of preserving a "high-growth, high technological society" for maintaining "a high state of material and social well-being; the ability to achieve human goals ... [through] technological progress"; the belief in the use of "rationality . . [as] the basis of decision making in society"; and a preference for "centralization . . . for efficient production and management" (pp. 99-100). Another aspect of Worldview A is a faith in the "sustainability 
or substitutability of critical resources" (p. 99), evident in OPG's (2013b) expressed view that the DGR meets numerous “sustainability considerations” (pp. 11-12). Finally, as we have seen, Buss, Craik, and Dake (1986) found that adherence to Worldview A generally aligned with a low concern for the risk of nuclear power and a high regard for its benefits (pp. 102-103).

\subsection{Reflections on the Interpretive Policy Analysis}

This analysis has treated the communication of OPG as a policy actor whose interests are driven not merely by classic enterprise goals (e.g., profits, avoidance of liability, domination over Ontario's energy fate, etc.), but rather as expressive of culturally anchored norms, beliefs, and feelings that motivate a certain version of "the good," consisting of a prosperous, wellresourced, and well-protected society. It might seem unusual to be so analytically generous towards a Crown Corporation, as corporations are presented as the villains in discourse analyses of environmental risk policy situations, which commonly anatomize how technocratic uses of language operate to maintain elite power (e.g., Hajer, 2003; Wynne, 1996). ${ }^{19}$ Certainly, society has benefited from analyses of the environmental power dynamics that are relatively severe in their treatment of corporate and other institutional actors. However, a distortion can also emerge from analyses that attribute purely strategic motivations to powerful policy actors. It is not difficult to identify problematic features in the discourse of OPG, for instance its dismissal of the legitimacy of its opposition as well as the cultural and environmental concerns of First Nations

\footnotetext{
${ }^{19}$ Wynne's (1996) famous essay, "May the sheep safely graze? A reflexive view of the expert-lay knowledge divide" portrays how scientists in England dismissed the concerns of sheep-farmers that high radiation levels in their grazing soils were caused by leakage from the nearby Sellafield nuclear waste refinery, a position that turned out to be true and marked a broader failure of the scientists to credit local and cultural knowledge of industrial practices and contexts. Hajer's (2003) essay “A frame in the fields: policymaking and the reinvention of politics" describes the resistance that emerged in Netherlands when technocratic planners failed to incorporate local, community-based concerns and perspectives into national land use plans. In both of these well-known essays, the analysis is very much to the credit of the plucky and insightful local actors and to the discredit of the overbearing and dismissive institutional actors.
} 
communities. Yet often uncredited to Worldview A holders is how their ultimate concern is often with problems of producing and distributing welfare goods. Most individuals I have encountered in the nuclear industry — at OPG and elsewhere - appear to be sincerely focused on the problem of how to generate adequate and affordable electricity to meet the needs of Canadian communities without adding to the burden of climate change, a requirement that remains unachievable through solar panels and other renewable energy technologies favoured by Worldview B holders (Clack et al, 2017). Since the problem of supplying profuse low-carbon energy stands to be highly relevant in the coming century, it is important to continue incorporating the analytical risk approaches of Worldview A in conversations around sociotechnological fates. Within this context, purely censuring attitudes toward such policy actors stand to be counterproductive in forging solutions which address the need to sustain the simultaneous goals of energy development, environmental protection and community building. 


\section{Chapter 5: Interpretive Policy Analysis of STGLND's Discourse}

\subsection{Overview}

Chapter 4 described the generative metaphor of the strong rock and its singular place in OPG's framing of the DGR as a rock vault, a use of nature that could, augmented by scientific expertise, engineering technology, and institutional controls, safely house and isolate nuclear waste in such a way as to keep humans and others safely protected from it. This chapter in turn identifies a profound generative metaphor supporting the policy frame of the community action group Stop the Great Lakes Nuclear Dump (STGLND): the pure water of the Great Lakes, a representation of nature they evoke as highly susceptible to despoilment by intrusive technologies created by scientific and engineering expertise managed by large institutions. We further saw in Chapter 4 that the Enlightenment-inspired picture of nature offered by OPG, as robust, bountiful and amenable to good technological usage, was interwoven with the bulk of its norms, beliefs, and feelings. This underlying view of nature lent OPG a sense of security in the face of probabilistically low risks and confidence in its ability to manage harms that might arise. STGLND presented a contrasting Romantic picture of nature as vulnerable and antagonized by technological usage that is likewise interwoven with its beliefs, norms, and feelings. Its idea of nature in the image of water-pure until it becomes contaminated by human impactsheightened their concerns around risks and aroused precautionary attitudes that were sharply antagonistic towards OPG's probabilistic approach.

\subsection{Features of STGLND's Discourse}

5.2.1 Generative metaphor. STGLND's overriding focus in its representations of nature was on the preciousness of water and the need to protect it. A great deal of symbolic value was invested in the inviolateness of the Great Lakes, which, in STGLND's submission to the 
environmental assessment, was variably described as "fresh" (2013, p. 7), “clean” (p. 9.), and “precious (p. 7), as having "sanctity" (p. 40), and "life-giving" (Meyer, 2013). In opposition to the lake water's purity and preciousness, the generative metaphor of STGLND cast the low and intermediate level nuclear waste to be placed in the DGR as exceedingly threatening and risky. In keeping with Douglas's (1965) anthropological account of the taboo or risk object as producing a binary classification of "purity and danger," STGLND enforced a rigid antagonism between supposedly pure Great Lakes water and nuclear waste, which they characterized as "the most toxic and lethal substance that humans have ever created" (p. 7). The binary opposition of natural purity and artificial toxicity could be seen in the group's banner logo, which portrayed the symbol for nuclear hazard floating incongruously amidst blue lake water (see Figure 3).

Yet this binary opposition, like virtually all such oppositions, is a simplification. The Great Lakes are not in fact especially pure, having long been polluted by surrounding industries and especially by steel producers and coal generators, with the latter continuing to deposit mercury by-products directly into the Lakes (Natural Resources Defence Council, 2012, p. 2). The implicit idea that radioactive elements cannot be filtered, in contrast with other polluting elements, is untrue (Bolisetty \& Mezzenga, 2015). ${ }^{20}$ Most significantly, the claim that low and intermediate level nuclear waste encased and buried behind a kilometer of rock has the potential to add significantly to the burden of pollution that is currently being dumped, leaked, and precipitated into the Great Lakes is dubious. Nonetheless, STGLND held to the view that nuclear waste presented an exceptional threat to the Great Lakes, aligning with the observation by

\footnotetext{
${ }^{20}$ While low- and intermediate-level waste are toxic, they are not the most toxic type of substances, either natural or unnatural (Science Learning Hub, 2012). Nor is nuclear waste one of the toxins that is most concerning in terms of its impact on the Great Lakes, despite the 33 nuclear power plants and waste storage facilities already sited around them (Sierra Club, 2013); rather, the most concerning toxins, in terms of the contamination of the lake ecosystem, are mercury from coal-burning as well as various industrial byproducts such as PCBs (Willis, 2016).
} 


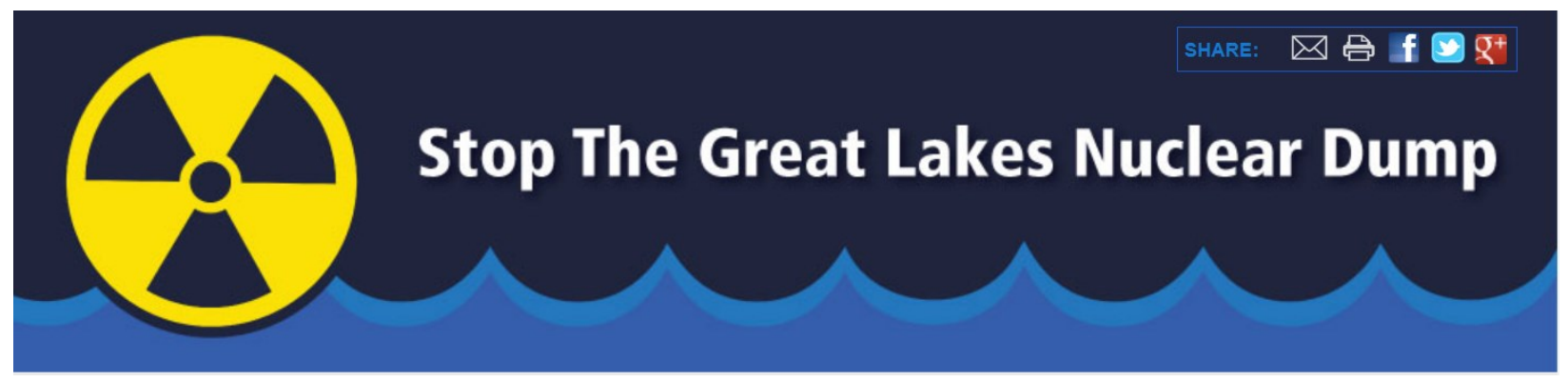

Figure 3: Banner logo of Stop the Great Lake Nuclear Dump (2016a)

Easterling and Kunreuther (1995) that, for many people, "radiation threats seem special" (p.

131). This exceptional status of nuclear substances could spring from how these wastes are associated with particularly dreadful health risks such as cancer and genetic mutations, or from the symbolic sense that they "involve an invisible 'energized' agent" as opposed to being a more stable entity such as a toxic metal (Easterling \& Kunreuther, 1995, p. 132). Easterling and Kunreuther (1995) have observed particular dread and shame associated with burying nuclear material in the earth, due to the sense that it would allow radioactive waste to "fester and infect the planet" (p. 141). Slovic, Layman, and Flynn (1990) likewise have found nuclear waste burial to be associated with a large number of value-laden ideas such as "evil" and "against nature" (Appendix 1-10).

Another key to why STGLND portrayed nuclear waste as exceptional lies in their emphasis on how nuclear waste is a man-made poison, with the underlying assumption that this makes it morally worse than naturally-occurring poisons such as mercury. As Schön and Rein (1994) point out, certain common political symbols operate on the principle of a "strong affinity for the 'natural' and a deep distrust of the 'artificial,"' according to whose logic "present problems are understood as falling away from a more ideal state attributed to the past" (p. 28). These symbols are in keeping with the legacy of Romanticism, a current of thought that has long 
opposed technological projects and processes (Pepper, 1999, pp. 188-205). In STGLND’s discourse, the symbolic logic of Romanticism also meanwhile supported a call to revive the authority of organic communities bridged by common values and experiences over artificial societal institutions such as OPG. Thus, just as OPG's generative metaphor of the stable rock underlying the DGR site transferred beyond implications for the project to affirm institutional authority and processes for securing humanity, SGTLND's evocation of the need to preserve the Great Lakes from artificial nuclear waste suggested a broader normative requirement to protect communities from those same institutions and procedures, which were alternatively portrayed as alienating and ruinous.

5.2.2 Beliefs. Congruent with STGLND's focus on the purity of water and the toxicity of nuclear waste, its most frequently coded beliefs described the threat by "[t]his dump" to "the fresh water of the Great Lakes"; see Table 7 (Stop the Great Lakes Nuclear Dump, petition, 2012). This threat was elaborated repeatedly in their submission to the environmental review (2013), where they reinforced the need to protect the water from nuclear waste at all costs, since "[i]f any of the predictions of OPG's consultants prove to be incorrect ... and if any leakage ultimately results in any contamination of the Great Lakes . . the outcome would be devastating for the 40 million people and the generations to follow who rely on the Great Lakes for their drinking water," and in other words, "catastrophic" (p. 40-42). These assertions that any leakage from a DGR would be devastating to the lake notably neglect the criterion of dosage, which, in

\begin{tabular}{|l|c|}
\hline Belief expressed by STGLND & \# of times \\
\hline Leak would harm all Great Lakes users perpetually & 39 \\
\hline DGR technology has failed in all cases & 9 \\
\hline Radioactive waste is particularly toxic & 5 \\
\hline Great Lakes water is now clean and safe & 4 \\
\hline
\end{tabular}

Table 7: Frequency of beliefs expressed by STGLND. 
environmental impact assessments, establish the basis for predictions of whether a facility will pose risk to proximate environments and humans. Given the very low — and by virtually any standard sub-hazardous - levels at which radiation can be measured, STGLND's repeated assertion that any measurable leak would be "catastrophic" is classed in this study as a "belief," that is, as a speculative position. ${ }^{21}$

5.2.3 Norms. We can begin to see the basis of a strong normative divide between the two opposing policy actors in this issue. Both parties agreed that nuclear waste produced as a byproduct of electricity generation is hazardous, and that the water of the Great Lakes and its surrounding ecology requires protection. But their generative metaphors supported completely opposed takes on how this protection ought to be achieved. In Chapter 4, I observed that OPG's metaphor of the rock vault implied that human systems alone are weak, but that rocks and rocklike institutions can safeguard these systems if they are meticulously selected and engineered through expert processes of technical analysis and construction. By contrast, STGLND’s generative metaphor emphasized elements of nature that naturally support human existence such as pure water. According to this logic, to best preserve humans we must protect nature from technological interferences.

Given its sense of a paramount need for nature to be protected, the community group's second most frequently expressed norm was the need to adhere to a stringent version of the precautionary principle in deciding about the DGR (see Table 8). This principle was expressed

${ }^{21}$ There is a divide over where a radiological dose becomes relevant, with most standards incorporating a linear no-threshold model according to which there is no safe minimal dose of radiation. However, many who work in the field of nuclear risk find this model far too conservative and suppose there is likely a threshold under which nuclear radiation is harmless, especially given that nuclear radiation exists naturally at a range of low background levels everywhere on earth, and variations have not been seen to correlate with harms (Jenkins, 2015). 
through normative policies that would halt any technology that may conceivably present a risk to humans or the natural world, despite any benefits it could also provide. The signature articulation of the precautionary principle is found in the United Nation's Rio Declaration on Environment and Development, Principle 15: "Where there are threats of serious or irreversible damage, lack of full scientific certainty shall not be used as a reason for postponing cost-effective measures to prevent environmental degradation" (United Nations Environmental Programme, 1992). More common instantiations of the precautionary principle hold that the burden of proof for the safety of a project lies with its proponents, or in the words of STGLND, "any risk of radioactive nuclear waste contaminating the Great Lakes is too great a risk to take and need not be taken" (pp. 7, 40). In keeping with this argument, the Bayesian logic of science, which never rules out possibilities completely but formulates them in probabilistic terms, is untenable for securing important resources: "no scientist or geologist can provide a 100,000-year guarantee that this toxic nuclear waste will remain fully and completely contained and stay safe" (Stop the Great Lakes Nuclear Dump, 2013, p. 41). STGLND therefore asserted that the probabilistic conclusion of OPG's Environmental Impact Statement (2011) — that the DGR is "not likely to result in any significant residual adverse effects" — “fails to apply precautionary principles" and so is "not good enough" (pp. 8, 44).

\begin{tabular}{|l|c|}
\hline Norm expressed by STGLND & \# of times \\
\hline Broad definition of community acceptance & 30 \\
\hline Precautionary approach to risk & 22 \\
\hline Duty of stewardship over Great Lakes & 18 \\
\hline Alternative sites should have been considered & 8 \\
\hline Public participation should be meaningful & 7 \\
\hline Disinterested public opinion is of high value & 6 \\
\hline "Common sense" should be deciding factor & 6 \\
\hline
\end{tabular}

Table 8: Frequency of norms expressed by STGLND 
STGLND's precautionary norm entailed some of its other norms about what kinds of judgments ought to be trusted in making decisions. The proper basis for making sociotechnological decisions is not the probabilistic laws of science but the "common sense" of ordinary people with more direct intuitive access to the value of what is threatened, in this case the purity and sanctity of Great Lakes water. Testifying to the superiority of common sense to science as a form of knowledge about technology, STGLND spokesperson Beverley Fernandez (2015) argued, “[y]ou don’t have to be a rocket scientist to know that radioactive nuclear waste buried beside $21 \%$ of the world's surface fresh water supply defies common sense," regardless of what scientists might conclude about it. Like Beck’s (1988) description of “social rationality” (p. 29), STGLND's depiction of common sense concerning risks is "not dependent on ... scientific validity," but is instead a precautionary form of reasoning ethically attuned response to the “catastrophic potential" of the threats they present (pp. 29, 34). Thus, in contrast with OPG's norm that professional judgment should underpin evaluations of DGR sites, STGLND (2013) called for a wide swath of ordinary citizens to make the ultimate decision pertaining to the OPG DGR. They held that what is required to legitimize the DGR was "independent acceptance by all communities comprising the 40 million people who rely on the Great Lakes for their drinking water" (p. 38). ${ }^{22}$

This call for geographically widespread consent to the DGR proposal was not met by OPG, presumably because OPG's Environmental Impact Statement (2011) did not calculate a

22 "Community acceptance" is not a regulatory requirement of a project under the Canadian Environmental Assessment Act or the Canadian Nuclear Safety Commission, but rather a feature of some risk benefit assessments and environmental impact assessments submitted by proponents in defense of projects. For instance, the United States Environmental Protection Agency Title 40 Protection of the Environment (2012) requires proponents of hazardous waste facilities to submit a statement detailing the degree of" community acceptance" of alternatives as one criteria for the ultimate selection (p. 30). There is no similar formal requirement to convey "community acceptance" in Canadian environmental assessments, however. 
leak from the DGR into Lake Huron being a realistic possibility due to the geological barriers between them. Rather, Kincardine was the only municipality anticipated as having the potential to be impacted by a flaw in the DGR, in case of a severe shaft failure, where radionuclides might issue up through the ground (p. 46). On that basis, Kincardine was the only community that OPG surveyed on the acceptability of the proposal. It could be judged that, in terms of the pragmatics of siting, OPG did not undertake a sufficiently broad consultation to genuinely establish the acceptability of the DGR site. Easterling and Kunreuther (1995) hold that consultation for a nuclear waste solution should engage "all potentially affected stakeholders in the process through which the technology is chosen and the siting procedure is established," as "local opposition to a facility such as a nuclear-waste repository will go unchecked as long as ... residents can legitimately argue that they did not participate in the formulation of the siting policy" (p. 233). On similar grounds, STGLND's (2013) most prominent norm was a call for expanded democratic consultation and a contention that OPG failed to meet CEAA's standards to create “opportunities for timely and meaningful public participation throughout the environmental assessment process" (p. 30).

Given that OPG did not survey the broad sweep of communities around the Great Lakes on their opinion of the DGR project, STGLND (2013) proposed that community acceptance of the project could more accurately be gleaned from the evidence of their petition, "the vast majority" of whose signators "reside outside of Bruce County" (p. 18), and from the passing of motions they championed against the OPG DGR at 184 town councils in Canada and the United States. The support for their petition, they held, reflects the "tip of the iceberg" of Great Lakes residents and of the Canadian and public, amongst whom a "[s]ignificant and growing number .. . are strongly opposed to OPG's plan" (p. 31). Given the outbreak of resistance to the OPG DGR 
in the region that their petition captured, "the JRP cannot logically conclude there is broad support for the OPG proposal" (Stop the Great Lakes Nuclear Dump, 2013, p. 31). As they further held, the unacceptability of the project was reinforced by the wide range of people who supported the petition, whom they portray as "a broad cross section of Canadian and American society" consisting of "prominent Canadians, doctors, scientists, teachers, legal professionals, a former deputy member of Environment, former member of Seaborn Panel, First Nations chiefs, church leaders, and members of the military" (pp. 6-7). Still, STGLND had no way to verify based on its petition that opponents to the OPG DGR represents a majority of Canadian and American citizens from the regions, any more than OPG could establish that opposition through the region represent a small minority of uninformed individuals. STGLND additionally attributed credibility to their petition based on the participation of "people from countries around the globe who share our concerns for the protection of this precious natural resource," though it is likewise impossible to establish whether this support was garnered to a dispersed community of meaning a critical mass of global citizens (Stop the Great Lakes Nuclear Dump, 2013, p. 33).

In any event, the norm advanced by STGLND that projects such as the OPG DGR ought to be acceptable to a broad community of ordinary people ties in with the generative metaphors that drive the group's discourse as a whole. STGLND's generative metaphor of the prospective poisoning of pure water focalized the vulnerability of the Great Lakes not merely to an injudicious project, but to technological intervention as such. Amidst this normative logic, the protection of the Lakes must depend not on the scientific calculations of technocracy, but on the wise resistance to that technocracy wielded by ordinary humans guided by common sense and a sure sense of values and priorities. 
Another of STGLND's norms was that a wider siting process should have been done than what OPG undertook; as they pointed out, "OPG did not consider ANY other sites for this nuclear waste dump except right beside the Great Lakes" whereas "due diligence" would have involved "soliciting other host communities and undertaking geo-scientific studies of other sites" (2013, p. 4). In this respect too, STGLND's position was affirmed by experts concerned with effective and acceptable nuclear waste siting, with former U.S. Nuclear Safety Commission Director Alison MacFarlane (2006) affirming that, "the characterization of multiple sites, and better yet, sites with different geologies" generates a sense of 'geographic equity' where the people who host the chosen site may understand that they are doing so because it was the best site in question" (p. 406).

Other norms expressed in STGLND's discourse reflected even stronger affinities with a widely distributed community of meaning resistant to the arrogance of experts and the incursion of technology, especially nuclear technology. Presumably to avoid being marked as ideologically motivated, STGLND claimed their position was not "never nuclear," but rather that if nuclear waste "must be buried, bury it far from the Great Lakes" (in Brown, 2015). Yet the group occasionally raised concerns regarding DGRs of the sort made by anti-nuclear scholars and activists. One of these was that, "[1] eaks in a buried facility can't be detected ... [so] by the time a below-ground breach is found, its contamination could reach land, air and water" (in Van Brenk, 2015). As we have seen, anti-nuclear activists such as the Canadian Council for Nuclear Responsibility are similarly incredulous regarding the reliability of the long-term geological and engineering predictions upon which the construction of DGRs must be founded, and so prefer above ground solutions. Also in common with anti-nuclear activists, STGLND demonstrated incredulity towards scientific expertise, anticipating that "if any of the predictions of OPG's 
consultants prove to be incorrect . . . and if any leakage ultimately results in any contamination of the Great Lakes, then the measurable effects of the DGR will extend far beyond the boundaries of the Great Lakes" (p. 40). As they contended, if the now-leaking German Asse II DGR, "with all its scientific proof, scientific computer modelling, and assurances, government reviews, strict rules and regulations" would have been located in Ontario, "the result would have been radioactive contamination of our Great Lakes" (2013, p. 43). Asse II was a former German salt mine in which nuclear waste was experimentally deposited in the 1960s and 1970s and which has subsequently been revealed to be leaky and possibly unstable. As the regulatory requirements imposed upon OPG and the modelling strategies available them did not exist during that period, the comparison is not completely credible; for more on this synecdoche, see Section 5.2.5.

5.2.4 Feelings. Feelings expressed in STGLND's discourse were congruent with their beliefs that the OPG DGR is an untrustworthy project with catastrophic potential. The most prominent feeling in STGLND's discourse was a sense of moral indignation expressed in quotations describing OPG's (2013) plan for the DGR as "woefully inadequate" (p. 26) and the project as a "crime against humanity, a crime against the Earth, and a crime against future generations" (in McCarthy, 2013). Concern was a feeling that is directly expressed, for instance in their petition, where STGLND (2012) emphasizes how they "stand with concerned citizens in opposition" to the project. Another feeling expressed by STGLND was dread toward nuclear waste, conveyed in how they (2013) repeatedly described it as the "most toxic and lethal substance humans have ever created" (p. 7). STGLND's discourse was more emotionally charged than OPG's overall, with 26 emotional expressions identified in their textual materials, versus only seven in OPG's (see Appendix B.1). This more pronounced emotional tone 
permeating STGLND's discourse is congruent with their criticism of the hyper-rational approach to site evaluation undertaken by OPG and the related assumption that appropriate decisions about technological fates need to be attuned to strongly-held convictions of ordinary people concerning what is valuable.

5.2.5 Synecdoches. STGLND most prominent use of synecdoches were ones in which they extrapolated incidents of past DGR and other repository failures as foretelling the future of the OPG DGR (see Table 9). Other nuclear waste repositories, according to STGLND's logic, foretell the fate of the DGR, as expressed in statement such as "[w]e cannot permit an error such as the one that happened at Maxey Flats to happen here in Canada" (2013, p. 42). ${ }^{23}$ Likewise, STGLND (2016) claims on its website that the Asse II DGR "went through a strict government approval process" (p. 43) and observed that "OPG claims their DGR will be different, but also notes they 'can't guarantee anything'." Fernandez (2015) similarly argued in a letter to the editor published in the Windsor Star that there have been "only three deep dumps that held radioactive nuclear waste on our entire planet," and that as all three have failed, "history proves a 100 per cent failure rate for nuclear waste dumps.” She points out that “in 2014, [the Western Isolation Pilot Plant in New Mexico] WIPP leaked a mere 15 years into its operational phase [and]

\begin{tabular}{|l|c|}
\hline Synecdoche expressed by STGLND & \# of times \\
\hline Other DGR failures predict outcome of this one & 4 \\
\hline Storyline expressed by STGLND & \# of times \\
\hline Reality of public opposition reflected on petition & 21 \\
\hline OPG failed to consult broadly enough & 8 \\
\hline Kincardine collusion/COI with OGP & 6 \\
\hline DGR will pave the way to spent fuel DGR & 5 \\
\hline DGR is controversial \& faces growing opposition & 5 \\
\hline
\end{tabular}

Table 9: Frequency of synecdoches and storylines expressed by STGLND.

\footnotetext{
${ }^{23}$ Maxey Flats, built in Kentucky, also in the 1960s, was one of the first nuclear waste repositories in the US. It buried waste in shallow unlined trenches that eventually flooded and spread contaminants through the surrounding area.
} 
radioactivity travelled to the next town" and that "WIPP is similar in depth and design to the Kincardine dump" (Fernandez, 2015). Yet STGLND's enumeration of three operating DGRs on the planet—counting WIPP as well as Asse II and Morsleben in Germany—excludes new cases of DGR technology currently under study and review in Finland and Sweden (Stop the Great Lakes Nuclear Dump, 2016b). Further, as the leak at WIPP was a brief emission at the atomic level that presented no risk of injury to its workers or the public, it might also be considered to fall short of a failure (Zuckerman, 2015). In these elisions of context, STGLND displays how the use of the synecdoche is a microcosm of the framing process in general, which selects and prioritizes certain types of information at the expense of others. The synecdoche is an essential form of policy communication that is central to elaborating an understanding of the world. However, as will be discussed further in Chapter 7, for a synecdoche to be a genuinely useful element of policy deliberation, it would ideally stand as a starting point for an exchange of arguments where its terms are submitted to interrogation and refinement. In this way, synecdoches would not be left standing on their own as narrative tropes whose usage is almost invariably partial and lacking context, as we likewise saw in OPG's usages of the synecdoche.

5.2.6 Storylines. STGLND's most prominent policy storylines were dedicated to contrasting the Municipality of Kincardine's vote of confidence in the DGR project with the geographically wider support STGLND received on their petition and for their campaign advocating town council petitions in communities surrounding the Great Lakes (see Table 9). One of STGLND's storylines was that Kincardine resident's perspectives were distorted by a conflict of interest with respect to the project, as "[m]any citizens in the town of Kincardine stand to benefit financially and with jobs from this DGR to entomb this toxic nuclear waste," and as "OPG has paid around 35.7 million" to the town in return for its support for the project (Stop 
the Great Lakes Nuclear Dump, 2013, p. 37). As STGLND saw it, the privileged position of Kincardine, contrasts with the condition of "millions of affected Canadians and Americans" who live outside of Kincardine and "receive nothing but risk and uncertainty from the proposal" (p. 32). STGLND accordingly judged that the "community acceptance" determined in the survey of Kincardine "grant[s] an extraordinary power and trust to 4,067 people in a small Ontario town" by permitting it to decide a matter affecting the 40 million people drawing drinking water from the Great Lakes, a decision they consider "highly undemocratic" (p. 37).

The framing of these storylines is, however, quite biased with respect to the motivations of Kincardine residents, exemplifying how political storylines frequently heighten tribal and identity-based themes. There were several other reasons why Kincardine residents might have viewed the DGR project favourably, apart from allegedly corrupted interests. Living close to the Bruce nuclear plant in Kincardine may also have dampened their fear of nuclear accidents, as has been shown to occur in other host communities that are familiar with nuclear technology and derive economic benefits from it (Kemp, 1992, p. 31). As well, the Municipality of Kincardine already hosts the Western Waste Management Facility, an above-ground nuclear waste storage facility that holds much of the material bound for the DGR, which they might regard as adding a premium of safety. Finally, Kincardine's favourable attitudes towards the project may possibly express more faithfully the attitudes of Ontarians towards nuclear facilities than STGLND's petition does, given how a survey inherently produces a biased sample. In any case, as was discussed in Chapter 4, storylines such as these, which are strategically oriented towards rallying in-group indignation, are prone to exacerbating social divisions around risk. Accordingly, it was judged that such policy storylines, while potentially interesting from the point of view of the 
political dynamics of environmental conflicts, were unlikely to be helpful in plumbing the risk concerns of the parties in a productive way that would initiate remediation of the risk situation.

\subsection{Facebook Posts}

The approach taken to analyzing STGLND's Facebook posts was different than their other policy texts, both because there were so many of them ( 278 unique posts) and because the discourses they reflected were much broader and more diverse than in the group's dedicated promotional materials and media statements. Instead of the discourse in the posts being coded for norms, beliefs, synecdoches, and storylines, each post was singularly coded for its most prominent theme and the themes were grouped to reflect the more generalized scopes of argument (see Appendix 3 for full list of Facebook posts themes). Taken together, STGLND's Facebook posts ranged outside of many of its key concerns reflected in its environmental submissions, which as we have seen, focus largely on problems with the specific DGR site and siting processes. STGLND's Facebook posts, by contrast were more proportionately concerned with broader issues, including the need for better ecological management (31\%); for precautionary socio-technological decisions $(20 \%)$; for community-focused types of environmental decision-making (15\%); for a move beyond nuclear technologies (14\%); and for a move beyond capitalist values (3\%) (see Table 10).

Ecological sentiments relating to the preciousness of water and concern for its protection were intensively represented in the Facebook posts. The proposition "Water is life," which originated in a statement by Saugeen First Nation's Chief Randall Kahgee, was reiterated both by STGLND and in the quotations of other signatories (see Figure 4). Also within the ecological theme were posts featuring quotations and pictures of well-known Canadian environmental leaders and activists who had signed the petition, such as broadcaster David Suzuki, novelist Farley Mowat, 
and Maude Barlow of the Council of Canadians, who described the DGR project as a "crime against the future" (Facebook post, February 2, 2014). Along the same thematic lines were expressions of concern for future generations and arguments about the threat posed by the project to the global water supply. These ecological sentiments were typically illustrated over pastoral

\begin{tabular}{|c|c|c|}
\hline $\begin{array}{c}\text { Themes in } \\
\text { Facebook posts }\end{array}$ & $\begin{array}{l}\text { \#s/percentage of } \\
\text { posts reflecting } \\
\text { the theme }\end{array}$ & Expressions of the theme \\
\hline Ecological & $(126 / 31 \%)$ & 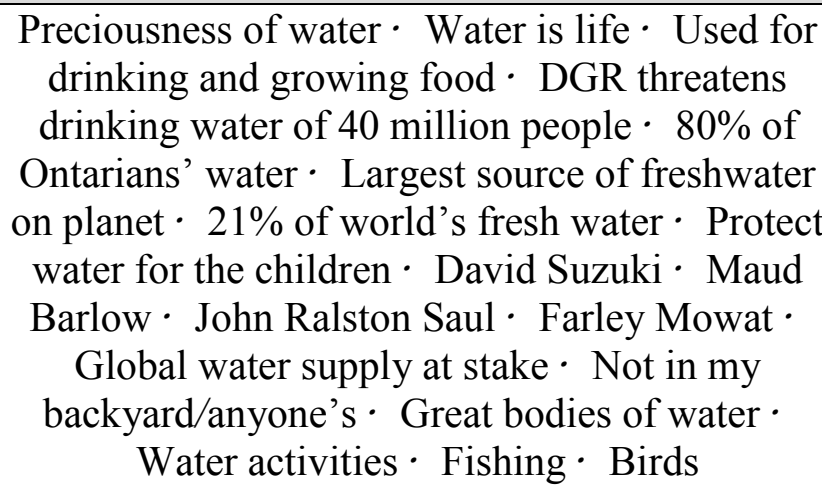 \\
\hline $\begin{array}{l}\text { Anti-Expert/ } \\
\text { Precautionary }\end{array}$ & $(84 / 20 \%)$ & $\begin{array}{l}\text { Defies common sense } \cdot \text { Worst idea ever/crazy } \\
\text { Past promises betrayed } \cdot \text { Experts have been } \\
\text { wrong } \cdot \text { Rolling the dice } \cdot \text { Gambling with safety } \\
\text { of water ' Experiment } \cdot \text { Learn from history } \\
\text { Titanic } \cdot \text { Not likely is not good enough } \\
\text { Scientists can't guarantee } \cdot \text { Any risk is too } \\
\text { much } \cdot \text { Irreversible }\end{array}$ \\
\hline Representation & $(61 / 15 \%)$ & $\begin{array}{c}\text { Did OPG ask you? } \cdot \text { It's your water } \cdot \text { Our } \\
\text { voices matter } \cdot \text { Act before it's too late } \cdot \text { Public } \\
\text { saying no } \cdot \text { \#s on petition } \cdot \text { Opposed } \\
\text { communities } \cdot \text { Wake up Ontario/Chicago }\end{array}$ \\
\hline Nuclear Fear & $(59 / 14 \%)$ & $\begin{array}{l}\text { Keep poison away from precious resource } \\
\text { Don't put poison beside well } \cdot \text { Fukushima } \\
\text { What would happen if you couldn't drink/bathe? } \\
\cdot \text { Radioactive } \cdot \text { Most toxic } \cdot \text { Carcinogenic } \\
\text { poison }\end{array}$ \\
\hline Anti-DGR & $(34 / 8 \%)$ & $\begin{array}{l}\text { Hiding the waste } \cdot \text { Abandoning the waste } \\
\text { Every DGR has failed } \cdot \text { WIPP, Asse II }\end{array}$ \\
\hline Anti-site & $(31 / 7 \%)$ & $\begin{array}{l}\text { Should have looked at multiple sites given size } \\
\text { of Ontario - Too close to civilization }\end{array}$ \\
\hline Anti-capitalist & $(12 / 3 \%)$ & $\begin{array}{l}\text { Shortsightedness of corporations } \cdot \text { Only care } \\
\text { about } \$ \cdot \text { Can't drink } \$ \text { or buy water } \cdot \text { OPG fail }\end{array}$ \\
\hline
\end{tabular}




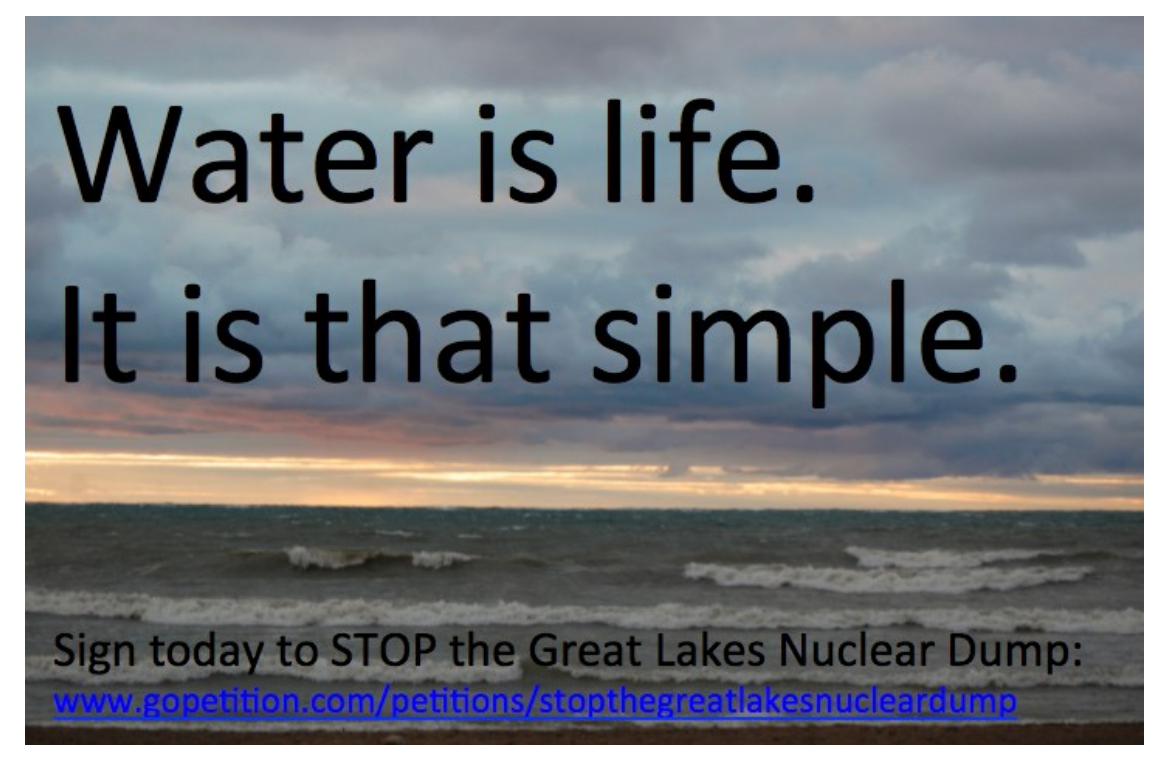

Figure 4: STGLND Facebook post from October 30, 2014.

scenes of the Great Lake shores that captured the irreplaceable value of pristine water in a graphically compelling way, with visual details such as clear water, sunsets, and wildlife.

Other major themes highlighted in the Facebook posts picked up on a general resistance to technocratic decision-making. Precautionary and anti-expert risk norms constituted the second most intensive theme in the Facebook posts. These included statements from STGLND that experts have been wrong in the past, with references to past tragedies ranging from the Titanic to the Fukushima nuclear disaster; as well as suggestions that the OPG DGR project "defied common sense," is “crazy," “completely nuts," and, from Farley Mowat, "smacks of a scenario from the Mad Hatter"; see Figure 5. The idea of irresponsibility was raised in the suggestion that, given its reliance on probabilities, the DGR project is an experiment and a "gamble," like "rolling the dice" with the safety of the Great Lakes and its inhabitants at stake. In turn, the need to widen representation in the decision-making process was the third most intensive theme, with claims that "40 million people were not consulted" and a call to action for citizens to "wake up," 


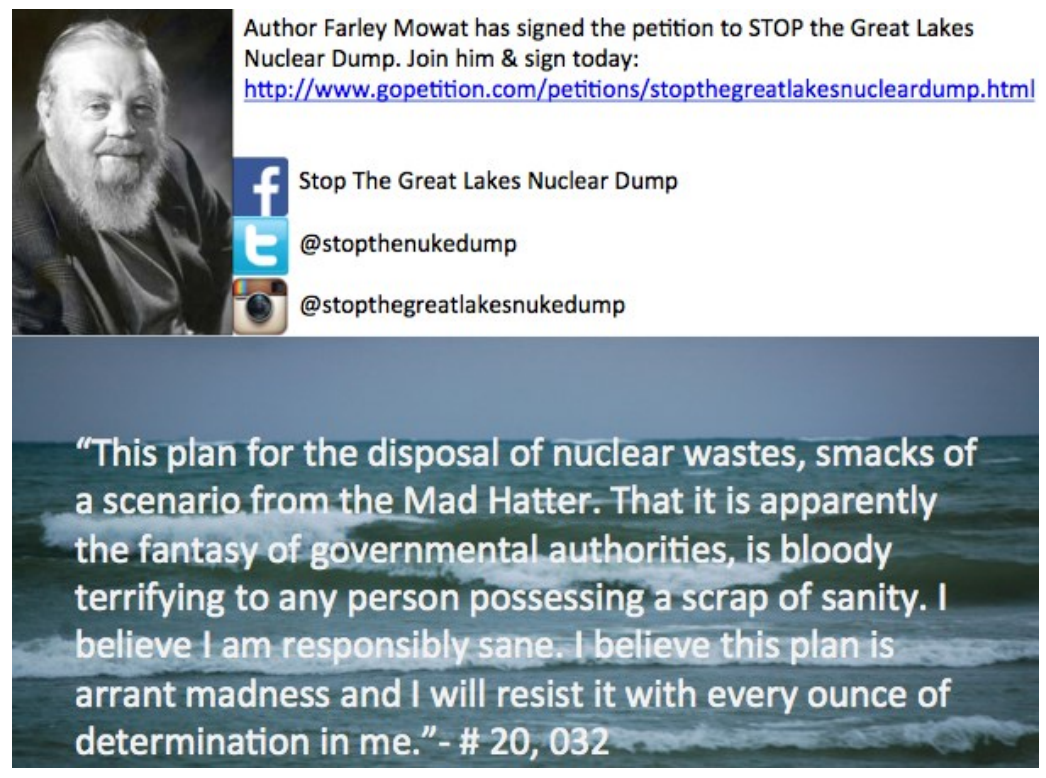

Figure 5: STGLND Facebook post from September 23, 2013.

and "act now before it's too late." As is explained further in the Worldview Analysis below, this theme demonstrated the linkage of anti-technology activism with concerns for democratic representation and social justice, as well as the preference amongst environmental activists for broad public input as the predominant factor guiding socio-technological decisions.

Broadly anti-nuclear themes were also represented in the Facebook posts. The fourth most intensive theme touched on versions of nuclear fear and dread of nuclear waste, with repeated dwelling on the especial toxicity and hazard posed by nuclear waste above all other substances. STGLND's highly affective invocations of what Weart (2012) calls "nuclear fear" conjoined specific concerns with the OPG DGR site to broader cultural anxieties about nuclear waste, a substance viewed by some socio-cultural groups to be exceptionally toxic, hazardous, and even immoral. Some of the gestures made in the anti-nuclear vein were, meanwhile, distinctly inaccurate, such as the reproduction of a map that was widely purported after 2011 to portray the spread of radiation out of the Fukushima nuclear plant after the Tōhoku earthquake, 
and which was later exposed as a tsunami map (see Figure 6). In the fifth position were suspicions of DGR technology, and in particular, suggestions that this technological approach constituted an irresponsible way of "abandon[ing]" the waste- - a term used in the discourse of anti-nuclear advocates such as Edwards (2015). The theme of the DGR as an irresponsible corporation was congruent with the broader theme of corporate and capitalist irresponsibility in the seventh place amid Facebook themes, expressed in quotations from signators that averred that OPG “do[es] not have the health and wellness of the planet in mind, only expediency and money" (Facebook post, June 27, 2014).

As can be seen, many of the most prominent themes in STGLND's Facebook posts were highly general ones that would be resonant among a dispersed community of meaning. The merging of local themes with broader ones presumably allowed STGLND to effectively support on their petition across a wide geographical scale. STGLND's effective use of Facebooks as a medium to share their perspective on the OPG DGR case with a geographically dispersed

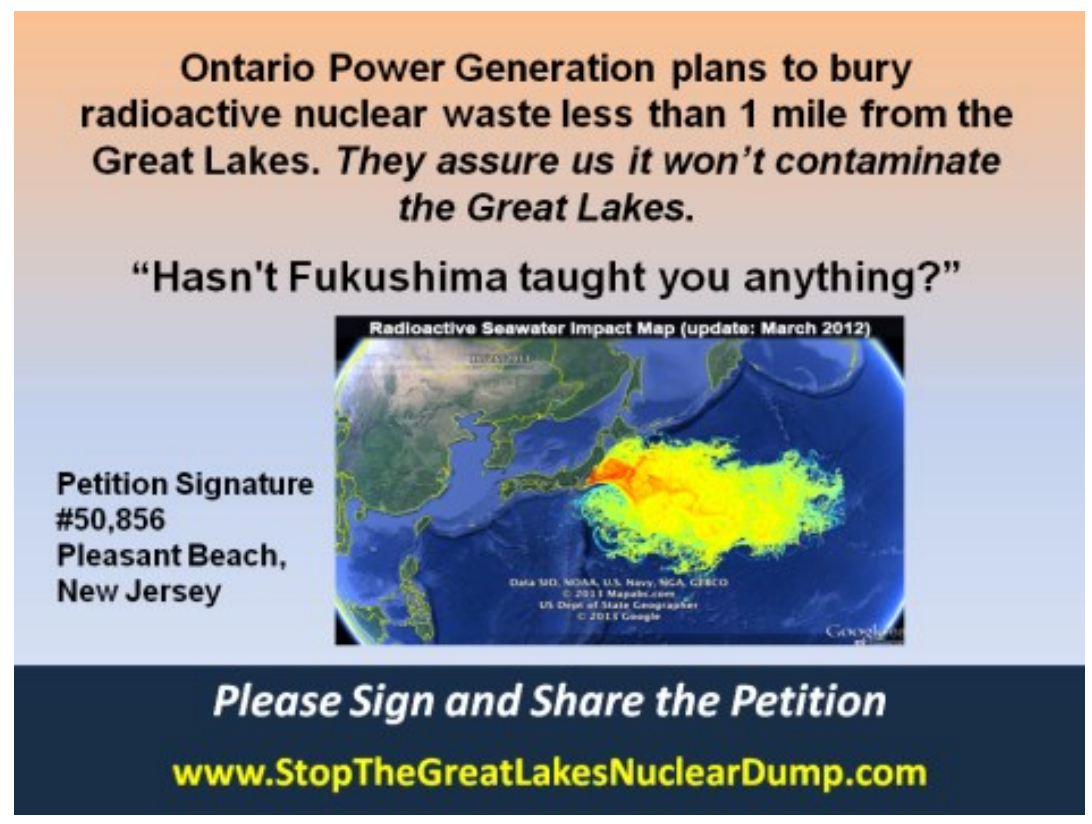

Figure 6: STGLND Facebook post from November 23, 2014. 
community of meaning, many of whose members likely had no connection or background information on the situation, reinforces the perspective advanced by policy frame theorists as well as cultural theorists of risk that policy issues tend to slot into readily available cultural worldviews. These cultural worldviews, in turn, provide the communities of meaning that hold them with pre-established frames and associated set of discursive modes, for comprehending and describing them.

The discursive interconnectedness of STGLND and its audience of petition-signers was especially visible in a rhetorical peculiarity of the Facebook posts, whereby the language of the quoted petitioners frequently echoed the discourse of STGLND, and vice versa. Certain phrasings, such as references to the Great Lakes as a "precious resource," arose repeatedly, suggesting that the petitioners either shared the same discourse on an intrinsic basis or that they instinctively parroted the words of STGLND in their comments (see Figure 7).

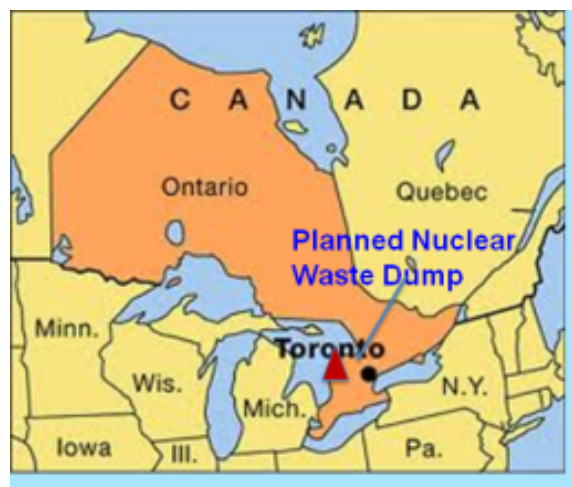

"There is no sensible reason for this waste site to be so close to our most precious resource." Help us defeat Ontario Power Generation's plan! Please Sign \& Share the Petition www.StopTheGreatLakesNuclearDump.com
Ontario contains over a million square kilometres, yet Ontario Power Generation plans to bury radioactive nuclear waste 1 kilometre from the Great Lakes Lainsburg, Michigan:
Petition Comment \#61,534

Figure 7: STGLND Facebook Post from November 16, 2014. 
The back-and-forth exchange of words and phrasings between STGLND and its petitioners exemplifies how forms of thought and language become shared through use and reuse amidst a community of meaning in a way that can turn them into collective "identity marker[s]" (Yanow, 2000, p. 10). Overall, it is clear Facebook offered fertile ground for STGLND to popularize its grievance amid a social media "enclave” (Sunstein, 2001) consisting of individuals who shared similar symbolical, normative, epistemological, and political affinities. Essentially, Facebook allowed STGLND to create a large network of alliances with such individuals based on shared frames for comprehending policy situations such as the OPG DGR. In this network, STGLND matched pre-given frames for understanding environmental policy controversies with their own discursive formulas for describing the OPG DGR policy situation and had these formulas taken up and reproduced among relevant communities of meaning. In turn, STGLND supplemented its discourse in an ongoing with additional discursive formulas gathered from the comment section on their petition, further expanding their relevance to that community of meaning and completing the cycle of "discourse structuration" (Hajer, 1993, pp. 45-46).

\subsection{Worldview Analysis}

Given the large self-selecting sample of the public that STGLND's petition attracted, it is reasonable to identify the signatories as geographically diffuse members of a shared cultural worldview that expresses strong affinities with the generative metaphor invoked in STGLND's discourse as well as the norms and beliefs that it animates. As we have seen, analysis of STGLND's campaign discourse shows that they preferred for the decision on the OPG DGR to be made in keeping with a precautionary principle that is characteristically suspicious of the potential impacts of technology. In turn, it revealed their belief that the public's "common sense" 
should guide decision-making about the socio-technological decisions such as DGR development.

Overall, STGLND's discourse indicates strong affinities with Buss, Craik, \& Dake's (1986) Worldview B, suggesting that its members and supporters, and likely most of its petitioners, constituted a community of meaning aligned with that worldview. As discussed in Chapter 2, Worldview B is a set of coherent socio-technological attitudes observed in research in the 1980s into bifurcated social views on technology and the environment. Holders of Worldview B see a new paradigm of intensive ecological scarcity emerging that signals the end of the "waste-absorbing capacity of the environment" and of the "resilience of planetary lifesupport systems" and tend to conclude that continued technological growth and increased energy consumption will lead to "intolerably high" social and environmental costs (Buss, Craike, and Dake, p. 100). As Buss, Craik, and Dake's (1986) study further demonstrated, holders of Worldview B attribute much higher risks and lower benefits to nuclear power and report far more negative attitudes towards it than holders of the "cornucopian" Worldview A (pp. 102103). Holders of Worldview B accordingly see a need to move towards "small, frugal, and decentralized technologies," such as solar panels and to reduce demands on material resources overall and would have societal decisions be made by the general public based on norms of acceptability and accountability (Buss, Craik, \& Dake, 1986, pp. 109, 116). Overall, just as OPG's discourse expresses continuity with the technocratic approach to socio-technological decision-making described as Worldview A by Buss, Craik, and Dake (1986), there is obvious discursive and framing continuity between STGLND and their petition-signers with the ecologically concerned, nuclear-suspicious, and community-based decision preferences captured in Buss, Craik, and Dake's (1986) Worldview B. 


\subsection{Reflections on the Worldview Analyses}

In Chapters 4 and 5, interpretive policy analyses showed that the discourse of OPG and STGLND reproduced the tenets of socio-technological Worldview A and Worldview B. These worldviews advance opposed norms and beliefs regarding whether technological developments in pursuit of material improvements for humanity present primarily benefits or risks, and whether scientific evidence or the public will should primarily be consulted for making sociotechnological decisions. These worldview-related norms and beliefs resonated strongly with the discourses of OPG and STGLND throughout their efforts to promote and to defeat the DGR project (Buss, Craik, \& Dake, 1986, pp. 99-100).

One possible explanation for this congruence is that policy actors know that if they evoke these respective traditions, it will make their policy proposals appeal to certain communities of meaning and help them gather sympathizers among them. However, another explanation—which is not exclusive of the first one-is that these worldviews were to some degree deterministic of the attitudes that these policy actors hold, as themselves members of those communities of meaning. That is, it is quite possible that due to the origins, personalities, relationships, and life experiences of individuals in these organizations, they have come under the influence of these cultural worldviews, making it feel natural and appropriate to portray the case of the OPG DGR in their terms, in keeping with Hajer's (1993) idea of "discourse structuration” (pp. 45-46).

In either case, the persistence and prominence of relatively stable socio-technological worldviews guiding the creation of policy frames helps to explain why policy controversies about technological risk issues are so intractable. With key policy actors anchoring their respective discourses in opposed worldviews, little accommodation of values is likely to be forged in either deliberative or regulatory forums; rather, these venues are likely to primarily 
serve as sites for those who are sympathetic to these worldviews and their associated frames to vocalize and reproduce them, and for those who are not sympathetic to ignore or dismiss them. This observation is congruent with the cultural theory of risk, which suggests that people tend to trust information and sources on controversial risk issues that affirm their prior views on these issues more than information that disconfirms them (Kahan, Braman, \& Jenkins-Smith, 2011).

This polarization appears, further, to remain in place in part because of the symbolic "diagnostic-prescriptive stories" at the core of divergent policy frames, which are unconsciously compelling and do not brook compromise, supporting irreconcilable values, ideals, and solutions (Schön \& Rein, 1994, p. 26). On the one hand, OPG's symbolic emphasis on how stable rock can, and should, be used to contain nuclear waste puts a premium on the benefits that nature allied with technology can provide for individuals and societies. For someone who places a high value on these benefits, it might understandably be difficult to accept that their provision should be curtailed if solutions appear open to providing them. On the other hand, STGLND's symbolic emphasis on pure water suggests that natural environments and the communities surrounding them are intensely susceptible to risks caused by the misuse and overuse of technology. For someone who strongly registers these risks, any compromise with the proponents of a technology that appears to present a threat could very well seem morally impermissible. Given such normatively bifurcated narratives in play, consultation and deliberation may well be unable to mediate and bridge entrenched issues involving technology benefit and risk trade-offs.

As such, this thesis argues that mediating controversial socio-technological risk policies requires a redirection of away from conventional consultative approaches that strongly favour the rehearsing and reproduction of policy narratives. Instead, it proposes that decision-making processes shine a more direct light on the underlying concerns of different communities of 
meaning these narratives reveal, upon analysis; and find ways to bridge these plural risk concerns amid collaborative processes oriented by principles of argumentative rigour and openendedness regarding what is known about a given situation and what is right for it. 


\section{Chapter 6: An Intertext for the OPG DGR controversy}

\subsection{Reflection on the Interpretive Policy Analyses}

The interpretive policy analysis of OPG and STGLND discourses concerning the proposed OPG DGR pursued in Chapters 4 and 5 investigated how norms, beliefs, and feelings these organizations express could be animated by generative metaphors with symbolic resonance amongst their respective communities of meaning. In the case of OPG, the generative metaphor identified as dominant within its discourse was its depiction of the DGR site geology as a powerful building or vault that could reliably house nuclear waste, a symbol with conservative institutional and Enlightenment science-oriented resonances. By contrast, STGLND and its community of meaning were compelled by the image of pure Great Lakes water vulnerable to contamination by industrially produced nuclear waste, a poignant image with anti-institutional and Romantic resonances. The analysis further showed the discourses of OPG and STGLND to be relatively consistent with Buss, Craik, and Dake's (1986) socio-technological worldviews, emphasizing, on one side, the material abundance that can be supplied by the earth's resources in combination with human technology, and on the other, the need to shift to more precautionary practices of decision-making to avoid environmental catastrophe.

One may ask which frame is more appropriate for application to the OPG DGR case. To this question, however, there is no obvious answer. In support of OPG's frame, nature is certainly capacious, robust, and, in many respects, resilient; and humans do possess exceptional ingenuity as engineers of successful technology. However, in support of STGLND's frame, many features of nature are vulnerable to human activities, and many types of technology show unforeseeable impacts on some level. 
In this vein, it may seem reasonable to take a granular approach to the environmental analysis of projects such as the OPG DGR, considering the virtues and risks of the project and site and investigating a range of likely as well as worst case-scenarios and whether the latter could be mitigated. Such a process is not that different from what is already undertaken within current regulatory decision processes. However, case-by-case decision-making is invariably complicated in the real world by the politically competitive claims-making practices of different interested organizations. As we can glimpse in the OPG DGR case, in regulatory contexts, organizations have tendencies to feature their characteristic policy frames-with their underlying cornucopian and catastrophic worldviews — as providing well-justified answers to all questions that arise. Accordingly, in the OPG DGR case, OPG presented the DGR technology and site as eminently able to contain the waste due to the rigour of the analysis that went into it, while STGLND presented the same project as worryingly suspect due to the history of past DGR failures. Meanwhile, more detailed issues concerning the degree of predictability that can be assigned to the materials and methodologies involved in the design of DGR — as well as the degree of risk that would be raised if the unpredictable occurred—were not as conspicuously gone into, presumably because they break against both OPG's techno-optimistic and STGLND's techno-pessimistic sets of frames.

As Schön and Rein (1994) describe, discussion of the concrete and specific details of cases - including relevant uncertainties - tend to fall by the wayside in policy discussions in favor of frames precisely because frames help dispel uncomfortable feelings of uncertainty that gather around complex issues. They state that when "a situation may begin by seeming complex, uncertain, and indeterminate ... if we can once see it in terms of a normative dualism such as health/disease, nature/artifice, or wholeness/fragmentation, then we shall know in what direction 
to move" (Schön \& Rein, 1994, p. 28). As Schön \& Rein go on to explain, however, political and social habits of imposing the same frame upon different situations eventually leads to policy failure, as ultimately "the world resists our acts of willing and interpreting, stubbornly presenting us with phenomena mismatched to our frames" (p. 42). Certainly, an overextension of either unconcerned or highly risk averse frames in the regulatory domain would eventually lead to some sort of policy failure, whether a glut of risk-prone infrastructure or of an inadequacy of infrastructure to supply requirements, recalling Aristotle's adjuration to seek "the golden mean" between being "rash and exceed[ing] in fear" (Section 2). Yet even when policies do begin to fail due to overly consistent application of frames, it is extremely difficult for people who are sympathetic with these frames to move beyond them. Presumably this is so because there is little incentive to undertake the difficult work of updating one's frame, and a good deal of incentive to maintain beliefs and norms coherent with those of the wider cultural community with whom one already associates, as Kahan et al. (2011) discuss. As a result, policy-makers are not generally able to create new consensus in controversial policy domains and instead must seek to satisfy one cultural community at a time, leading to conditions of stalemate around difficult files, or else to erratic political pendulum swings between one frame and another depending on the affiliations and interests of whichever party is in power (Schön \& Rein, 1994, p. 8).

The creator of narrative policy frame analysis, Emery Roe (1994), agrees with the conclusions from policy frame theory and the cultural theory of risk that policy-makers ought to try to reckon with diverse narratives surrounding a situation, rather than to choose from amongst them - and also that doing so is extremely difficult (p. 3). Given this difficulty, he sees policymakers most constructively bridging frames not through direct deliberation amongst policy actors but through the employment of "narrative policy analysts" (p. 10). Such analysts would 
"compare and contrast" prevailing narratives framing a policy situation to "generat[e] another narrative altogether, that could be more helpful than any of the positions on their own" (p. 19).

Essentially Roe's (1994) approach is designed to try to manage the messiness of pluralist societies - which inevitably generate multiple narratives in response to any situation — without foreclosing on any of them, seeing the full range of perspectives as holding epistemological and ethical richness for understanding the issue. Roe (1994) cites Irving Berlin's (1947, 2013) contention that in liberal societies, where "some ultimate values may be incompatible with one another," the best way of arbitrating among values is not to dismiss some in favour of others but to sustain an unstable equilibrium among them (Berlin, 1947, pp. 49-50; cited in Roe, 1994, 19).

One of Roe's (1994) approaches to generating such an equilibrium amongst apparently incompatible values and narratives relating to a policy issue is to search for an intertext in which they all simultaneously make sense, thereby lending the issue fuller dimension and depth. As he explains "the idea behind intertextual evaluation ... is not to find a way to get rid of the polarization driving the controversy, but rather to find a state of affairs whose very success depends on having that polarization in place" (p. 145). This dissertation hypothesized that Roe's approach of being determinately respectful of all sides in a polarized debate in a risk issue such as that of the OPG DGR was an approach amenable to taking risk seriously, by highlighting how the risk frames of social cultures highlight a range of broadly essential, human concerns, all of which call for stewardship.

Moving beyond the interpretive policy analysis of the OPG DGR controversy in the last two chapters, where a socio-cultural schism between the policy actors was displayed, this chapter accordingly applied Roe's methodology of narrative policy analysis to more fully confront — and hopefully, to begin to resolve - this schism. As Roe (1994) proposes, narrative policy analysis is 
designed to chart a way forward in a policy controversy comprised by high uncertainty (p. 13). Certainly, the OPG DGR controversy - and policy debates about nuclear waste management and nuclear energy in general — are characterized by diverse forms of uncertainty. These include uncertainties regarding the extent of the radiological risks involved in nuclear generation and waste storage to humans and the environment; and uncertainties regarding the the benefits that can be obtained through profuse GHG-free nuclear energy and whether these are necessary given the range of other available and emerging energy options, including renewables such as solar and wind power. DGRs themselves present further uncertainties in relation to the radiological risk they present to ecologies and communities proximate to them long into the future.

A galling problem in relation to the uncertainties associated with DGRs is, meanwhile, that they can probably never be fully eliminated. As Pielke Jr. (2007) points out, uncertainties loom around risk issues due to all sorts of epistemological gaps and contingencies, include limitations of scientific understanding and measurement; the prospect that if humans do things differently, different effects will unfold; and the sheer play of chance (pp. 67-70). As he notes, "in many instances, efforts to reduce uncertainty paradoxically have the opposite effects," as additional research generates a more nuanced perspective on the processes and conditions involved (Pielke Jr., 2007, p. 66). In such cases, more information "has the perverse effect of increasing political controversy rather than reducing it, a situation which ironically can lead to calls for even more research to reduce uncertainties" (p. 66). Sarowitz (2004) points out that uncertainties around a policy issue also propagate due to incoherence among the diverse types of scientific expertise brought in to address it, which are often oriented to different goals and norms and so can generate incommensurable conclusions and recommendations. Political polarization further exacerbates disciplinary uncertainty, as diverse policy actors mobilize incompatible types 
of expertise upon the issue. When an issue becomes highly polarized, "the certainty of uncertainty" is often deployed as an argument in itself, either by policy actors seeking to evade regulatory measures by casting doubt on observed impacts, or by advocates calling for precautionary measures on the account of uncertainties (Roe, 1994, pp. 110, 124). We saw STGLND (2013) doing the latter when they called for the DGR project to be rejected because OPG would not "guarantee" there would be no significant impacts but merely offer a very high probability, which they considered "not good enough" (pp. 41, 44). Yet as Roe (1994) proposes, it is usually necessary to move forward despite uncertainties, because decisions often "need to be taken now ... waiting is not possible, or when we do wait for better information . . that research all too often raises further questions and problems" (p. 8). Sarowitz (2004) agrees that, in many cases, it would be salutary to "abandon a political quest for definitive, predictive knowledge" in favour of "more modest, iterative, incremental approaches to decision making that can facilitate consensus and action” (p. 400).

\subsection{Narrative Policy Analysis}

In line with these recommendations - and in the interest of going beyond an explication of competing frames alone- my narrative policy analysis attempted to carve a consensual path through the uncertainty that looms around the OPG DGR case by mediating the narratives expressed in the two policy actors' core generative metaphors, each which spoke to questions of risk, uncertainty, and how these should be handled. As we saw, the generative metaphor of OPG was essentially that of the DGR as a strong house or vault capable of walling off nuclear waste and protecting humans and ecologies from it. By contrast, the generative metaphor of STGLND was that of naturally pure and vulnerable water that can never be adequately protected from artificial contamination and so threatening all who rely on that water. These generative 
metaphors can be slightly modified to reveal a beginning — middle — end structure that Roe calls for in a policy narrative, which can be articulated as follows:

1. OPG:

Beginning: The DGR project is approved because it will probably ${ }^{24}$ be stable and safely house the nuclear waste away from ecosystems for the duration it is designed to do so.

Middle: The DGR probably behaves according to the normal evolution scenario or a low-risk disruptive scenario anticipated by its designers for up to 100,000 years, or the duration that it needs to.

End: The DGR project is probably a success. Even if the DGR has leaked more than anticipated, all radiological contamination has probably been contained within the immediate geological vicinity of the site and has not migrated significantly beyond it. Or, if a major unanticipated leak and radiological contamination has reached the Great Lakes, it has probably become diffused and diluted at the point of entry into the lake to a point of insignificance in terms of its ecological impact.

\section{STGLND:}

Beginning: If the DGR is approved, that approval comes despite the fact it is a flawed technology irresponsibly sited beside a major source of fresh water into which it could possibly leak, against the will of the community.

\footnotetext{
${ }^{24}$ In restating the underlying storylines held by the two groups in a way that makes them parallel narratives about the OPG DGR, I have used italics to highlight the zones of uncertainty within them.
} 
Middle: Possibly the DGR leaks into the Great Lakes at some point in time to an extent its engineers did not think possible, possibly for a reason they did not anticipate.

End: Possibly all the water in the Great Lakes is significantly contaminated by the DGR and rendered irremediably undrinkable and useless for recreational and agriculture for thousands of years, if not hundreds of thousands, entailing dangerous health and environmental effects for those who depend upon it.

On the surface, these two narratives feature very different discursive characters, with the probabilistic mode of the former narrative presenting an aura of unworried confidence, and the possibilistic mode of the latter narrative expressing a tone of concern and anxiety.

It is instructive, meanwhile, to see what happens when the two stories are merged into a single narrative in which they are both "the case at the same time," in Roe's words (p. 134):

\section{OPG and STGLND}

Beginning: The DGR project is approved because it will probably stably and safely house the nuclear waste away from ecosystems for the duration it is designed to do so, despite its possibly being a flawed technology sited beside a major source of pure fresh water against the will of the community.

Middle: The DGR probably behaves according to the normal evolution scenario or a low-risk disruptive scenario anticipated by its designers for up to 100,000 years, but it possibly leaks into the Great Lakes at some point in time to an extent that its engineers did not think possible and for a reason they did not anticipate. End: The DGR project is a probably a success. Even if the DGR has leaked more than anticipated, all radiological contamination has probably been contained 
within the immediate geological vicinity of the site and does not migrate significantly beyond it. Or, if there has been a major unanticipated leak and radiological contamination has reached the Great Lakes, this radiation has probably become diffused and diluted at the point of entry to a point of insignificance. But possibly all the water in the Great Lakes has become significantly contaminated and rendered irredeemably and perpetually undrinkable and useless for recreational and agriculture for thousands of years-if not hundreds of thousands - entailing dangerous health and environmental effects for those who depend upon it.

While this exercise may seem excessively literal, it is also instructive. In particular, it is valuable to see that the two policy narratives of the two opposing groups - which on the surface seem like opposite framings of the same issue — can be combined into a paragraph that is semantically intelligible. This is because OPG's narrative logic is probabilistic, dealing with statistically calculated and modeled likely outcomes, and the narrative logic of STGLND is 'possibilistic,' dealing with potential exceptions to those likely outcomes.

As we have seen in the discourses of OPG and STGLND, these narrative logics support different norms concerning action. The probabilistic logic favored by OPG warrants the type of calculation-driven action that allows us to get on airplanes and cross streets in the understanding that we will probably land and arrive safely. By contrast, STGLND's possibilistic logic motivates action geared to preventing events that are improbable but sufficiently dreadful as to warrant prevention-for instance, the purchase of insurance or the pursuit of shelter in lightning storms. Clearly, both of these types of reasoning are useful, and a balance between them is likely desirable. In this respect, the combined narrative's overall effect is expressly rational, as it 
gathers together both probabilities and possibilities to give a sense of the case's full spectrum of potential outcomes, including both those that are to be expected and those that, although outliers, are nonetheless worrying.

Yet how can we balance off, or integrate, probabilistic and possibilistic types of reasoning? One option is to chart a middle course, or compromise, between the two positions. If we absolutely needed to run outside in a lightning storm, we might maximize our probability of safety by picking the shortest distance between shelters, for instance. A problem with this 'compromise' approach, however, is that it tends to be motivated by urgency, and the ultimate determination of where the midpoint is can be sub-optimal. A second option is to try to reduce the gap of uncertainty between probabilities and possibilities. If we are uncertain about whether to buy insurance, we might review the probabilities of sustaining expenses that would exceed the aggregate cost of the insurance over time. As well, we might think about what resources we would otherwise have at our disposal for coping with a range of uninsured health emergencies that might possibly arise.

Prospectively, investigative activity in the uncertainty gap between possibilities and probabilities could potentially also help policy-makers to bridge the gap between different worldviews bearing on technological projects such as the OPG DGR — for instance, by encouraging the comparison of the costs of action and inaction on a probabilistic basis, as well as by quantifying outlier possibilities and assessing available measures for responding to them.

\subsection{Identification of an Intertext}

What the previous exercise showed was that the narratives of the two policy actors are not fundamentally inconsistent, even if many of the norms and beliefs that these narratives anchor are. A basis for seeing consistency in apparently inconsistent policy narratives is also 
what Roe (1994) was also interested in supplying in some of his case studies through the mediation of what he calls an "intertext." Based on the literary theory of Riffaterre, Roe (1994) argues that the "intertext" for a policy issue consists of "one or more texts . . that the reader needs to know in order to understand how multiple and opposing readings of a given text are possible and even consistent" (p. 134). As he further describes, any such intertext is invariably to be found in the larger "sociolect" around a policy issue, or the broader discursive field in which that issue is suspended (130).

Surveying the discourse around the OPG and STGLND positions revealed two such texts. These texts consisted of testimonies quoted in STGLND's discourse of the importance of averting the impacts of hastily sited or inadequately tested DGRs, though they were advanced by geologists who elsewhere convey their beliefs that well-sited DGRs can properly contain nuclear waste. Understood in their full contexts, these views reflect an attitude towards DGR siting that is neither specifically technocratic nor anti-technocratic, but rather inquisitive and open-ended, with a keen view of the experimental and novel character of the technology, of the potential it holds, and of the risks that it retains.

One of these mediating views was expressed by Alison MacFarlane (2006), a geologist and recent chair of the United States Nuclear Safety Commission, in her portrayal of the uncertainty inherent in the geological modeling for a DGR siting process:

It is almost impossible to decipher the detailed history of a rock, let alone predict reactions into the geological future. Geology has not advanced far enough yet to expect that it can do this ... [because] many assumptions go into these models. The problem ... is that one cannot make assumptions about the processes or 
features that one is not aware of ... [so] these models cannot be validated or verified. (p. 397)

STGLND cited this perspective as an argument against the OPG project, but I would argue that MacFarlane's (2006) statement fits neither Worldview A nor Worldview B. While it suggests that one cannot presently know if one has made the all of the appropriate assumptions in modeling the geological future, it also holds out the possibility that geology and geological modeling will become more reliable for making predictions. Further, looking into the context from which this quotation was extracted, one finds that MacFarlane's (2006) line of reasoning was not to challenge the validity of the DGR concept, nor to dismiss modeling as a tool for DGR siting, but rather to call for modeling procedures in DGR siting to be accompanied by other means of analysis in order to make these siting procedures more reliable (p. 406). This quotation, like her entire book, which consists of submissions from various scientists and engineers on lingering uncertainties in their fields, questions some basic assumptions of technocracy. However, its central aim is not to replace technocratic processes, but to deepen their rigor and responsibility.

MacFarlane's (2006) perspective helps to augment the intertext for the OPG DGR. She argues that it is wrong to contend either that a DGR will behave as projected, as OPG does, or that it will not do so, as STGLND does. Rather, it reveals how we are lodged in a point of tension between these possibilities, which only ongoing scientific inquiry can help to settle. MacFarlane (2006) emphasizes the need to take the time for thorough and patient study in DGR siting, observing there to be "a false sense of urgency surround[ing] nuclear waste disposal" given the adequacy of current, above-ground storage systems; as she argues, there is "little to be gained, and much to be lost, from rushing a decision of such magnitude" (MacFarlane, 2006, pp. 
407-408). She therefore calls for the use of "multiple techniques to analyze the site, with weighting as judged reasonable by experience," along with comparative data from existing DGRs and test sites to lend a more empirical basis to the DGR siting process than modeling ever can (MacFarlane, 2006, p. 406). In her attempt to draw more fully upon the real-world experience of other DGRs and test sites, MacFarlane (2006) essentially proposes an expanded methodology of synecdoche, or of using information about what we do know to get a better bearing on what we do not know. To give an example: in the case of the OPG site, one feature that has played into the controversy is a perceived shortfall of knowledge of the adequacy of shale and limestone for long-term nuclear waste storage. An approach to reducing uncertainty around the siting could call upon OPG to find - or alternatively to generate-extended empirical tests of the chosen rock formations over a lengthy period of time, to observe how well they contain nuclear waste or a proxy for it. Such experiments could help to reveal if these geologies behave exactly as modeled.

Another expression of an intertext for this controversy is a quotation from William Fyfe, a geologist and nuclear waste expert likewise quoted by STGLND, who is reported to have stated in a media interview in 2004: "You do not put nuclear waste near things like the Great Lakes or the great rivers in case there's a leakage you haven't expected"' (in Lindgren, 2004). Like MacFarlane's (2006) quotation, this statement seems decisively against the OPG DGR on the surface, yet benefits from the introduction of more context from Fyfe's larger body of writing on the issue of nuclear waste burial for understanding its wider implications. Elsewhere, Fyfe (1999) explains that he "believe[s] that nuclear waste can be managed securely" in DGRs and that "there is expertise" to ensure that good sites are identified, appropriately assessed, and selected for their placement. Most instructive is a 1985 article in Nature, in which a high level 
international committee on DGRs led by Fyfe called for more extensive "geological studies related to proposed methods, materials, etc." via the "accelerated development of underground laboratories in all rock types" (Fyfe et al. 1984, p. 540). The committee also argued for the "need to consider the problem of how a major leak from a repository might be detected and treated" (Fyfe et al. 1984, p. 537). Ultimately, the committee called for "the best possible compromises between energy production and environmental deterioration," including that which would be wrought by ongoing use of fossil fuels if nuclear power were not fully exploited (p. 595). Such compromises, he argued, must be founded on robust study achieved by "mobilizing minds" to avoid the possibility of mistakes (Fyfe, 1999, p. 161). Like MacFarlane (2006), under circumstances of both uncertainty and urgency, Fyfe accommodates the possibilistic concerns about badly sited DGRs held by Worldview B holders as well as the probabilistic confidence in DGR technology overall of those whose views conform to Worldview A.

Taken together, the positions of MacFarlane (2006) and Fyfe (1999) constitute an intertext for the OPG DGR controversy of the "Responsible Geologist," which accommodates Worldview B's possibilistic logic to Worldview A's probabilistic logic of science in a similar way as the conjoining of their two narratives in section 6.1 This intertext occupies a middle ground by proposing that DGRs eventually be built, yet in a fashion that minimizes their risks as thoroughly as possible. The Responsible Geologist intertext is not novel, seeming to have been the signature narrative concerning the problem of DGR siting advanced by geologists for the past three decades, during which time it has presumably co-existed alongside more prominent probabilistic and possibilistic narratives of technocrats and environmentalists. Further, the Responsible Geologist narrative is necessary for understanding these two more prominent narratives in precisely the way that Roe (1994) attributes to the intertext. The emphasis on 
prolonged and intensive analysis reflected in OPG's Environmental Impact Statement (2011) implies the need for a geologically responsible approach to siting, as does STGLND's emphasis on the need to bury nuclear waste in well-verified geologies and to avoid vulnerable bodies of water. While each of these groups has honed their own positions, they have done so with standpoint of the Responsible Geologist intertext in view, with its focus on caution and optimality and on the avoidance of haste and opportunism.

Finally, with the its moderate tone, the Responsible Geologist narrative usefully straddles the middle ground of the two policy communities, and can potentially thus offer new grounds for continuing the policy conversation about whether or not, how, and where DGRs can be a feasible technology for storing nuclear waste in Canada going forward. The Responsible Geologist narrative is aligned neither with OPG's "cornucopian" story that suitable sites for storing nuclear waste are easily found in convenient places, nor with STGLND's "catastrophic" story that DGRs ought not be trusted because they have failed in the past. Rather than assuming an experimental technology such as the OPG DGR project will either succeed or fail, it takes an active and dynamic stance towards technological risk that is at once sceptical of unearned exuberance and hopeful concerning human faculties of learning and adaptation. In these ways, the Responsible Geologist intertext is more complex and multifaceted than either OPG's or STGLND's narratives, reflecting both the irreducible uncertainties contained in the enterprise of managing nuclear waste over the long term, as well as the prospective value of bearing up to these uncertainties, particularly at a time when creating infrastructure to enable the production of low carbon energy appears to be urgent.

This is not to say that all geologists are necessarily perfectly benign and impartial investigators of academic issues. However, writers in the DGR field have long described the 
angle that geologists bring to bear on nuclear waste repository siting as distinctly open-minded, rigorous, and oriented to the prevention of mistakes. In the words of geotechnical engineer Richard Meehan, geologists have a "preference for contemplation and debate" about geological issues relating to nuclear waste disposal that make them "perfect for confounding" the project engineers who are more disposed to "decision and action" (1986, p. 130). A wider adoption of the geological mindset could even foreseeably lead to its own problems, such as an indefinite foreclosure on policy movement. However, insofar as geologists' rigorous and cautious attention to detail presents a foil both to Worldview A interests in advancing projects and Worldview B interests in quashing them, it nonetheless holds considerable value as a reference point within the regulatory sphere. The Responsible Geologist intertext would not likely be adopted in toto by either of the policy communities, as it dispenses with both the easy confidence of one and the easy cynicism of the other. However, its alignment with neither of the major public positions of the policy communities concerned with the DGR could turn out to be a virtue for policy-makers, since, as an attitude towards the DGR policy issue that is relatively amicable and inclusive, it could potentially invite sympathizers from the softer edge of both these communities. The intertext thus plausibly holds potential to initiate a more constructive dialogue between the two policy communities than the one that is currently ongoing.

\subsection{Leveraging the Intertext}

The question remains as to how to leverage the Responsible Geologist intertext to lead to a resolution about whether the OPG DGR project should, or should not, go ahead. In similar cases of policy disagreement, Roe (1944) recommends providing resources to critical actors to flesh out their concerns in more detail (pp. 73, 83). Insofar as parties are unequally resourced, the disadvantaged group is likely to remain in the mode of critique, which "serve[s] only to intensify 
the ambiguities" of issues such as how to manage environmental problems, rather than to shed light upon those issues (p. 74). Rip (1986) likewise observes that "left to themselves ... the parties [in a technology risk controversy] lack stimulus to articulate their view," and so proposes that neutral actors such as regulators take measures to enable and motivate parties to undertake this articulation process (pp. 358-359).

We can see these limiting effects in the discourse of STGLND, which did not quantify any pathways or critical dosages through which nuclear waste stored in the DGR might contaminate the Great Lakes or aspects of its ecology, but mostly gestured in a critical way at what it considers to be looming uncertainties. In this regard, STGLND would helpfully be challenged to empirically quantify its concerns about the leakage of the proposed DGR, to ensure that its discourse is shedding light and not merely shadow upon the project. Some empirical questions STGLND could be resourced to investigate more fully, in order to give body to its concerns, might be:

- When have nuclear waste repositories and/or underground waste repositories flouted the expectations of their engineers in the past, to what degree, and why? In what ways have these circumstances been similar, and not similar, to those surrounding the OPG DGR?

- How often do present-day nuclear waste repositories constructed using modern types of analysis and engineering leak, and to what degree do they do so? What are the impacts associated with these leaks?

- How are materials and geological sites for DGRs tested for their performance over extensive periods of time, and are there better ways of doing so that could be used? 
- Can it be empirically tested how much nuclear waste would move into groundwater if it prematurely leaked out of its enclosures, and to track whether it could in turn move into the Great Lakes?

- Can it be empirically tested, or determined based on past experiences of leakages, what would happen if a significant amount of radioactive material from the waste stored in the DGR travelled through groundwater to the lake. For instance, where the contamination would go? Would it remain close to the site of entry, or would it significantly spread through the Great Lakes, and if so, what would the resulting concentrations throughout the lake look like?

- What would the impacts be of a radiological contamination of the Great Lake system, and how long would they last? Would there be ways of existing ways of hastening this process, or of filtering the water for use?

Many of these inquiries have already been made by OPG and scientists contracted by them, and certainly for STGLND to reinvestigate them in parallel would be expensive and time-consuming. Further, it is unclear whether if STGLND was asked and resourced to do this type of work, they would. Possibly, they would judge that to admit the relevance of critical dosages would be to concede significant strategic ground. Nonetheless, an official call for STGLND to more fully articulate and quantify their concerns - even if ignored - might constructively improve the terms of the policy conversation, holding out the norm that groups should move beyond the rhetorical mode of exacerbating ambiguity in favour of the deliberative mode of substantive claimmaking. $^{25}$

\footnotetext{
${ }^{25}$ The Canadian government funds intervenor groups participating in regulatory process. However, in a Canadian Nuclear Safety Commission audit of the CEAA's Participant Funding Program (2015), respondents to the target group survey "considered the funding levels low" (p. 28).
} 
Another, prospectively more reliable alternative for giving substance to public concerns around community projects such as the OPG DGR would be to have the regulatory system strike a collaborative panel stocked with diverse stakeholders to assess risk concerns bearing on the project. An environmental impact assessment conducted through such a collaborative process would evolve from being a monologue by the proponent towards the regulator on the risks involved in a project, as the current one essentially is. Instead, such an environmental impact assessment would be an official, authorized dialogue on those risks, conducted amongst representatives of more diverse communities of meaning.

Accordingly, in Chapter 7 a range of regulatory and deliberative options to improve deliberation about risk are presented and ultimately synthesized to envision a more expansive, collaborative, and democratic, and yet more disciplined conversation on risk issues than the OPG DGR controversy presented. It is argued that such a conversation could allow a diverse, but competent, range of participants to discuss and render judgment on the acceptability of projects such as the OPG DGR around which significant levels of uncertainty abide. 


\section{Chapter 7: Improving the Methods and Conditions of the Debate}

The essential need... is the improvement of the methods and conditions of debate, discussion, and persuasion... It is not necessary that the many should have the knowledge and skills necessary to carry on the needed investigations; what is required is that they have the ability to judge of the bearing of knowledge supplied by others upon common concern.

-Dewey (1927), p. 50

\subsection{Addressing the Problem of the Public}

As the above quotation from John Dewey (1927) indicates, the problem of how to sustain democratic principles of oversight and critique in societies organized around increasingly complex technologies and practices has been salient for nearly a century. Nonetheless, it appears that contemporary society is still far from achieving the condition that Dewey (1927) hoped for: an improvement "of the methods and conditions of debate" on technical subjects that would enable citizens "to judge of the bearing of knowledge" supplied by those claiming expertise or authority on those subjects (p. 50). C. P. Snow (1959) saw the gulf between science and society continuing to persist mid twentieth-century, and in 2014 an Expert Panel on the state of science knowledge in Canada concluded that Snow's "gulf remains," with "over half of Canadians likely lacking the level of knowledge of scientific concepts and processes necessary to grasp much of the coverage of science and technology issues in the media" (Council of Canadian Academies, 2014, pp. vii, 81).

With little understanding of the complex technologies supporting our daily lives, we persist in social confusion and discord about which official and cultural authorities to trust on complex issue areas such as technology, health, and the environment. As Kahan et al. (2011) observe, societal judgment is especially imperiled by our captivity to cultural worldviews, which keep us divided in polarized enclaves amidst which we trust only the judgments of our favoured experts. In our enclaves, we are blocked from the kind of open-minded consideration that would 
allow us to render reliable judgments about modern complex technologies and the credibility of the risks and benefits attributed to them. Instead, we maintain generalized stories about technologies: stories about how they virtually always meet needs and expectations, or all-toooften fail to. As the discourse, worldview, and narrative analyses in this dissertation have shown, policy actors compete to establish their selective narrative frames as heuristics to guide sociotechnological decision-making, despite how these heuristics are too crude to inform the types of intelligent, case-by-case selection processes that would be most beneficial for society and the planet. Under such circumstances, it is difficult to engender the clear-sighted judgment that Dewey (1927) saw the public as needing to contribute in valuable ways to conversations about our shared technological fates.

Moreover, within the polarized atmosphere engendered by this discursive competition around technological risk, trust is destroyed that might otherwise support the collaborative forms of investigation needed to inform widely acceptable as well as effective socio-technological decisions. In the case of the OPG DGR, despite how the Joint Review Panel was structured to permit construction deliberation, encounters between proponents and opponents of the project primarily exacerbated distrust and contempt. My observation from attending some of the hearings and speaking with participants afterwards was that both proponents and opponents of the DGR emerged viewing the other policy community as irrational, narrow, wrongheaded, selfinterested, and even malignant. An anti-DGR intervenor I interviewed was "shock[ed]" by how “[OPG] didn't know so many things"; i.e., by all the uncertainty in the DGR project (A. Tillman, personal communication, September 9, 2014). A representative of OPG meanwhile expressed exasperation at the "low ... science literacy" of the opposition to the DGR, conjecturing that its arguments were "rationales" concocted to support an unreflective "gut feel" (K. Powers, personal 
communication, September 9, 2014). These attitudes of distrust and contempt between the communities were upheld in the discourse analysis, which showed OPG dismissing the opposition as uninformed, and STGLND regarding both OPG and citizens of Kincardine who voted in favour of the DGR as beholden to money interests over ecological ones. Certainly, the predominance of factional conflict and distrust over respectful, collaborative investigation during the hearings for the OPG DGR demonstrate that we remain far from having solved Dewey's (1927) "problem of the public" through the "improvement of the methods and conditions of debate, discussion, and persuasion" (p. 50).

\subsection{Creating Collaborative Regulatory Procedures}

Helpfully, narrative policy analysis can provide part of a solution to this problem, in its approach of both acknowledging the diversity of narratives that surround polarized policy debates, and attempting to coordinate them through the construction of new, more neutral narrative that subsumes them. As I showed in Chapter 6, a narrative policy analysis of the OPG DGR issue delimited a zone of uncertainty between the probability the DGR would not impact the lake, to which OPG testified, and the possibility that it could, to which STGLND. An intertext that accommodated both these two narratives was identified and entitled the Responsible Geologist intertext. The vantage point of the Responsible Geologist intertext was proposed to guide discussion and investigation of the issues such as the OPG DGR to ensure that such projects would only be constructed in the safest ways and locations, but also to ensure that the full weight of argumentation and evidence in favour of the site and engineering of these projects would be credited.

Based on the literature, the best way to orient public conversations about technological projects to integrate a range of perspectives is to design a democratic regulatory risk assessment 
involving plural stakeholders representing these different perspectives. Jasanoff (1995) suggests that robust regulatory outcomes are more likely to emerge from well-designed regulatory panels permitting the negotiation of claims by a range of government and independent experts, along with citizens representing diverse scientific and philosophical positions, than from hearings in which scientific debate is politically polarized and adversarial (pp. 290, 284-285). MacFarlane (2006) cites a related proposal by Jasanoff's (1995) that, where there is significant uncertainty about impacts, regulatory decision-making should promote continuous consultation between the scientists contracted to analyze relevant conditions, independent scientific experts, the public, and policy-makers (279-293). Kasperson et al. (1992) similarly holds that decision processes "geared to [ameliorating] social distrust" around hazardous waste siting should not involve the public in only perfunctory ways but engage them extensively as the needs assessment for the community is being established, the content of the risk debate is being circumscribed, and the risk communication process is being designed (p. 179). Easterling and Kunreuther (1995) agree that a siting process capable of gaining public acceptance must be a "broad-based participatory process" that gives "representatives of all affected groups... the resources needed for effective participation"; the "chance to review the recommendations of facility proponents"; and the opportunity to participate in "a joint fact-finding process [that] allows for the collection, analysis, and dissemination of data regarding the risks, costs, and benefits" of siting proposals" (p. 186). Shrader-Frechette (1985) likewise recommends for nuclear waste decisions the formation of "technology tribunals" made up of scientists and citizens who would consider evidence, deliberate over alternatives, and recommend conclusions (p. 207).

Envisioning how such democratic risk assessment processes might be devised, Jasanoff (1995) draws attention to the United States National Research Council's (US NRC) guidelines 
on incorporating public concerns into risk assessment in a way that is both democratically responsive and rigorously scientific (p. 289). Guidance from the US NRC that emerged shortly after Jasanoff's study was even more explicit on how a risk assessment process might be undertaken that is simultaneously democratic and scientifically rigorous. In a US NRC publication entitled Understanding Risk: Informing Decisions in a Democratic Society, Stern and Fineberg (1996) describe an "analytic-deliberative process...for improving risk characterization, informing decisions, and making those decisions more acceptable to interested and affected parties," including citizens or stakeholders (p. 20). The methodology they developed combine scientific processes of analysis — "rigorous, replicable methods developed by experts to arrive at answers to factual questions"-with phases of deliberation using "processes such as discussion, reflection, and persuasion to communicate, raise and collectively consider issues, increase understanding, and arrive at substantive decisions" (p. 20). Stern and Fineberg (1986) characterize their envisioned process as one in which experts, citizens, and stakeholders would all participate in selecting which questions would be analyzed in an environmental impact

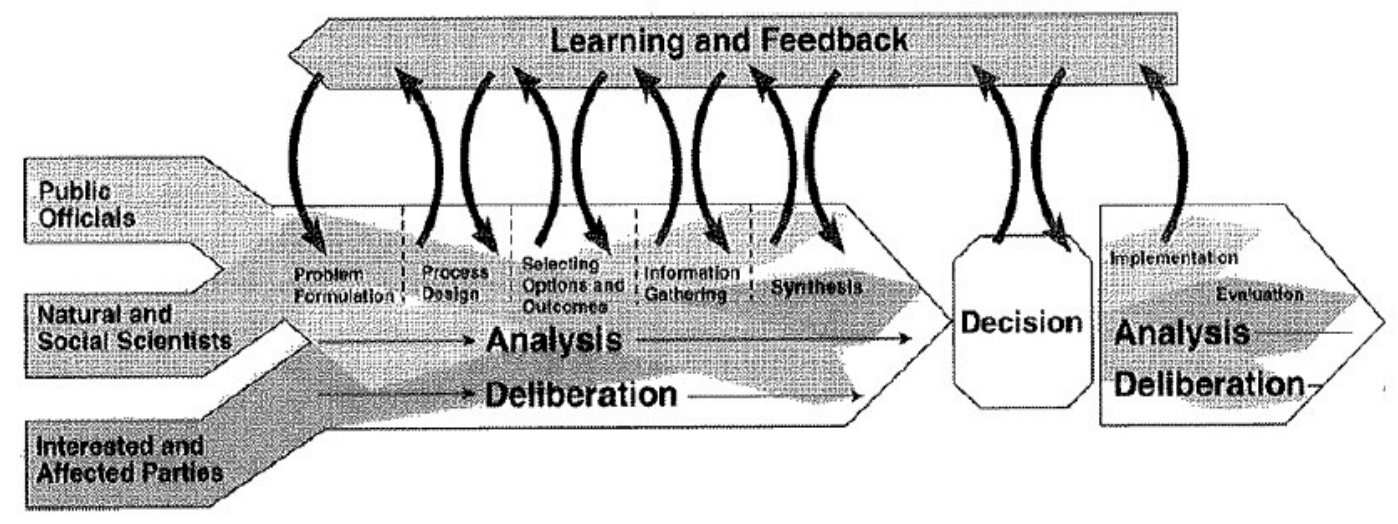

Figure 8: U.S. National Research Council analytic-deliberative risk assessment process (Stern \& Fineberg, 1996, p. 20). 
assessment, in developing information informing the assessment, and in deliberating upon that information (p. 30); see Figure 8.

The publicly accountable, democratic risk and environmental impact assessment process described by Stern and Fineberg (1996) may be precisely what is needed to help community action groups such as STGLND reach a robust social consensus with proponents such as OPG about appropriate sites and structure for disposing of nuclear waste. Such collaborative risk assessment processes would permit representatives of groups such as STGLND to contribute to the questions investigated through scientific assessment and to deliberate upon the answers provided. These processes would be far more democratic than standard environmental impact assessments, which are typically contracted by project proponents in relation to regulatorestablished guidelines and questions, and then submitted to the public for review as fait accompli. Jasanoff (2003) has described such processes in terms of Gibbons et al.'s (1994) call for an evolution from "Mode 1" knowledge, produced and validated by self-contained and relatively siloed scientific disciplines, to "Mode 2" knowledge, in which scientific validity "is determined by a wider set of criteria ... reflect[ing] the broadening social composition of the review system" (pp. 7-8). As Jasanoff (2003) points out, the shift to Mode 2 knowledge creation need not entail a weakening of the criteria of scientific review, but instead involves adding to these criteria one of public accountability, in which science is understood to be "embedded in, and...accountable to, society at large" (p. 235).

To evaluate the type of collaborative risk assessment procedures outlined by Stern and Fineberg (1996), Douglas (2005) reviewed a range of decision processes in which it was applied, including one for selecting a tugboat for oil transport and another for determining a process of disposing of chemical weapons. He found that continuous citizen input produced better outcomes 
in terms of improving the definition of the problem, developing better criteria for assessing alternatives, improving the data quality, examining and weighing uncertainties more thoroughly, and ultimately producing solutions that were more acceptable to the public (pp. 159-161). A third process concerning nuclear waste cleanup was less successful in these regards due to including a longstanding legacy of distrust, unequal competencies, and fewer shared goals between stakeholders and experts (pp. 159-161). However, Douglas observed that this failure reaffirmed the importance of designing such collaborative processes to facilitate conditions of mutual trust, shared goals, and communicative competency.

Flüeler (2006) has likewise observed an international trend in the domain of nuclear waste management towards a more democratic style of environmental impact assessment process. In Flüeler's (2006) description, a transition has already been widely undergone from the original technocratic "Decide_-Announce-Defend" (DAD) approach, in which projects were fully conceptualized and sited by proponents and then defended to communities, to the pluralist "Meet—Understand-Modify" (MUM) approach, where after proponents develop a project's essential concept, they meet with communities to see where these concepts need to be modified to satisfy the conditions for public approval (p. 199; see Figure 19). This latter approach is essentially the mode of the OPG DGR environmental review, which gathered public input at several stages, as described in Chapter 1. Yet Flüeler (2006) describes the need to keep scaling up the curve of public involvement towards a third approach he calls "Propose — Learn — ShareDecide" (PLSD), in which the public participates with proponents as "stewardship partners" in the development of "societally robust decisions" (pp. 263, 199); see Figure 19. Such decisions are more able to survive political pressures exerted by diverse constituencies because "most arguments, evidence, social alignments, interests, and cultural values lead to a consistent option" 


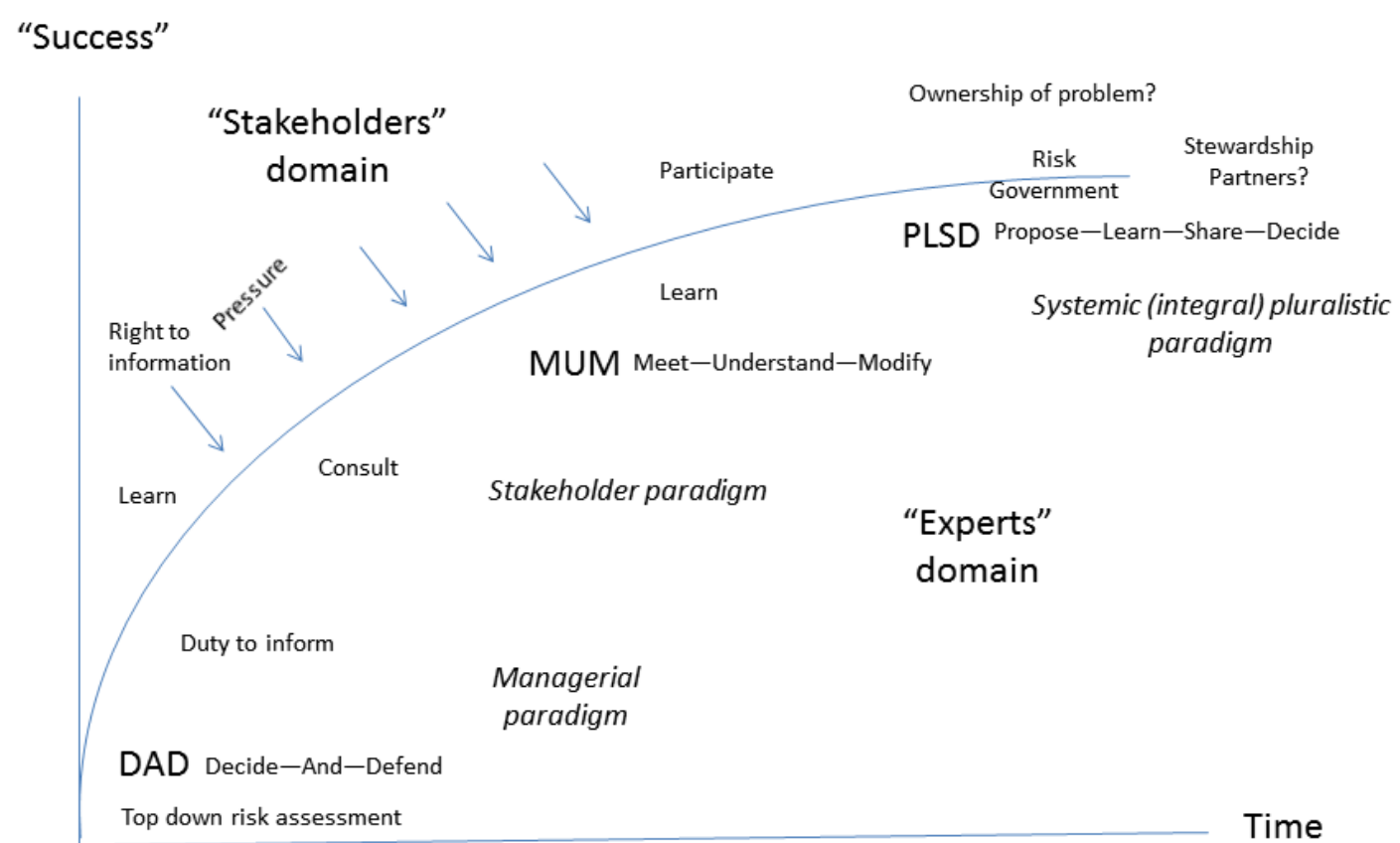

Figure 19: Abbreviated version of Flüeler's (2006) "Learning Curve" for public participation in nuclear radioactive waste governance and research (p. 198).

(Flüeler, 2006, p. 24). As Flüeler holds, a "dynamic approach with mutual learning [that] is more time-consuming" is in the long run likely to be "more effective as well as more efficient than previous approaches" (p. 253). Rip (1986) agrees that if there is no "interaction between contending parties and problem definitions" relating to technological risks, that "no social learning can be expected" (358-59). Easterling and Kunreuther (1995) agree that in the case of nuclear waste, "it is prudent to spend a few extra years to find a solution with which we, as a nation, can be comfortable" (p. 237).

Importantly, Flüeler (2006)'s account of the need for more dynamic models of engagement on nuclear waste issues is not primarily a call for openness and inclusiveness of yet larger numbers of people in such processes. Rather, what Flüeler (2006) describes as essential is the engagement of a sufficient number of "perspectives" to generate an adequately 
“dimensional” discourse on subjects such as nuclear waste, in which he includes ethical, technical, ecological, economic, political, societal, spatial, and temporal dimensions (p. 213). For Flüeler (2006), it is less important in a deliberation for everyone with something to say to be personally heard - as tends to be the priority in constructing Canadian environmental review procedures and policy consultations ${ }^{26}$--than for the discussion and output to reflect the broad base of social perspectives and values. Likewise, in a new paper, Gregory (2017) observes that the quality of environmental hearings is being compromised by an emphasis on "inclusivity," which is allowing stakeholder positions to be probed only in a very shallow and undigested way (171). Stakeholders' values, as well as the implications of their values, are never clearly specified in such contexts; conflicts between these values are never constructively addressed; and opportunities for those with different views to develop trusting relationships in which to work out conflicts between them are not enabled. Thus, instead of the standard Canadian practice of making regulatory hearings open to all comers, as was drawn upon in public engagement pertaining to the OPG DGR, Gregory (2017) recommends the facilitation of small and sustained deliberative processes involving representatives of stakeholder groups and other perspectives. As he suggests, more in-depth and rigorous deliberative processes would provide the means and scope for participants "to identify and articulate their fundamental values at risk, to become

\footnotetext{
${ }^{26}$ A new report on the future of environmental assessment that was produced by an expert panel struck by Environment and Climate Change Canada (ECCC) (2017) auspiciously echoes some of the suggestions raised in Chapter 7 suggesting that a meaningful participation process in environmental review should not only inform final outcomes, but incorporate "inclusive and accessible opportunities for early and on-going engagement" including during the shaping of "the considerations studied in the assessment" (Environment and Climate Change Canada, 2017, Section 2.4.1). The report also recommends supplementing "adversarial" elements of regulatory procedures with "dialogue-focused [options] such as workshops" (Section 2.4.1), moving towards Jasanoff $(1993,2003)$ 's recommendations. Finally, the report points to the need to maintain standards around science and evidence used as the basis for claims and recommendations (Section 2.4.3) in agreement with Webler (1995), while allowing, like Webler, that evidence relevant to environmental assessment might "come in many forms and includes Indigenous knowledge and community knowledge" (Executive Summary). However, as the ECCC (2017) retains an emphasis on inclusive open forums, they may not advance much in their ability to mediate polarized socio-technological policy frames, but continue to be forums in which such frames are heard out and contend with each other.
} 
better informed about relevant facts by asking questions of qualified experts, and through both introspection and deliberation to decide which impacts and trade-offs are most important" (p. $160)$.

Ultimately what these researchers ultimately see as required to reform regulatory processes around issues such as nuclear waste to produce more socially robust answers is a more integrative perspective on these issues, whereby "authorities. . . stop separating technical from political issues" (Flüeler, 2006, pp. 251-254). This thesis opened with an accounting of the distinctive technical and political issues involved in nuclear waste management decisions. Yet, as Flüeler (2006) holds, "as long as the 'technical' and 'political' aspects" involved in technology risk issues "do not converge, there is no chance for a 'closure' of the issue (p. 277). The OPG DGR case illuminates the stakes for more closely integrating the technical and political elements of technology risk decision-making, demonstrating that if people with diverse worldviews and values are not involved in the early scoping stage of technology processes, but primarily confined to the political, decision-brokering stage towards the ends of these processes, they will amplify their roles at that stage by aiming to block projects or otherwise control outcomes. By contrast, Easterling \& Kunreuther (1995) hold that workable social consensuses around technologies such as nuclear waste disposal can emerge "if the interested parties are able to fully weigh the available alternatives, rather than being presented with a preordained solution" (p. 233).

\subsection{Building Communicative Competence}

Integrating the technical and social aspects of environmental impact and risk assessment requires careful thought about what styles of participation and deliberation would help to serve these goals. As we have seen in the NWMO consultative process described by Fuji Johnson 
(2009), relatively loose deliberative processes are well-structured for bringing out oppositional perspectives but may be less functional for integrating them into functional agreements. Fuji Johnson (2008) describes how NWMO facilitators were instructed to "run dialogues in a way that would allow for the voicing of perspectives 'on a level playing field'...premised on principles of respect for the equality of each other and of each other's views" (p. 100). Yet a common emphasis of the above scholars concerned with both democracy and functionality is that participating parties must be willing to distinguish between more and less credible evidence for guiding decision-making and to subscribe to commonly accepted standards for weighing conflicting evidence. For Stern and Fineberg (1996), an analytic-deliberative risk assessment process requires not only "getting the right participation" and "getting the participation right," but also "getting the right science," "getting the science right," and "developing an accurate, balanced and informative synthesis" of available information (pp. 5-6). Easterling and Kunreuther (1995) likewise hold that citizen deliberators in a process for appraising nuclear waste disposal processes must "make a major commitment to learning about a given technology before being able to make an informed value judgement regarding its appropriateness" (p. 236). Jasanoff (2003) similarly specifies that successful democratic approaches to risk assessment require "an intellectual environment in which citizens are encouraged to bring their knowledge and skills to bear on the resolution of common problems" (p. 227). Douglas (2005), who evaluated applications of Stern and Fineberg's (1996) democratic risk assessment model, affirms that the "expression of values" that was "not informed by the scientific or technical details" contributed far less to constructive outcomes than discourse that was informed by such details (p. 167). Kinney and Leschine (2002) similarly observed that a stakeholder deliberation on nuclear waste clean-up near the Columbia River broke down because some citizens who were not fully 
resourced to challenge technical claims engaged entirely in "normative debates about power relations" that rendered the deliberative environment impossibly adversarial (pp. 94-96). Finally Flüeler (2006), after analyzing nuclear waste management decision-making procedures around the world, likewise concluded that productive citizen and stakeholder processes need to be conducted on "a common factual basis" consisting of "the basic knowledge of specialists" (pp. $254,251,263)$.

Taken together, these scholars implicitly invoke the Habermasian (1970) idea of "communicative competence" in their call for more exacting standards of discourse than those that are commonly expected in conventional public deliberations upon policy and regulatory issues. As discussed in Chapter 2, Webler (1995) draws from Habermas's discourse ethics to define communicative competence as the ability of a deliberating group to collaboratively construct "the most valid understandings and agreements possible given what is reasonably knowable at the time" based on knowledge gathered through science and other collective enterprises (pp. 64, 58). Webler (1995) specifies that communicative competence includes the ability of such a group to "access ... knowledge needed to make validity claims and criticize others" thereby to develop the informed judgements on technical matters and authorities called for by Dewey (1927). Webler (1995) also proposes that competent deliberators should be willing to evaluate "the factual implications of [their] normative choices," including "anticipated physical and social consequences" (p. 84). To give some examples from the OPG DGR case, participants holding out a norm of trusting scientific expertise might be expected to consider a range of scenarios in which the scientific expertise turns out to be faulty, while those advocating for a precautionary norm might be called upon to demonstrate that the risks of building the DGR are greater than the risks of not building it. 
Some exceptions may be taken with this call for a higher standard of deliberation. It could be argued that upholding the idea of standards for evidence-based arguments in public deliberation converge with the aspirations of Worldview A, given that the socio-cultural worldviews of Worldview A specifically affirm the use of evidence in socio-technological decision-making (Buss, Craik, \& Dake, 1986). However, the inclusion of a wider range of citizen and stakeholder perspectives in the types of socio-technological decision-making processes that these scholars propose already supports Worldview B aspirations for broader public involvement. As such, facilitation of citizen and stakeholder deliberation on risk issues to incorporate evidence-grounded arguments can alternatively be considered an approach that is synthetic of the two worldviews, in keeping with Gibbons et al.'s (1994) idea of "Mode 2" knowledge that harmonizes science amid the larger society.

Along the same lines, it might be contended that requiring those participating in a public deliberation to encounter standards of evaluation for the evidence they introduce to that deliberation is epistemologically biased towards proponents such as OPG, who are more used to working with evidence and indeed, have scientists on contract to produce that evidence, over the positions of groups such as STGLND, who have fewer resources to do either. It is true that holding out expectations for the empirical substantiation of claims would raise the deliberative bar to be met by representatives of community action groups such as STGLND. However, there would be a positive trade-off for such groups — and for society as a whole — in attempting to raise the standards of deliberation in this way. Higher expectations of empirical argument placed on groups such as STLGND — along with greater resources to scientifically justify their concerns, as described in Chapter 6, could help them augment the credibility of their positions and increase their ability to intervene successfully. Propounding expectations that claims advanced regarding 
technical topics such as the OPG DGR meet standards of evidence could also help to reduce the types of socio-cultural polarization diagnosed in this dissertation. In particular, claims circulating around issues such as the OPG DGR might carry more weight outside of the siloed communities of meaning from which they emerge if they were more conspicuously supported by empirically justified claims, leading to depolarization of the debate around these issues. For instance, if STLGND substantiated their claims that a leak from the OPG DGR site would have a detrimental effect on the Great Lakes with pathways and dosages, a wider range of individuals beyond holders of Worldview B might be persuaded to oppose the project.

To give another example of how expectations of communicative competency could advance dialogue on environmental risk, I described in Chapters 4 and 5 how policy actors frequently make use of policy synecdoches that generalize from parts to wholes or from one circumstance to another (Stone, 1988). An expectation of communicative competence would raise the likelihood that such policy synecdoches would be openly interrogated. In the case of the OPG DGR, under conditions of communicative competence it would be expected that OPG would offer a fully substantiated comparison of Canadian Shield geology with the geology around the Great Lakes, rather than merely a rhetorical claim that they are similar (2016b). Likewise, STGLND would be expected to explain precisely how the processes of siting and engineering the OPG DGR was similar and dissimilar to that of other "failed" DGRs, rather than simply to suggest that the fate of the latter portends that of the former (Stop the Great Lakes Nuclear Dump, 2016b). A deliberative forum that normalized communicative competence and ensured that rhetorical narrative-style claims were invariably interrogated would contribute far more to averting harmful technological and environmental mistakes than looser deliberative 
forums, in which such narratives frequently pass unchallenged and can have detrimental persuasive effects on the collective understanding of issues.

Standards of communicative competence could also help in putting the uncertainties involved in projects like the OPG DGR in perspective. In policy matters, choices around whether to proceed with projects despite uncertainties are often made on arbitrary political bases reflective of which disciplinary experts are dominant in the context of a certain issue in a given moment (Sarowitz, 2004). By contrast, a deliberative body invested with communicative competence may be able to come to more rational agreements around how much uncertainty is too much in a given situation (Webler, 1995, p. 61). Jasanoff (1995) has observed that regulatory trade-offs between "more data and quicker action, or, more crudely, between science and safety" are highly fraught, but participants in deliberative regulatory processes could develop strategies that are both rational and democratic for determining what levels of scientific uncertainty are too much in the context of certain benefits and risks (p. 288). To return to the case of the OPG DGR, it would certainly be valuable to have a framework collaboratively developed by stakeholders, citizens and others that could help to specify a non-arbitrary line between go and no-go projects involving uncertainties. In that way, if a judgement was made by a collaborative regulatory panel that the current OPG DGR site was too risky due to the exposure of large international freshwater supplies, an indication might offered as to what type of site could be more acceptable, breaking down the simple dichotomy of go and no-go that the primarily policy narratives around DGR siting hold out, as we have seen.

\subsection{Cultivating Responsible Innovation}

A potential supplement to the collaborative risk assessment process described above would be the launching of broader forums for Canadian citizens to investigate norms and values 
pertaining to technology and the environment in more general terms. Such forums have been proposed by the Responsible Innovation framework, which seeks to foment "public debate and reflection about the desirability of technologies and their plausible ramifications" (Guston et al, 2014). As Guston et al. (2014) describe, technological developments throw up implicit normative questions such as "[w]hat kind of role do we want technology to play in our lives? How do we want to live?" and "[h]ow can technology and our choices about it support us in leading that life?" Energy questions, including those around nuclear power and waste, raise even broader questions such as " $[\mathrm{w}]$ hat kind of society do we want to create, and how can [energy] help us do that?" Contributors to the Responsible Innovation framework - the inspiration for my entitling of the "Responsible Geologist" intertext—have posed multiple potentially useful approaches for stimulating broad, open-ended thought and deliberation on these matters. These approaches hold potential to dissolve the persistent socio-cultural bifurcation between Worldview A and Worldview B by encouraging citizens to challenge their moral framings of technology and to cultivate new ways of thinking that update old heuristics and habits.

One approach proposed by Responsible Innovation scholars is "scenario thinking," which would lead participants to think beyond technologically deterministic and doomsday-type images of the future, envisioning creative proposals for "alternative socio-technical arrangements" that could lead to "a better world" (Nordmann, 2014). Another approach they have piloted involves allowing members of the public to generate "additional design criteria" apart from engineering and commercial criteria that would constrain how technologies are implemented in given social contexts (Guston \& Sarowitz, 2002). In general, most of their practices are oriented towards opening and challenging conventional normative approaches rather than towards seeking prescribed "normative ends" in predetermined ways (Stilgoe, Owen, \& Macnaghten, 2013). 
Accordingly, rather than engendering a manifesto of what is right and wrong in technological innovation, the Responsible Innovation scholars tend to advocate a "case-by-case" approach to technological evaluation. Such case-by-case evaluative processes would draw on "the joint participation of those in favour of and opposed to the action," and facilitate them to collaboratively "weigh the risks of both action and inaction and pursue the course of action [they] judge to be most likely to mitigate the harms of both" (Holbrook \& Briggle, 2014). Other envisioned practices would make norms around technology more transparent, in the way that this dissertation has sought to do, facilitating discussion of values implicated by technological choices as well as "trade-off[s] that decide which value should take priority" in specific instances (Taebi, Correljé, Cuppen, Dignum, \& Pesch, 2014). Overall, the mechanisms Responsible Innovation scholars envision for involving citizens in technological forecasting, creation, design, selection, and approval are intended to allow publics to attain greater understanding of, connection to, and comfort with the complex technologies that surround us, thereby helping societies approach Dewey's goals of improved dialogue and judgement on such matters.

\subsection{Envisioning Democratic Regulatory Processes}

As Stern and Fineberg (1980), Flüeler (2006), and Jasanoff (2012) hold, panels of citizens and stakeholders representative of diverse perspectives on risk issues but willing to submit to empirical, expertise-driven fact-finding and solution-forging exercises may be capable of providing constructive, integrative decisions about technological projects. Precedents for such panels can be found in the idea of the consensus conference, a dialogic policy evaluation process where citizens frame questions to experts and then deliberate over the insights to create consensual reflections on the policy issue (Eisendel \& Eastlick, 2000). As Einsendel, Jelsoe \& Breck (2001) have observed, consensus conferences "bridge" expert and participatory 
approaches to technology that might otherwise be "incommensurable" (p. 95). Auspiciously, participants in a Canadian consensus conference on genetically modified organisms shifted from holding "vague" and "stereotypical" views of the technology towards more "sophisticated" views (Eisendel \& Eastlick, 2000, pp. 334-335). Another Canadian consensus conference on "biobanks" for tissue sample storage led participants to develop nuanced appreciation of the normative complexities involved and to energetically address value-based trade-offs (Secko, Preto, Niemery, \& Burgess, 2009).

Yet despite the success of these consensus conferences, evidence on the ground suggests it may be harder to achieve positive deliberative outcomes in relation to nuclear waste. A panel entrusted with developing a viable solution to nuclear waste management in a given situation would require a more prolonged commitment than one dedicated to evaluating a technology in abstract terms. Other difficulties are also likely to stem from the pre-existing polarization around the nuclear waste issue explored in this dissertation. As Manning (2016) observed in an South Australian citizen jury on nuclear waste, many participants maintained unyielding positions and some even pursued strategies to bias the process so the its ultimate output would express their own viewpoint. For Flüeler (2006), such rigidity is likely to block progress; he suggests that while participation in a deliberative risk assessment process about nuclear waste need not change their "core principles" they must be willing to make "modifications in th[e] secondary aspects" of these principles so they can identify common ground with other participants (p. 252). Flüeler (2006) more broadly sees participants in such a process as needing to be able to agree at the outset on fundamental constraints of the dialogue, such as:

1. Problem recognition (waste exists, problem to be tackled, "solved");

2. Main goal consensus (degree of protection and intervention); and 
3. Procedural strategy ("rules of the game"). (p. 213)

Yet as Fuji Johnson described in her account of the NWMO consultation, groups and individuals from different communities of meaning wanted to frame the issue of nuclear waste in Canada as either inclusive or exclusive of questions around ongoing nuclear power generation (Fuji Johnson, 2008, p. 99; 2009, p. 105). In Flüeler's (2006) terms, the inability of Canadian communities of meaning to set mutually-agreeable bounds on relevant questions to be taken up by a deliberative panel for assessing nuclear waste management strategies could be fatal to its success.

Another challenge in striking such a panel is that, given how it would optimally be struck in advance of a site selection, it would need to involve citizens interested in the topic of nuclear waste in general, rather than merely in how it could bear on them personally. A difficulty with organizing such a panel, Flüeler (2006) suggests, is that aside from its potential local impacts "[v]irtually no one is genuinely interested in waste, except for the directly involved technical waste community" (p. 263). Hajer (2003) has likewise described how many citizens become animated in relation to environmental issues after projects are sited, forming "communities of fate" (p. 97). As we saw, a specific community of fate was aroused in the case of the OPG DGR when community action groups around Lake Huron arose in specific response to its contentious siting. All these circumstances may militate against the creation of engaged, committed, spirited, and diverse panel of citizens prepared to deliberate on nuclear waste management solutions, possibly for a significant length of time, and ideally in advance of any specific siting.

An alternative to a citizen-participant process would be to derive participants from established stakeholder groups. Based on the literature on environmental deliberation, this is the conventional alternative and can be the most promising direction, with Douglas (2005) observing 
that the most successful collaborative risk assessment processes she observed involved "clearly defined stakeholders... with some resources" (p. 160). Yet as we have seen, however, drawing on established stakeholder groups in Canada could also be difficult, insofar as many such groups hold larger goals of enabling or disabling the fate of nuclear power generation in Canada, which tends to bear on nuclear waste management preferences, as discussed in Chapter 1. Further, as Fuji Johnson (2008) has observed, "people with a history of activism or with direct stakes" pertaining to nuclear waste in Canada are often not interested in "reasoning towards a shared interest (p. 109). However, in Flüeler's (2006) words, there must be “a minimum of relationship of trust" among participants for "discussions of technical aspects of risk management to be usefully conducted," (Flüeler, 2006, p. 256). Given these obstacles to involving appropriate Canadian citizens or stakeholders, an expanded risk assessment process for a project such as nuclear waste management would likely difficult to set on the right track, and may well unfold in an imperfect way. Yet, based on the weight of evidence from environmental deliberation scholars, more deliberative environmental processes are worth trying, and if conducted repeatedly could plausibly lead to gradual improvements at the interface of democracy and technology in Canada. 


\section{Conclusion}

\section{Contributions of the Dissertation}

In analyzing the conflict around the OPG DGR project, this dissertation has sought to advance societal and academic understanding of pressing technological and environmental risk controversies, with a focus on nuclear waste controversies. It began by observing affinities between cultural approaches to risks - especially those currently being developed by Kahan et al. at the Cultural Cognition School--and the policy frame theory of Schön and Rein (1994) and Yanow (2000), which characterize policy frames as discursive clusters of beliefs and norms shared by communities of meaning. The persistent influence of unconscious cultural symbols on policy frames these scholars observe offers an explanation for why the risk frames of sociocultural communities are resistant to disruption through information and deliberation (Kahan et al, 2011). The observed influence of symbolic narratives on policy frames and worldviews further suggested a methodology for understanding and mediating risk controversies, consisting of sequencing 1) an interpretive policy analysis (Yanow, 2000) to discover latent symbols with narrative implications and 2) a narrative policy analysis to find an intertext that bridges these narratives, which may be less irreconcilable than the beliefs and the norms that they support (Roe, 1994).

As the interpretive policy analysis revealed, the policy dialogue over the OPG DGR featured two competing frames about the DGR in its Lake Huron site, each with powerful symbols at their core that imply a different narrative revolving around the relationship of humans to technology and to nature. OPG depicted nature in terms of rock: solid, reliable, and adequate to human uses in conjunction with well-engineered technology and institutions to design and oversee them. STGLND depicted nature in terms of water: susceptible to taint and despoilment 
by the same technology and institutions. The worldview analysis in turn revealed how these symbols and their associated narratives encapsulate techno-optimistic and techno-pessimistic worldviews with pedigrees dating back to the Romantic and Enlightenment movements. The backdrop of this long-standing division over how to coordinate technology with nature in turn helped to explain why members of different socio-technological worldviews "talk past each other" in social forums about technological risk such as the OPG DGR hearings, contemptuously dismissing each others' ideas rather than working through and bridging them (Beck, 1988, p. 30). Accordingly, the final contribution the dissertation sought to make was to suggest some practical mechanisms for mediating socio-cultural conflicts around risk in the regulatory sphere where decisions around projects such as the OPG DGR are made. Ideally, it suggested, better decision-making processes would bring the two groups - along with their extended communities of meaning - into a dialogue that could synthesize what both groups know, value, and fear to generate widely acceptable solutions. Difficulties in achieving such a synthesis were, however, glimpsed in the conflict between the two policy actors on what ways of understanding and representing the issues involved should hold precedence. For OPG, with its emphasis on optimal design and siting, the need to rely on and credit expert analysis and adjudication was paramount. For STGLND, with its emphasis on environmental protection at all costs, democratic engagement was primarily needed to tap into communities' protectiveness towards their environmental locales. In theory, these approaches to treating nuclear waste are reconcilable. Most experts I reviewed suggested decisions about technology and the environment should be made through a combination of scientific expertise and robust political deliberation (Stern \& Fineberg, 1986; Fischer, 2000; Eisendel, Jelso \& Breck, 2001; Flüeler, 2011, Jasanoff; 2013). Yet the keen divide in the discourses over how to rate expert-driven against intuitive forms of 
knowledge is not easily surmountable through available deliberative approaches, which tend to split on this point. Fuji Johnson (2008) argues that in Canadian decision-processes around nuclear waste management, "expert views should [not] be weighted more heavily than 'nonexpert' views," which are "not less informed" (p. 83). However, the literature on the pragmatics of environmental decision-making demonstrates that participants' agreement to privilege wellsourced expertise is essential for achieving discursive closure and functional decisions.

To bridge this gap, I argued that more common ground must be discovered over how to frame risk policy issues, and an intertext was sought for doing so. Happily, the academic spirit of Responsible Geologists married the energy for technological advance exemplified by OPG with a grave sense of the high stakes of the commission expressed by groups such as STLGND. The Responsible Geologist intertext presented hope that participants in a collaborative, deliberative stakeholder and citizen panel struck to investigate nuclear waste solutions could aspire to a similar spirit of seriousness, curiosity, and courageousness. As such, the Responsible Geologist intertext pointed beyond well-rehearsed narratives about the fates of technology and the environment, pointing towards the need for a more contextualized approach to addressing nuclear waste management problems. Roe's policy solutions (1994) often call for resolving ethically challenging policy controversies by pushing beyond overly generalized formulas propounded by policy actors towards a more sensitive "case by case" approach that maintains a spirit of epistemological open-endedness and ethical "tolerance" and prioritizes ongoing recalibration in response to emerging knowledge and circumstances (p. 83, 151). An incremental "case-by-case" approach that manages policy issues by undertaking one contextualized decision at a time was likewise observed in Responsible Innovation mechanisms for enhancing public input into innovation described in Chapter 7, as well as in Habermasian "communicative 
rationality" as such, a mode of democratic decision-making that thrives on well-justified arguments about the facts and norms involved in specific cases (1990). As Responsible Innovation scholars describe, relatively open-ended, case-by-case, communicative approaches to technology decisions are appropriate because the complex of humans interwoven with our technologies evolves in ways that are impossible to fully foresee (Guston et al., 2014, p. 2). Thus, rather than calling for the creation of rigid principles, norms, and decision-rules to guide technological development, they see the need for "forward-looking" processes that build democratic capacity to identify problems with innovation as they arise, turn back from mistakes, and move in alternate directions where new innovations might hold more promise (Stilgoe et al., 2013). The dissertation similarly proposes a communicative, case-by-case approach to risk assessment of technological applications such as nuclear waste repositories, which would have them be considered in contexts by panels of stakeholder and citizen panels who would be facilitated to move beyond habitual narratives and to embrace, and interrogate, new evidence and incoming information about evolving circumstances in open-minded ways.

This proposal is in line with current literature on policy-making around technological and environmental decisions that hold that more public engagement is required to make these decisions more acceptable. However, the dissertation is original insofar as it moves beyond the inadequate 'citizen vs. experts' framing of problems of technology controversy to diagnose and propose remedies for the distinctly socio-cultural discord that has settled around these issues. Drawing on policy frame theory and cultural theories of risk, it sees the airing of different citizen voices and viewpoints along with the circulation of better expert information as inadequate for mediating environmental and technological controversies. It observes that more viewpoints and better information are unlikely on their own to disrupt the hardened policy frames held by both 
citizens and experts belonging to divergent socio-cultural communities of meaning. Major policy frames relating to environmental and technological risk, the dissertation suggested, are deeply entwined with socio-cultural worldviews that supply the same answer to every risk question and are normatively and epistemologically incompatible with each other. The inability of participants to transcend these frames within decisionary forums — be they elite-driven or deliberative-leads to democratic conflicts and breakdowns and the potential for deeply inadequate policy solutions and policy failures. In agreement with the Cultural Cognition School, the thesis accordingly contends that unique processes of facilitation must be systematically designed to mediate persistent, and deepening, socio-cultural polarization around controversial risk issues such as nuclear waste management. Specifically, it proposes that procedures need to be created that encourage stakeholders to clarify their risk concerns associated with projects and policies, to take them seriously and investigate them carefully in keeping with the highest standards of evidence, and to be reconcile them in well-designed risk solutions with the potential to command credibility amongst their diverse communities of meaning.

\section{Limitations of the Dissertation}

A central assumption of the dissertation is that such processes are, in theory possible: that more structured deliberative review processes among a circumscribed number of participants could mediate longstanding division on contentious issues of environmental risk, in part by raising the level of trust and standard of interaction among stakeholders to a level where this could be achieved. For Flüeler (2011), one goal of making environmental review processes more inclusive of multiple perspectives is to gradually alleviate the mistrust between policy actors that tends to compound in difficult decision-making processes (p. 255). In the case of OPG and STGLND, mistrust between actors was visible in the contemptuous policy storylines tagged in 
the interpretive policy analysis, which showed each protagonist dismissing the views and goals of the other by describing them as ignorant or corrupt. Whether such manifestations of interpersonal distrust between individuals and groups with different perspectives on risk issues could be alleviated through regulatory processes structured to facilitate more constructive conversations between stakeholders, thereby paving the way to actionable consensus around culturally polarized questions, is a testable question, but one that requires significantly more empirical investigation than what was achievable here.

Methodologically, some limitations of the research reflect the absence of certain testing procedures that might have lent additional validity to the results. One procedural modification to highten validity would have been to involve another coder in the interpretive policy whose findings could have been triangulated with my own. However, this modification is not frequently called for in social sciences qualitative research, due to wide acceptance of the terms of the "hermeneutic circle" that ensures that when one is investigating questions of social meaning, an analyst must ultimately rely on his or her own personal socially-engendered insights, which are_-in the expression of Charles Taylor (1971)_ “unformalizable” into reproducible practices of data gathering (1981, p. 53). As discussed in the Methodology section, another procedure not included was a member-testing stage, which would have involved interviewing the policy actors about the meanings that were elicited from the analysis of their discourse (Seale, 2012, p. 80). A research ethics application was accepted for me to perform such interviews, but the unwillingness of the leaders of STGLND to be interviewed by me led me to cancel this envisioned stage of the research process. Further, the hermeneutic approach of textual interpretation, which underpinned my analytical methodology, does not typically call for member checking for verification of the conclusions; as Yanow describe, "a hermeneutic 
approach leads to a focus on policy-relevant texts" with media reports featuring as a "surrogate for interviews" (Yanow, 2007, p. 14). Some examples of such hermeneutic analyses of policy conflicts that identify meanings within the texts include Linder's (1995) analysis of how five interpretive communities framed the issue of electromagnetic frequencies in policy documents, position papers and speeches, and Swaffield's (1998) analysis of the differing ideas of "landscape" held by a range of interpretive communities.

On another front, a more ethnographically-informed account of the dynamics within the policy communities involved in the OPG DGR controversy could certainly have illuminated the issues addressed here in more qualitatively rich ways. More elaborate 'thick descriptions' of the interconnections between OPG and the NWMO, with its long-term interest in finding a site for nuclear fuel waste, and of linkages between STGLND and organizations opposing nuclear power would have been useful for gauging how willing the various players in the conflict might be to participation in an open-ended deliberation about nuclear waste management solutions for Canada. As Roe contends, policy actors with large-scale or ideological agendas have less incentive to cooperate in local problem-solving in a sincere way (pp. 124-125). If either OPG or STGLND have broader, undisclosed strategic objectives pertaining to nuclear waste disposal technologies beyond the optimality of these technologies for a given context, these groups may not be regarded as trustworthy collaborators in such processes.

Moving beyond the issue of regulatory procedures, further research into facilitation of public deliberation is necessary to understand how participants can move beyond the rehearsal of well-worn exultant or dreadful narratives about policy issues to adopt more open, flexible, and contextually ethical positions. How to create truly deliberative spaces that are normatively tolerant and yet challenging for their participants is, in general, an area of research that needs to 
be further developed. Additional research is especially required into the role played by sociocultural identity factors in contentious policy issues in Canada, and into strategies for disentangling these identities from the full range of knowledge required for collaborative problem-solving (see Kahan, 2015b).

Other types of analysis would also additionally extend understanding about the communicative features of contemporary environmental risk conflicts such as the OPG DGR. Further examination is required of the specifically strategic uses of communications used by different policy actors to advance their positions within technological policy decisions and how they are interpreted. A discourse analysis that more frankly investigated the strategic contention between the two policy actors as a political contest for power and control would forge sharper directions in such an inquiry (see for example Hajer, 1993, 2003). Additionally, more mediacentric studies could extend the work initiated in the section on STGLDN's Facebook posts in this dissertation, considering how contemporary media and communication styles—and especially new media technologies and platforms — are augmenting the repertoire of tools available to community action groups. These studies could meanwhile probe empirically whether new media tools are primarily helpful in disseminating information on complex subjects, or whether they are hardening public positions into more polarized, and possibly more simplistic, sets of alternatives.

\section{Final Reflection}

I began this dissertation with a sense of impatience about the need to advance the social consensus around nuclear waste and other contentious technologies in Canada. However, I am ending it in a humbler and more patient note. Presumably, I have been converted to humility and patience in relation to decision-making around complex technologies because these are the 
qualities of some of the best thinkers I came across while working on this dissertation - from MacFarlane (2006) and Fyfe (1999), to Kunreuther and Easterling (1990), to the Responsible Innovation framers, Guston et al. (2014). Their perspectives have revealed to me that what is finally most important in a society is not the technological infrastructure it builds, but the processes it erects to make decisions about difficult issues involving complex, often conflicting views. In a world besieged by information about risk, where social conflicts appear to be getting more confused and enflamed as each year goes by, procedures such as those recommended by Stern and Fineberg (1996), and Jasanoff (2003) offer eminent solutions. Such procedures could productively train more members of our societies in the competencies and sensitivities required to take the wide range of risk concerns that loom around us seriously while addressing them collectively and collaboratively. Progressing as a public on a journey of learning about how to attend to the risks that intuitively concern us, tempered and informed by what the full range of evidence reveals to us, is worth our collective and individual time and effort. Such a project would finally empower us to redeem the 'problem of the public', training us in the forms of judgement we need to inhabit our technological condition, with all its extraordinary uncertainty and ambiguity. 


\section{Works Cited}

Abbey-Lambertz, K. (2014, May 20). 53 million gallons of nuclear waste may soon be stored right next to the Great Lakes. Huffington Post.

Aikin, A. M., Harrison, J. M., \& Hare, F. K. (1997). The management of Canada's nuclear wastes: Report of a study prepared under contract for the Minister of Energy, Mines and Resources. Ottawa, CA: Government of Canada.

Aristotle (350 BCE). Nicomachean ethics: Book II. Cambridge, MA: MIT Press. Retrieved from http://classics.mit.edu/Aristotle/nicomachaen.2.ii.html.

Battagello, D. (2015, May 12). Fight heats up to stop plan to bury nuclear waste near Great Lakes. Windsor Star.

Beck, U. (1988). Risk society: Towards a new modernity. London, UK: Sage.

Berkhout, F. (1991). Radioactive waste: Politics and technology. New York, NY: Routledge.

Best, J. (1993). But seriously folks: The limits of a strict constructionist interpretation of social problems. In J. A. Holstein (Ed.), Reconsidering social constructionism: Debates in social problem theory (pp. 129-147). New York, NY: Aline De Gruyter.

Bolisetty, S., \& Mezzenga, R. (2015). Amyloid-carbon hybrid membranes for universal water purification. Nature Nanotechnology, 11, 365-371.

Brown, D. (2015, May 6). A federal panel recommends Ontario Power Generation be allowed to build an underground storage site deeper than Canada's tallest structure. London Free Press.

Brown, P. A., \& Letourneau, C. (2001). Nuclear waste fuel policy in Canada. In G. B. Doern (Ed.), Canadian nuclear energy policy: Changing ideas, institutions, and interests (pp. 113-128). Toronto: University of Toronto Press. 
Burns, M. E., \& Briner, W. H. (1987). Setting the stage. In M. E. Burns (Ed.), Low-level radioactive waste regulation: Science, politics, and fear (pp. 1-44). Chelsea, MI: Lewis.

Buss, D. M., Craik, K. H., \& Dake, K. M. (1986). Contemporary worldviews and perception of the technological system. In V. T. Covello, J. Menkes, \& J. L. Mumpower (Eds.), Risk evaluation and management (pp. 93-130). New York, NY: Plenum.

Canadian Environmental Assessment Agency (2016, July). Basics of environmental assessment. Retrieved from Canada.ca: https:/www.canada.ca/en/environmental-assessmentagency/services/environmental-assessments/basics-environmental-assessment.html

Canadian Nuclear Association (2012, June 9). 2012 Public opinion research national nuclear attitude survey. Retrieved from https://www.cna.ca/wp-content/uploads/2014/05/2012Public-Opinion-Research-\%E2\%80\%93-National-Nuclear-Attitude-Survey.pdf Canadian Nuclear Safety Commission (2015). Participant funding program evaluation: Final report. Retrieved from http://www.nuclearsafety.gc.ca/pubs_catalogue/uploads/internalaudits/Audit-of-PFP-evaluation-eng.pdf

City of Toronto (n. d.). R. L. Clark water treatment process. Retrieved from http://www1.toronto.ca/wps/portal/contentonly?vgnextoid=c18540f65dc7f310VgnVCM1 0000071d60f89RCRD\&vgnextchannel $=\mathrm{d} 46409 \mathrm{f} 8 \mathrm{e} 0 \mathrm{c} 7 \mathrm{f3} 10 \mathrm{VgnVCM} 10000071 \mathrm{~d} 60 \mathrm{f} 8 \mathrm{RC}$ RD

Clack, C. T. M., Staffan, A., Qvist, J. A., Bazilian, M., Brandt, A. R., Caldeira, K., Davis, S., Diakov, V., Handschy, M., Hines, P. D. H., Jaramillod, P., Kammenm, D. M., Long, J. C. S., Granger Morgan, M., Reed, A., Sivaramr, V., Sweeney, J., Tynan, G. R., Victor, D. G. Weyants, J. P., \& Whitacre, J. F. (2017). Evaluation of a proposal for reliable low-cost grid power with 100\% wind, water, and solar. PNAS, Vol. 114, No. 26, pp. 6722-6727. 
Cotgrove, S. (1982). Catastrophe or cornucopia: The environment, politics, and the future. New York, NY: Wiley.

Council of Canadian Academies (2014). Science culture: Where Canada stands (Expert Panel report). Ottawa: Council of Canadian Academies.

Cultural Cognition Project (n. d.). The Cultural Cognition Project at Yale Law School. Retrieved from http://www.culturalcognition.net/

Dake, K. (1991). Orienting dispositions in the perception of risk: An analysis of contemporary worldviews and cultural biases. Journal of Cross-Cultural Psychology, 22(1), 61-82.

DeLuca, K. M., Image Politics: The New Rhetoric of Environmental Activism. New York, NY., 1999.

Dewey, J. (1927, 2003). The public and its problems. In J. Gripsrud, H. Moe, \& A. Molander (Eds.), The Idea of the public sphere: A reader (pp. 43-53). Plymouth, UK: Lexington.

Dinan, W. \& Miller, D. (2008). Journalism, public relations, and spin. In K. Wahl-Jorgensen \& T. Hanitzsch (Eds.) The Handbook of Journalism Studies (pp. 150-64). New York, NY: Routledge.

Doelle, M. (2012). CEAA 2012: The end of federal EA as we know it?. Journal of Environmental Law and Practice 1(24), 1-17.

Douglas, H. (2005). Inserting the public into science. In S. Maasen \& P. Weingart (Eds.), Democratization of expertise?: Exploring novel forms of scientific advice in political decision-making (pp. 153-169). New York, NY: Springer.

Douglas, M. (1965). Purity and danger: An analysis of the concepts of pollution and taboo. London, UK: Routledge. 
Douglas, M., \& Wildavsky, A. (1982). Risk and culture: An essay on the selection of technological and environmental dangers. Berkeley, CA: U California P.

Dubé, E., Laberge, C., Guay, M., Bramadat, P., Roy, R., \& Bettinger, J. (2013, August 1). Vaccine hesitancy: An overview. Human Vaccination and Immunotherapy, Vol. 9, Issue $8,1763-1773$.

Dunlap, R. E. (1983). Ecologist vs. exemptionalist: The Erlich-Simon debate. Social Science Quarterly, 64, 200-203.

Durant, D. (2009a). An official narrative: Telling the history of Canada's nuclear waste management policy making. In D. Duran \& G. Fuji Johnson (Eds.), Nuclear waste management in Canada: Critical issues, critical perspectives (pp. 31-51). Vancouver, BC: UBC Press.

Durant, D. (2009b). Public consultation as performative contradiction: Limiting discussion in Canada's nuclear waste management debate. In D. Durant \& G. Fuji Johnson (Eds.), Nuclear waste management in Canada: Critical issues, critical perspectives (pp. 69-89). Vancouver, BC: UBC Press.

Durant, D. (2009c). The trouble with nuclear. In D. Durant \& G. Fuji Johnson (Eds.), Nuclear waste management in Canada: Critical issues, critical perspectives (pp. 11-30). Vancouver: UBC Press.

Easterling, D., \& Kunreuther, H. (1995). The dilemma of siting a high-level nuclear waste repository. Amsterdam, ND: Springer.

Edwards, G. (2015). Nuclear waste: Abandonment versus rolling stewardship. Retrieved from http://www.ccnr.org/Rolling_Stewardship.pdf 
Eisendel, E. \& Eastlick, D. (2000). Consensus conferences as deliberative democracy: A communications perspective. Science Communication, Vol. 21, Issue 4, pp. 323-343.

Einsendel, E., Jelsøe, E., \& Breck, T. (2001). Publics at the technology table: The consensus conference in Denmark, Canada, and Australia. Public Understanding of Science. Vol. 10 , Issue 83 .

Entine, J. (2015, January 29). AAAS Scientists: Consensus on GMO safety firmer than for human-induced climate change. Huffington Post.

Environment and Climate Change Canada (2017). Building common ground: A new vision for impact assessment in Canada (Expert Panel report). Retrieved from https://www.canada.ca/en/services/environment/conservation/assessments/environmental -reviews/environmental-assessment-processes/building-common-ground.html\#_Toc025

Environmental Protection Agency. (2012). Code of Federal Regulations: Title 40_Protection of the Environment. Washington, DC: United States Government.

Fairclough, N. (2001). Language and power. $2^{\text {nd }}$. ed. New York, NY: Routledge.

Fernandez, B. (2015, June 4). Toxic editorial at best. Windsor Star.

Fischer, F. (2000). Citizens, experts, and the environment: The politics of local knowledge. Durham, NC: Duke University Press.

Fischer, F. (2003). Reframing public policy: Discursive politics and deliberative practices. New York, NY: Oxford University Press.

Fischoff, B., Slovic, P., Lichtenstein, S., Read, S., \& Combs, B. (1978). How safe is safe enough? A psychometric study of attitudes towards technological risk and benefits. Policy Sciences 9, 127-152. 
Flüeler, T. (2006). Decision making for complex socio-technical systems: Robustness from lessons learned in long-term radioactive waste governance. Amsterdam, ND: Springer.

Flynn, J., Slovic, P., \& Mertz, C. K. (1993). Decidedly different: Expert and public views of risks from a radioactive waste repository. Risk Analysis, 13(6), 643-648.

Friess, S. (2015, August 22). Nuclear waste site bid makes waves on Lake Huron. Al Jazeera Americas.

Fuchs, D. (2007). Business power in global governance. Boulder, CO: Lynne Reiner.

Fuji Johnson, G. (2008). Deliberative democracy for the future: The case of nuclear waste management in Canada. Toronto, ON: Univesity of Toronto Press.

Fuji Johnson, G. (2009). The darker side of deliberative democracy. In D. Durant \& G. Fuji Johnson (Eds.), Nuclear waste management in Canada: Critical issues, critical perspectives (pp. 90-105). Vancouver: UBC Press.

Fuji Johnson, G., \& Durant, D. (2009). Critical perspectives on the nuclear story. In D. Durant \& G. Fuji Johnson (Eds.), Nuclear waste management in Canada: Critical issues, critical perspectives (pp. 1-10). Vancouver: UBC Press.

Fulford, R. (1999). The triumph of narrative: Storytelling in the age of mass culture. Toronto, ON: Anansi.

Funk, C., Kennedy, B., \& Podrebarac Sciupac, E. (2016, July 26). Public sees science and technology as net positives for society. Retrieved from http://www.pewinternet.org/2016/07/26/public-sees-science-and-technology-as-netpositives-for-society/

Fyfe, W. S. (1985). Nuclear waste disposal: When, where? Geology, 595. 
Fyfe, W. S. (1999). Nuclear waste isolation: An urgent international responsibility. Engineering Geology 52, 159-161.

Fyfe, W. S., Babuska, V., Price, N. J., Schmid, E., Tsang, C. F., Uyeda S., \& Velde, B. (1984). The geology of nuclear waste disposal. Nature, 310 (16), 537-540.

Geertz, C. (1973). The interpretation of cultures: Selected essays. New York, NY: Basic Books.

Gibbons, M., Limoges, C., Nowotny, H., Schwartzman, S., Scott, P., \& Trow, M. (1994). The new production of knowledge: The dynamics of science and research in contemporary society. London, UK: Sage.

Gibson, R. B. (2012). In full retreat: The Canadian government's new environmental assessment law undoes decades of progress. Impact Assessment and Project Appraisal, 179-188.

Goffman, E. (1971). Frame analysis: An essay on the organization of experience. Cambridge, MA: MIT Press.

Gowen, R. (2017, April 7) CEAA seeks more DGR information. Owen Sound Sun Times.

Green Party of Ontario. (2016, January 19). Ontario's plan to rebuild nuclear plants is reckless and irresponsible. Retrieved from https://gpo.ca/blog/2016-01-19/ontarios-plan-rebuildnuclear-plants-reckless-and-irresponsible

Greenberg, J., Dubé, E., and Driedger, M. (2017, March 3). Vaccine hesitancy: In search of the risk communication comfort zone. PLOS Current Outbreaks. Edition 1.

Greer, S. (2014, September 9). Personal interview.

Gregory, R. (2017). The Troubling Logic of Inclusivity in Environmental Consultations. Science, Technology, \& Human Values. Vol 42, Issue 1, p. 144-165.

Guston, D. H., \& Sarewitz, D. (2002). Real-time technology assessment. Technology in Society, 24(1-2), 93-109. 
Guston, D. H., Fisher, E., Grunwald, A., Owen, R., Swierstra T., \& van der Burg, S. (2014). Responsible innovation: motivations for a new journal. Journal of Responsible Innovation, 1(1).

Habermas, J. (1970). Towards a theory of communicative competence. Inquiry 13(1-4), 360-375.

Habermas, J. (1984a). Theory of communicative action, Volume I. Boston, MA: Beacon.

Habermas, J. (1984b). Theory of communicative action, Volume II. Boston, MA: Beacon.

Habermas, J. (1990). Moral consciousness and communicative action. Cambridge MA: MIT Press.

Habermas, J. (1992/1996). Between facts and norms. Cambridge, MA: MIT Press.

Hajer, M. A. (1993). Discourse coalitions and the institutionalization of practice: The case of acid rain in Britain. In F. Fischer and J. Forester (Eds.), The argumentative turn in policy analysis and planning (pp. 43-76). Durham, NC: Duke University Press.

Hajer, M. A. (2003). A frame in the fields: Policymaking and the reinvention of politics. In M. A. Hajer \& H. Wagenaar (Eds.), Deliberative policy analysis: Understanding governance in the network society (pp. 88-110). Cambridge, UK: Cambridge University Press.

Hanaina, J., Jenden, J., Lloyd, E., \& Donev, J. (2015). Canadian support for nuclear power. Energy Education. Retrieved from http://energyeducation.ca/encyclopedia/Canadian_support_for_nuclear_power Hayes, D. (1977). Rays of hope: Transition to a post-petroleum world. New York, NY: W. W. Norton.

Hempling, S. (2014). "Regulatory capture": Sources and solutions. Emory Corporate Governance and Accountability Review, Issue 1. Retrieved from http://law.emory.edu/ecgar/content/volume-1/issue-1/essays/regulatory-capture.html 
Holbrook, J. B., \& Briggle, A. (2014). Knowledge kills action: Why principles should play a limited role in policy-making. Journal of Responsible Innovation, 1(1), 51-66.

International Atomic Energy Agency. (2007, October). International project on innovative nuclear reactors and fuel cycles manual: Waste management. Retrieved from https://www.iaea.org/NuclearPower/Downloads/INPRO/Files/NESA_Support_Package/I NPRO_Methodology_TECDOC-1575/TE_1575_vol4.pdf

Inverhuron Committee. (2013, January). Inverhuron committee. Retrieved from http://www.inverhuroncommittee.ca/uploads/1/8/7/4/18747728/the_inverhuron_committe e_january_2013_newsletter.pdf

Jasanoff, S. (1995). Procedural choices in regulatory science. Technology in Society, 17, 279293.

Jasanoff, S. (2003). Technologies of humility: Citizen participation in governing science. Minerva, 223-244.

Jasanoff, S. (2012). Science and public reason. New York, NY: Routledge.

Jenkins, W. H. (2015, December 1). A nuclear paradigm shift? Wall Street Journal.

Jenkins-Smith, H. C., Silva, C. L., Herron, K. G., Ripberger, K. G., Nowlin, M., Bonano, T., \& Rechard, R. P. (2013). Public preferences related to consent-based siting of radioactive waste management for storage and disposal: Analyzing variations over time, events and program design. Washington, D.C.: United States Department of Energy.

Jensen, M., Lam, T., Luhowy, D., McLay, J., Semec, B., \& Frizzell, R. (2009). Ontario Power Generation's proposed L\&ILW deep geological repository: A review of geoscientific studies. GeoHalifax (pp. 1339-1347). Halifax, NS. 
Kahan, D. (2014, April 2). MAPKIA! Episode 49: Where is Ludwick?! Or what *type* of person is worried about climate change but not about nuclear power or GM foods? Retrieved from the Cultural Cognition Project at Yale Law School:

http://www.culturalcognition.net/blog/2014/4/2/mapkia-episode-49-where-is-ludwick-orwhat-type-of-person-is.html

Kahan, D. (2013, November 5). We aren't polarized on GM foods-- no matter what the result in Washington state. Cultural Cognition Project Blog. Retrieved from http://www.culturalcognition.net/blog/2013/11/5/we-arent-polarized-on-gm-foods-nomatter-what-the-result-in.html

Kahan, D. (2014, January 31). The culturally polarizing effect of the "anti-science trope" on vaccine risk perceptions. Cultural Cognition Project Blog. http://www.culturalcognition.net/blog/2014/1/31/the-culturally-polarizing-effect-of-theanti-science-trope-o.html

Kahan, D. (2015a). Climate-science communication and the measurement problem. Advances in Political Psychology, 1-43.

Kahan, D. (2015b). What is the "science of science communication"? Journal of Science Communication, 14(3), 1-10.

Kahan, D., Braman, D., \& Jenkins-Smith, H. (2011). Cultural cognition of scientific consensus. Journal of Risk Research, 14, 147-174.

Kahan, D. Wittlin, M., Peters, E., Slovic, P., Larrimore Oulette, L., Braman, D., and Mandel, G. (2011). The Tragedy of the Risk-Perception Commons: Culture Conflict, Rationality Conflict, and Climate Change, Yale Law \& Economics Research Paper, No. 435. 
Kasperson, R. E., Golding, D., \& Tuler, S. (1992). Social distrust as a factor in siting hazardous facilities and communicating risks. Journal of Social Issues, 48(4), 161-187.

Kasperson, R. E., Renn, O., Slovic, P., Brown, H. S., Emel, J., Goble, R., Kasperson, J. X., \& Ratick, S. (1988). The social amplification of risk: A conceptual framework. Risk Analysis, 8(2), 177-187.

Kemp, R. (1992). The politics of radioactive waste disposal. New York, NY: Manchester UP. Kingwell, M. (2016, June 18). Who needs the truth in this post-factual world? Globe and Mail. Retrieved from http://www.theglobeandmail.com/opinion/who-needs-the-truth-in-thispost-factual-world/article30507031/

Kinney, A. G., \& Leschine, T. M. (2002). A procedural evaluation of an analytic-deliberative process: The Columbia River comprehensive impact assessment. Risk Analysis, 22(1), 83-100.

Kowalski, K. M. (2013, September 9). Study supports nuclear waste disposal near Great Lakes. Midwest Energy News.

Kunreuther, H., Easterling, D., Desvousges, W., \& Slovic, P. (1990). Public attitudes toward siting a high-level nuclear waste repository in Nevada. Risk Analysis, 10(4), 469-484.

Lakoff, G., \& Turner, M. (1989). More than cool reason: A field guide to poetic metaphor. Chicago, IL: University of Chicago Press.

Leapmanifesto.org. (2016). The Leap Manifesto. Retrieved from https://leapmanifesto.org/en/the-leap-manifesto/\#manifesto-content

Lincoln, Y. S., \& Guba, E. G. (1985). Naturalistic Inquiry. Thousand Oaks, CA: Sage.

Linder, S. H. (1995). Contending discourses in the electric and magnetic fields controversy: The social construction of EMF risk as a public problem. Policy Sciences 28(2), 209-230. 
Lindgren, A. (2004, October 24). OPG under fire for plan to bury nuclear waste near Lake Huron. Ottawa Citizen.

Lindlof, T. R., \& Taylor, B. C. (2011). Qualitative communication research method. $3^{\text {rd }}$. ed. Thousand Oaks, CA: Sage.

Lochbaum, D. (1996). Nuclear waste disposal crisis. Tulsa, OK: Pennwell.

Lövbrand, E., Pielke Jr., R., \& Beck, S. (2010). A democracy paradox in science and technology. Science, Technology, \& Human Values, 1-23.

MacFarlane, A. M. (2006). Uncertainty, models, and the way forward. In A. M. MacFarlane \& R. Ewing (Eds.), Uncertainty underground: Yucca Mountain and the nation's high-level nuclear waste (pp. 393-410). Cambridge, MA: MIT Press.

MacFarlane, A. M., \& Ewing, R. (2006). Uncertainty underground: Yucca Mountain and the nation's high-level nuclear waste. Cambridge, MA: MIT Press.

Manning, H. (2016, November 11). Inside the "chaos" and "bias" of the citizens' jury. IN Daily.

Mansbridge, J. (2016). 1996: A good year for deliberative theory, 20 years later (Roundtable). American Political Science Association. Philadelphia, PA.

Marshall, L., \& Rossman, G. B. (2011). Designing qualitative research. $5^{\text {th }}$ ed. Thousand Oaks, CA: Sage.

McCarthy, S. (2013, September 12). Ontario's \$1-billion plan to bury its nuclear waste. Globe and Mail.

McKay, B. (2013, May 29). Michigan Senate calling for thorough review of proposed OPG DGR. Kincardine Independent. 
McPhee, J. (2012, September 18). Coalition formed to oppose nuclear DGR plans in area . Walkerton Herald-Times. Retrieved from http://www.southwesternontario.ca/newsstory/5985505-coalition-formed-to-oppose-nuclear-dgr-plans-in-area/

Meehan, R. (1986) The Atom and the Fault: Experts, Earthquakes, and Nuclear Power. Cambridge, MA: MIT Press

Metlay, D. (2013, July-August). Consent-based siting: What have we learned? Radwaste Solutions, 28-36.

Meyer, S. (2013, November 21). Don't bury nuclear waste near our water supply: Panel. London Community News.

Murphy, B., \& Kuhn, R. (2009). Situating Canada's approach to siting a nuclear waste management facility. In D. Durant \& G. Fuji Johnson (Eds.), Nuclear waste management in Canada: Critical Issues, critical perspectives (pp. 150-167). Vancouver, BC: UBC Press.

Natural Resources Defence Council. (2012, June). Poisoning the great lakes: Mercury emissions from coal-fired power plants in the Great Lakes region. Retrieved from https://www.nrdc.org/sites/default/files/poisoning-the-great-lakes.pdf

Nordmann, A. (2014). Responsible innovation, the art and craft of anticipation. Journal of Responsible Innovation, 87-98.

Northwatch. (2012). Northwatch: Acting today for tomorrow. Retrieved from web.net/nwatch: http://web.net/nwatch/

Nuclear Waste Management Organization. (2003). Asking the right questions? The future management of Canada's used nuclear fuel. Toronto: NWMO. 
Nuclear Waste Management Organization (2005). Choosing a way forward: The future management of Canada's used nuclear fuel (Final Study). Toronto: NWMO.

Ontario Power Generation. (2005). Deep geological repository for low and intermediate-level nuclear waste: Project description. Toronto, ON: Ontario Power Generation. Retrieved from nuclearsafety.gc.ca.

Ontario Power Generation. (2011). OPG's deep geologic repository project for low and intermediate level nuclear waste: Environmental impact statement summary. Toronto, ON: Ontario Power Generation.

Ontario Power Generation. (2012). OPG responses to environmental impact assessment information requests in Joint Review Panel IR package \#3. Toronto, ON: Ontario Power Generation.

Ontario Power Generation. (2013a). OPG's deep geologic repository for nuclear waste. Retrieved from http://www.opg.com/generating-power/nuclear/nuclear-wastemanagement/DGR\%20pdfs/DGR\%20Overview\%20Brochure_Updated\%20Feb\%202013 .$p d f$

Ontario Power Generation. (2013b). Request for a decision regarding environmental assessment for Ontario Power Generation's application to prepare a site and construct a deep geologic repository for low and intermediate level waste. Toronto, ON: Ontario Power Generation.

Ontario Power Generation. (2016a). Background information. Retrieved from http://www.opg.com/generating-power/nuclear/nuclear-waste-management/DeepGeologic-Repository/Pages/Background-Info.aspx 
Ontario Power Generation. (2016b). Deep geologic repository. Retrieved from http://www.opg.com/generating-power/nuclear/nuclear-waste-management/DeepGeologic-Repository/Pages/Deep-Geologic-Repository.aspx

Ontario Power Generation. (2016c, February). Frequently asked questions about OPG's deep geological repository for low and intermediate-level nuclear waste. Retrieved from http://www.opg.com/generating-power/nuclear/nuclear-wastemanagement/DGR\%20pdfs/FAQs.pdf

Owens, S. (2000). Engaging the public: Information and deliberation in environmental policy. Environment and Planning A, 32, 1141-1148.

Pekinpaugh, T. L. (1987). The politics of nuclear waste disposal. In M. E. Burns (Ed.), Low-level radioactive waste regulation: Science, politics, and fear (pp. 45-62). Chelsea, MI: Lewis.

Pepper, D. (1999). Modern environmentalism: An introduction. London, UK: Routledge.

Perkel, C. (2015a, May 4). Lake Huron nuclear waste dump assessment due this week. Canadian Press.

Perkel, C. (2015b, May 6). Burying nuclear waste near Lake Huron safest option, panel concludes. Canadian Press.

Peters, E., \& Slovic, P. (1996). The role of affect and worldviews as orienting dispositions in the perception and acceptance of nuclear power. Journal of Applied Social Psychology, 26, 1427-1453.

Pielke Jr., R. A. (2007). The honest broker: Making sense of science in policy and politics. Cambridge, UK: Cambridge University Press.

Powers, K. (2014, September 9). Personal interview. 
Province of Ontario. (2015). Eating ontario fish. Retrieved from https://www.ontario.ca/document/guide-eating-ontario-fish

Rauschmayera, F. \& Risseb, N. (2005, August). A framework for the selection of participatory approaches for SEA. Environmental Impact Assessment Review, Vol. 25, Issue 6. pp. 650-666.

Rip, A. (1986). Controversies as informal technology assessment. Science Communication, 8(2), 349-371.

Roe, E. (1994). Narrative policy analysis: Theory and practice. Durham, NC: Duke UP.

Ropeik, D. (2016, September 2). The dangers of radiophobia. Bulletin of the Atomic Sciences, $72(5)$.

Rosa, E. A., Tuler, S. P., Fischhoff, B., Webler, T., Friedman, S. M., Sclove, R. E., ShraderFrechette, K., English, M. R., Kasperson, R. E., Goble, R. L., Leschine, T. M., Freudenburg, F., Chess C., Perrow, P., Erikson, K., \& Short, J. F. (2010). Nuclear waste: Knowledge waste? Science, 329, 762-763.

Rucke, K. (2014, June 26). Great Lakes communities struggle against proposed nuclear waste Facility. Mintpress News.

Sarmadi, D. (2015, June 3). Europe should "keep its hands off coal", German study says. Euractiv.

Sarowitz, D. (2004). How science makes environmental controversies worse. Environmental Science \& Policy, 7(5), 385-403.

Save Our Saugeen Shores [SOS] (2016, May). Save our Saugeen Shores rebrands and expands to stop the nuclear threat to the great lakes-May 2016 update. Retrieved from 
http://www.saugeentimes.com/104\%20x/Back\%20Yard\%20Gets\%20Bigger/SOS\%20Re brands.pdf

Schön, D., \& Rein, M. (1994). Frame reflection: Toward the resolution of intractrable policy controversies. New York, NY: Basic Books.

Science Learning Hub. (2012, September 4). Poisons and toxins. Retrieved from http://sciencelearn.org.nz/Contexts/Toxins/Science-Ideas-and-Concepts/Poisons-andtoxins

Seale, C. (2004). Validity, reliability, and the quality of research. In C. Seale (Ed.), Researching Society and Culture. Thousand Oaks, CA: Sage.

Secko, D., Preto, N., Niemeyer, S., \& Burgess, M. (2009). Informed consent in biobank research: A deliberative approach to the debate. Social Science \& Medicine, Vol. 68, Issue 4, oo, 781-789.

Sense About Science USA. (2016). American Association for the Advancement of Science. Washington, DC.

Shrader-Frechette, K. (1985). Risk analysis and scientific method: Methodological and ethical problems with evaluating societal hazards. New York, NY: Springer.

Shrader-Frechette, K. (1993). Burying uncertainty: Risk and the case against geological disposal of nuclear waste. Berkeley, CA: University of California Press.

Sierra Club. (2013). Great lakes nuclear hot spots. Retrieved from http://www.sierraclub.org/michigan/great-lakes-nuclear-hot-spots

Slovic, P. (1993). Perceived risk, trust, and democracy. Risk Analysis, 13(6), 675-682. 
Slovic, P., Layman, M., \& Flynn, J. H. (1990). What comes to mind when you hear the words "nuclear waste repository"?: A study of 10,000 images. Carson City, Nevada: Nevada Nuclear Waste Project Office.

Spears, J., \& Pelley, L. (2015, May 6). Kincardine nuclear waste site gets federal seal of approval. Toronto Star.

Starr, C. (1969). Social benefit versus technological risk. Science, 1232-1238.

Stempson, W. E. (2000). Disease and diagnosis: Value-dependent realism. Philosophy and Medicine, Vol. 63. Amsterdam, NE: Springer.

Stern, P. C., \& Fineberg, H. V. (1996). Understanding risk: Informing decisions in a democratic society. Washington, DC: National Academy of Science.

Stilgoe, J., Owen, R., \& Macnaghten, P. (2013). Developing a framework for responsible innovation. Research Policy, 42(9), 1568-1580.

Stone, D. A. (1988). Policy paradox: The art of political decision making. New York, NY: Norton.

Stone, D. A. (1989). Causal stories and the formation of policy agendas. Political Science Quarterly, 104(2), 281-300.

Stop the Great Lakes Nuclear Dump, petition (2012) Recovered April 8, 2017 at https://www.gopetition.com/petitions/stopthegreatlakesnucleardump.html

Stop the Great Lakes Nuclear Dump (2013). Stop The Great Lakes Nuclear Dump submission to the Joint Review Panel concerning the OPG DGR. Guelph, Ontario.

Stop the Great Lakes Nuclear Dump (2016a). Reasons to be concerned: 3. failed track record of deep geologic repositories (DGR). Retrieved from http://www.stopthegreatlakesnucleardump.com/pages/failedDGRs1.php 
Stop the Great Lakes Nuclear Dump (2016b). Stop the Great Lakes Nuclear Dump. Retrieved from http://www.stopthegreatlakesnucleardump.com/

Sturm, C. (2016, May 20). Germany's energiewende: The intermittency problem remains. Bulletin of the Atomic Sciences. Retrieved from http://thebulletin.org/germany\%E2\%80\%99s-energiewende-intermittency-problemremains 9469

Sunstein, C. (2001). Republic.com. Princeton, NJ: Princeton UP.

Swaffield, S. (1998). Contextual meanings in policy discourse: A case study of language use concerning resource policy in the New Zealand high country. Policy Sciences, 31(3), $199-224$.

Swanson, S., Archibald, J. F., \& Mueke, G. (2015). Joint Panel Review environmental assessment report deep geologic repository for low and intermediate level nuclear waste. Ottawa: Canadian Environmental Assessment Agency.

Taebi, B., Correljé, A., Cuppen, E., Dignum, M., \& Pesch, U. (2014). Responsible innovation as an endorsement of public values: the need for interdisciplinary research. Journal of Responsible Innovation, 1(1), 118-124.

Talbott, W. (2008) Bayesian epistemology. In Stanford Encyclopedia of Philosophy. Retrieved from https://plato.stanford.edu/entries/epistemology-bayesian/

Taylor, C. (1971). Interpretation and the Sciences of Man. The Review of Metaphysics, (25.1), 351.

Tillman, A. (2014, September 9). Personal interview. 
United Nations Environmental Programme. (1992). Rio Declaration on Environment and Development. Retrieved from http://www.unep.org/documents.multilingual/default.asp?documentid=78\&articleid=1163 United States Department of Energy. (2016, February 25). What happened at WIPP in February 2014. Retrieved from http://www.wipp.energy.gov/wipprecovery/accident_desc.html

Van Brenk, D. (2015, May 4). Deep divisions. London Free Press.

Verweij, M., Douglas, M., Ellis, R. J., Engel, C., Hendriks, F., Lohmann, S., Ney, S., Rayner, S., $\&$ Thompson, M. (2013). Clumsy solutions for a complex world: The case of climate change. In M. Douglas \& R. Fardon (Eds.), Cultures and crises: Understanding risk and resolution (pp. 146-174). London, UK: Sage.

Walker, J. S. (2006). The road to Yucca Mountain. Berkeley, CA: U California P.

Weart, S. R. (2012). The rise of nuclear fear. Cambridge, MA: Harvard UP.

Webler, T. (1995). "Right" discourse in citizen participation: An evaluative yardstick. In O. Renn, T. R. Webler \& P. Weidemann (Eds.), Fairness and competence in citizen participation (pp. 35-86). Amsterdam, ND: Springer.

Weinberg, A. M. (1995). Social institutions and nuclear energy-II. Journal of Nuclear Science and Technology, 32(11), 1071-1080.

Willis, T. (2016, February 29). EPA study finds high levels of toxins in Great Lakes fish. Retrieved from http://www.waterkeeper.ca/blog/2016/2/28/epa-study-toxin-levels-ingreat-lakes-fish

Winner, L. (1980). Do artifacts have politics? Daedalus, 121-136.

Woolgar, S., \& Pawluch, D. (1985). Ontological gerrymandering: The anatomy of social problems explanations. Social Problems, 3(2), 214-227. 
Wynne, B. (1996). May the sheep safely graze? A reflexive view of the expert-lay knowledge divide. In S. Lash, B. Szerszynski, \& B. Wynne (Eds.), Risk, environment and modernity: Towards a new ecology. London, UK: Sage.

Yanow, D. (2000). Conducting interpretive policy analysis. London, UK: Sage.

Yanow, D. (2007). Interpretation in policy analysis: On methods and practice. Critical Policy Studies, 1(1), 110-122.

Yim, M. (2009). The intersection of nuclear waste disposal engineering and social decisionmaking in the US. Society for Social Studies of Science Conference. Washington, DC.

Young, I. M. (2000). Inclusion and democracy. New York, NY: Oxford University Press.

Zuckerman, L. (2015, March 27). Wrong kitty litter led to radiation leak at New Mexico nuke waste dump. Reuters. 


\section{Appendix A: List of Documents Analyzed}

\section{A.1 Ontario Power Generation Documents}

\section{A.1.1 Submissions to the Joint Review Panel:}

1. PMD 13-P1.1A Request for a decision regarding environmental assessment for Ontario Power Generation's application to prepare a site and construct a deep geologic repository for low and intermediate level waste, July 23, 2013.

\section{A.1.2 Promotional Materials}

1. OPG's deep geologic repository for nuclear waste, 2013 (brochure)

2. FAQs about OPG's DGR for low and intermediate-level nuclear waste, May 5, 2014, updated February 2016

3. Background information, 2016 (web page)

4. Deep geologic repository, 2016 (web page)

\section{A.2 Stop the Great Lakes Nuclear Dump Documents}

\section{A.2.1 Submissions to the Joint Review Panel}

1. Stop The Great Lakes Nuclear Dump Inc. submission to: Members of the Joint Review Panel concerning: Ontario Power Generation's proposed deep geological repository for low and intermediate level nuclear waste, May 13, 2013. http://www.ceaa.gc.ca/050/documents/p17520/89334E.pdf

\section{A.2.2 Petitions}

1. Petition, published by Stop the Great Lakes Nuclear Dump on November 24, 2012.

\section{A.2.2 Promotional Materials}

1. Main website, http://stopthegreatlakesnucleardump.com, retrieved October 28, 2015.

2. Press release \& fact sheet, released January 7, 2013. 


\section{A.3 Mass Media Coverage of OPG and/or STGLND}

1. "DGR opposition group launches online petition." Shoreline Beacon, January 18, 2013. http://www.shorelinebeacon.com/2013/01/18/dgr-opposition-group-launches-onlinepetition

2. "Bruce County group opposes burying nuclear waste near Lake Huron." The Record, January 23, 2013. http://www.therecord.com/news-story/2620835-bruce-county-groupopposes-burying-nuclear-waste-near-lake-huron/

3. Kowalski, K. M. "Study supports nuclear waste disposal near Great Lakes." Midwest Energy News, September 9, 2013 http://midwestenergynews.com/2013/09/09/studysupports-nuclear-waste-disposal-near-great-lakes/

4. McCarthy, S. “Ontario's \$1-billion plan to bury its nuclear waste." Globe and Mail, September 12, 2013 http://www.theglobeandmail.com/news/national/ontarios-nuclearwaste-solution-bury-the-problem/article14300723/?page=all\#full_story

5. Spears, J. "Kincardine nuclear waste site debate heats up." Toronto Star, September 13, 2013. http://www.thestar.com/business/economy/2013/09/13/kincardine_nuclear_waste_site de bate heats up.html

6. "Fears surface over Lake Huron nuke dump proposal," USA Today. October 27, 2013. http://www.usatoday.com/story/news/nation/2013/10/27/fears-surface-over-lake-huronnuke-dump-proposal/3265423/

7. Pfeiffer, R. "Mayor, opponent face off on deep geologic repository." Durham Region Metro. October 23, 2013. http://www.durhamregion.com/news-story/4182488-debatingnuclear-waste-storage-near-the-great-lakes/ 
8. Meyer, S. "Don't bury nuclear waste near our water supply: panel. London Community News, November 21, 2013. http://m.londoncommunitynews.com/news-story/4227789don-t-bury-nuclear-waste-near-our-water-supply-panel

9. Roy, R. L. “A look at the future of Canada's relationship with nuclear waste.” Vice, April 29, 2014. http://www.vice.com/en_ca/read/a-look-at-the-future-of-canadas-relationshipwith-nuclear-waste

10. Abbey-Lambertz, K. "53 million gallons of nuclear waste may soon be stored right next to the Great Lakes.” Huffington Post, May 20, 2014. http://www.huffingtonpost.com/2014/05/20/lake-huron-nuclear-wasteunderground n $5359955 . \mathrm{html}$

11. Rucke, K. "Great Lakes communities struggle against proposed nuclear waste facility." Mintpress News, June 26, 2014. http://www.mintpressnews.com/great-lakescommunities-struggle-against-proposed-nuclear-waste-facility/193028/

12. Van Brenk, D. “Deep divisions.” London Free Press, May 4, 2015. http://www.theobserver.ca/2015/05/03/the-proposed-deep-burial-site-for-nuclear-wastewould-extend-deeper-underground-in-ancient-rock-than-the-cn-tower-is-tall-as-thegraphic-above-from-ontario-power-generation-shows

13. Perkel, C. "Lake Huron nuclear waste dump assessment due this week." Canadian Press, May 4, 2015. http://www.canadianmanufacturing.com/technology/lake-huron-nuclearwaste-dump-assessment-due-this-week-147618/

14. Spears, J., and Pelley, L. "Kincardine nuclear waste site gets federal seal of approval" Toronto Star, May 6, 2015. http://www.thestar.com/news/canada/2015/05/06/federalpanel-gives-seal-of-approval-to-kincardine-nuclear-waste-site.html 
15. Perkel, C. "Burying nuclear waste near Lake Huron safest option, panel concludes." Canadian Press, May 6, 2015. http://www.ctvnews.ca/canada/burying-nuclear-wastenear-lake-huron-safest-option-panel-concludes-1.2362660

16. Flesher, J. "Canadian panel endorses plan for nuclear waste disposal near Lake Huron." Associated Press, May 6, 2015. http://www.canadianbusiness.com/businessnews/canadian-panel-endorses-plan-for-nuclear-waste-disposal-near-lake-huron/

17. Brown, D. “A federal panel recommends Ontario Power Generation be allowed to build an underground storage site deeper than Canada's tallest structure.” London Free Press, May 6, 2015. http://www.lfpress.com/2015/05/06/a-federal-panel-recommends-ontariopower-generation-be-allowed-to-build-an-underground-storage-site-deeper-than-canadas$\underline{\text { tallest-structure }}$

18. "Nuclear waste: Five things to know about the Lake Huron bunker project" $C B C$ News. May 7, 2015 http://www.cbc.ca/news/canada/nuclear-waste-5-things-to-know-about-thelake-huron-bunker-project-1.3065407

19. Joseph, G. "Panel approves underground nuclear waste facility near Lake Huron." Macomb Daily, May 7, 2015 http://www.macombdaily.com/article/MD/20150507/NEWS/150509710

20. Fernandez, B. spokesperson, Stop the Great Lakes Nuclear Dump. "Toxic editorial at best.” Windsor Star, June 4, 2015. http://windsorstar.com/news/local-news/toxic$\underline{\text { editorial-at-best }}$

21. McCarthy, S. "Decision on Lake Huron nuclear waste facility delayed until after election." Globe and Mail, June 7, 2015. 
http://www.theglobeandmail.com/news/national/decision-on-lake-huron-nuclear-wastefacility-delayed-until-after-election/article24838999/

22. Friess, S. "Nuclear waste site bid makes waves on Lake Huron." Al Jazeera Americas, August 22, 2015. http://america.aljazeera.com/articles/2015/8/22/bid-for-nuclear-wastesite-on-lake-huron.html

23. Nelson, J. "Nuclear dump controversy." Watershed Sentinal, September 16, 2015.

24. Carmody, S. "New Canadian government could derail plans for nuclear waste dump near Lake Huron." Associated Press, Oct 22, 2015. http://michiganradio.org/post/newcanadian-government-could-derail-plans-nuclear-waste-dump-near-lake-huron\#stream/0 


\section{Appendix B: Features Coded in OPG's and STGLND's Discourse}

\section{B.1 Features Coded in OPG's Discourse}

Feelings No. of iterations

1. Concern about fulfilling responsibilities regarding long-term waste storage 3

2. Confidence in predictions of environmental impact assessment

3. Certainty about security of project and ability to manage problems

$\underline{\text { Beliefs }}$

1. Geology of the site will permanently contain waste

2. Long-term engineering plan is robust \& unlikely to be disrupted

3. Environmental impacts can foresee or caught through monitoring

4. Nuclear waste intended for this DGR is not the dangerous kind

5. Radiation doses to the public from this DGR will be far below regulatory limits 3

6. Storing the radioactive material in a DGR is relatively safe

7. Nuclear waste is manageable

Storylines

1. Rigorous independent scientific analysis underlies project

2. Project was developed in bottom-up collaborative way

3. Those opposed to the project are in minority

4. DGR will be carefully engineered \& monitored

5. There are more regulatory hurdles to come

6. Very few residents in the community view nuclear waste as a threat

7. There will be beneficial socio-economic effects

$\underline{\text { Norms }}$

1. Radiological safety 
3. Producer/Consumer responsibility

4. Positivist decision-making process based on what can be known and measured 9

5. Environmental responsibility $\quad 8$

6. Meeting Regulatory Requirements $\quad 7$

7. Transparent and consultative process 4

8. Social license 3

9. Conservative approach to analysis 3

10. Ongoing monitoring 3

11. Respect for the views of others 3

12. Economic responsibility 2

13. Democracy 1

14. Economic benefits 1

15. Clean energy 1

16. Consumer benefits 1

Generative metaphors

1. The well-suited geology of the area will protect all life from the nuclear waste 8

$\underline{\text { Synecdoches }}$

1. Conditions of the past and present predict conditions of the future 6

2. Scientific knowledge is generalizable and transferable 5

3. International best practices support building DGRs near nuclear plants 1

4. Lessons learned at other DGRs can be applied to this DGR 1

5. Site comparable to Canadian Shield 1 


\section{B.2 Features Coded in Stop the Great Lakes Nuclear Dump's Discourse}

Feelings

No. of iterations

1. Indignation

2. Concern

3. Dread

4. Urgency

5. Appreciation of Great Lakes

6. Disappointment

$\underline{\text { Beliefs }}$

1. DGR leak would substantially harm everyone around Great Lakes in perpetuity 16

2. DGR technology failed in all cases despite equivalent analysis and engineering 9

3. Radioactive waste is particularly toxic

4. Great Lakes water is now clean and safe

5. Putting the DGR near a Great Lake is an obviously bad idea

6. DGR waste almost as dangerous as spent fuel

7. There are better solutions so the DGR risk need not be taken

8. Issue is of national and international importance

9. L-T computer models cannot be validated or verified

Norms

1. Broad definition of community acceptance required 30

2. Precautionary approach to risk / guarantee of safety not offered

3. National and international duty of stewardship over Great Lakes

4. Alternative sites should be considered

5. Public participation should be meaningful

6. Disinterested public opinion 
$\begin{array}{ll}\text { 7. "Common sense" } & 6\end{array}$

$\begin{array}{lll}\text { 8. Not overstating scientific confidence } & 6\end{array}$

9. Avoid affecting large numbers of people 3

10. Fairly distributed risk 2

11. Not abandoning the waste 2

12. Leadership 2

13. Transparency 1

$\underline{\text { Storylines }}$

1. Reality of public opposition reflected on STGLND's petition 21

2. OPG failed to consult broadly enough 8

3. OPG \& Kincardine colluded on approval/Kincardine has conflict of interest 6

4. DGR will pave the way to spent fuel DGR 5

5. OPG DGR is controversial and faces growing opposition 5

6. STGLND intent is to fill communication gap 3

7. OPG did not do due diligence / analysis was not rigorous 2

8. It is not STGLND's job to suggest where DGR should be located 1

Generative Metaphors

1. Natural purity of great lakes at risk 9

Synecdoches

1. Experiences of other failed nuclear waste repositories apply to this project 4 


\section{Appendix C: Themes in STGLND's Facebook Posts (Disaggregated)}

Theme

No. of iterations

1. Did OPG ask you / let you know / is this okay with you / your water / our voices matter / act now before it's too late / sign petition

2. Defies common sense / clearly nuts / insane / worst idea ever / crazy

3. Preciousness of water / water is life / used for drinking and growing food

4. Should have been multiple sites / no other sites looked at despite large size of Ontario (map graphic)

5. Every DGR has failed / WIPP / Asse II

6. Keep poison away from precious resource / don't dump NW near my drinking water / don't put poison beside well

7. Threatening drinking water of 40 million people / $80 \%$ of Ontarians

8. Protect water for the future generations / children

9. Largest source of freshwater on planet / $21 \%$ of world's fresh water

10. Past promises of safety betrayed / experts have been wrong/rolling the dice / gambling with safety of water / learn from history / Titanic

11. Not likely is not good enough / scientists can't guarantee

12. Fukushima / Chernobyl 13

13. What would happen if you couldn't drink / bathe / all water contaminated / jeopardize millions

14. Those opposed vastly exceed those for the DGR / public is saying no / \#s on petition / opposed communities

15. Hiding the waste / abandoning the waste / out of sight, out of mind

16. David Suzuki / Maud Barlow / John Ralston Saul / Farley Mowat

17. Not worth the risk / too much risk / any risk is unacceptable

18. Too close to population / should be farther from civilization/people

19. Shortsightedness of corporations / only care about $\$$ / can't drink $\$$ or buy water 8

20. Radioactive / most toxic \& carcinogenic poison humans have ever created 8

21. Water supply at stake

22. Not in my backyard / anyone's backyard / no waste near any bodies of water/ great bodies of water 
23. Wake up Ontario / Chicago / Toronto 6

24. Water activities / fishing / birds 6

25. Unprecedented unproven project design (limestone) / experiment 5

26. Irreversible 5

27. OPG' environmental impact assessment not credible / OPG "Fail" 4

28. Regulations cover other risks, why not protecting Great Lakes 4

29. Toxic for 100,000 years / must stay isolated for 100,000 years 4

30. Can't predict 100,000 years in future 4

31. All affected Canadians and Americans not consulted 4

32. Importance to Aboriginals, Metis 3

33. Premiere Wynne should stop it 3

34. Payout to Kincardine 1 